NBER WORKING PAPER SERIES

DOES FEMALE EMPOWERMENT PROMOTE ECONOMIC DEVELOPMENT?

\author{
Matthias Doepke \\ Michèle Tertilt \\ Working Paper 19888 \\ http://www.nber.org/papers/w19888 \\ NATIONAL BUREAU OF ECONOMIC RESEARCH \\ 1050 Massachusetts Avenue \\ Cambridge, MA 02138 \\ February 2014
}

\begin{abstract}
We thank the editor Oded Galor, two referees, Nava Ashraf, Abhijit Banerjee, Lori Beaman, Chris Blattman, Antoine Bommier, Areendam Chanda, Stefan Dercon, Garance Genicot, Doug Gollin, Andreas Irmen, Dean Karlan, Martina Kirchberger, John Knowles, Per Krusell, Ghazala Mansuri, Sonia Oreffice, Josefina Posadas, Mark Rosenzweig, Nancy Stokey, Silvana Tenreyro, Duncan Thomas, Hitoshi Tsujiyama, Dominique van de Walle, Martin Zelder, and participants at many seminar and conference presentations for helpful comments that greatly improved the paper. Financial support from the World Bank's Gender Action Plan, the National Science Foundation (grants SES-0820409 and SES-0748889), the European Research Council (grant SH1-313719), and the German Science Foundation through CRC TR 224 (project A03) is gratefully acknowledged. Titan Alon,Marit Hinnosaar, Vuong Nguyen, XiaodiWang, and Veronika Selezneva provided excellent research assistance. The views expressed herein are those of the authors and do not necessarily reflect the views of the National Bureau of Economic Research.
\end{abstract}

NBER working papers are circulated for discussion and comment purposes. They have not been peerreviewed or been subject to the review by the NBER Board of Directors that accompanies official NBER publications.

(C) 2014 by Matthias Doepke and Michèle Tertilt. All rights reserved. Short sections of text, not to exceed two paragraphs, may be quoted without explicit permission provided that full credit, including (c) notice, is given to the source. 
Does Female Empowerment Promote Economic Development?

Matthias Doepke and Michèle Tertilt

NBER Working Paper No. 19888

February 2014, Revised July 2019

JEL No. D13,J16,O10

\begin{abstract}
$\underline{\text { ABSTRACT }}$
Empirical evidence suggests that money in the hands of mothers (as opposed to fathers) increases expenditures on children. Does this imply that targeting transfers to women promotes economic development? Not necessarily. We consider a noncooperative model of the household where a gender wage gap leads to endogenous household specialization. As a result, women indeed spend more on children and invest more in human capital. Yet, depending on the nature of the production function, targeting transfers to womenmay be beneficial or harmful to growth. Transfers to women are more likely to be beneficial when human capital, rather than physical capital or land, is the most important factor of production. We provide empirical evidence supportive of our mechanism: In Mexican PROGRESA data, transfers to women lead to an increase in spending on children, but a decline in the savings rate.
\end{abstract}

\author{
Matthias Doepke \\ Northwestern University \\ Department of Economics \\ 2211 Campus Drive \\ Evanston, IL 60208 \\ and NBER \\ doepke@northwestern.edu \\ Michèle Tertilt \\ Department of Economics \\ University of Mannheim \\ L7, 3-5 \\ 68131 Mannheim \\ Germany \\ tertilt@uni-mannheim.de
}




\section{Introduction}

Across countries and over time, there is a strong positive correlation between the relative position of women in society and the level of economic development (Duflo 2012; Doepke, Tertilt, and Voena 2012). Based on this correlation, among policy makers the idea has taken hold that there may be a causal link running from female empowerment to development. If this link were to prove real, empowering women would not just be a worthy goal in its own right, but could also serve as a tool to accelerate economic growth.

Indeed, in recent years female empowerment has become a central element of development policy. In 2006, the World Bank launched its Gender Action Plan, which was explicitly justified with the effects of female empowerment on economic development. ${ }^{1}$ Female empowerment also made its way into the United Nations' Millennium Development Goals, again with reference to the claimed effects on development: "putting resources into poor women's hands while promoting gender equality in the household and society results in large development payoffs. Expanding women's opportunities $[\ldots]$ accelerates economic growth." ${ }^{2}$

To the extent that female empowerment means reducing discrimination against women in areas such as education and labor markets, a positive feedback from empowerment to development is highly plausible. However, a number of empowerment policies go beyond gender equality, and explicitly favor giving resources to women instead of men. For example, many family cash transfer programs such as Oportunidades in Mexico pay out benefits to mothers instead of fathers. Further, in 2008 the World Bank committed $\$ 100$ million in credit lines specifically to female entrepreneurs. Today, the majority of micro credit programs around the world are available exclusively to women. While these policies may in part be designed as a remedy for existing inequities (such as higher barriers for women in accessing financial markets), in large part they are founded on the belief that they yield returns in terms of economic development.

In this paper, we provide the first study to examine the development implications of gender-specific transfers from the perspective of economic theory. Specifically, we incor-

\footnotetext{
${ }^{1}$ At the launch of the Gender Action Plan, World Bank president Paul Wolfowitz said that "women's economic empowerment is smart economics [...] and a sure path to development" (quoted on World Bank web page, accessed on January 17, 2014). Similarly, in 2008 then-president Robert Zoellick claimed that "studies show that the investment in women yields large social and economic returns" (speech on April 11, 2008, quoted on the World Bank web page, accessed on January 17, 2014).

${ }^{2}$ See http: / / www . worldbank. org/mdgs/gender. html, accessed on January 17, 2014.
} 
porate a theory of household bargaining into a model of economic growth, and examine whether targeting transfer payments to women really promotes economic development. At first sight, it may appear that existing empirical evidence is sufficient to conclude that these policies boost economic growth. A number of studies suggest that when transfer payments are given to women rather than to their husbands, expenditures on children increase. ${ }^{3}$ To the extent that more spending on children promotes human capital accumulation, this may seem to imply that empowering women will result in faster economic growth. In this study, we take the empirical link from resources in the hands of women to investment in children as given. Nonetheless, we argue that such evidence is not sufficient to establish the impact of empowerment on development. Instead, the true effect of targeted transfers turns out to depend on the specific mechanism that leads women to spend more money on children.

The conventional interpretation of the observed gender expenditure patterns relies on the assumption that women and men have different preferences, which we term the "preference hypothesis." 4 And indeed, if all women highly valued children's welfare whereas all men just wanted to consume, putting women in charge of allocating resources would probably be a good idea. However, we show that the facts can also be explained without assuming that women intrinsically care more about children than men do. We develop a model in which women and men value private and public goods (such as children's human capital) in the same way, but that nevertheless is consistent with the empirical observation that an increase in female resources leads to more spending on children. Our result is driven by endogenous division of labor in the household, and hence we refer to this alternative theory as the "specialization hypothesis." According to this hypothesis, the implications of targeted transfers for economic development are not clear cut. In particular, we find that empowering women is likely to accelerate growth in advanced economies that rely mostly on human capital, but may actually hurt growth in economies where physical capital accumulation is the main engine of growth.

We begin our analysis of the specialization hypothesis by developing a tractable theory

\footnotetext{
${ }^{3} \mathrm{~A}$ positive relationship between the female income share and child expenditures has been documented by Thomas (1993), Lundberg, Pollak, and Wales (1997), Haddad, Hoddinot, and Alderman (1997), Attanasio and Lechene (2002), Duflo (2003), Qian (2008), and Bobonis (2009).

${ }^{4}$ Studies that feature a preference gap between husband and wife include Lundberg and Pollak (1993), Anderson and Baland (2002), Basu (2006), Atkin (2009), Bobonis (2009), Browning, Chiappori, and Lechene (2010), and Attanasio and Lechene (2014), although none of these papers explicitly considers the growth effects of transfers to women. In Browning (2000) a preference gap (women discount the future less) arises endogenously from higher female longevity. We examine the effects of transfers in a preference-based model in an earlier version of this paper (Doepke and Tertilt 2011).
} 
of decision making in a household composed of a wife and a husband. The spouses split their time between working in the market and in household production, with the only asymmetry between the spouses being a difference in their market wages. Each spouse makes decisions taking the actions of the other as given, i.e., the household allocation is a Nash equilibrium. An important feature of the environment is that a large number of public goods is produced within the household. Public goods are goods from which both spouses derive utility; examples include shelter, furniture, and the many aspects of spending on and investing in children. Household public goods are differentiated by the importance of goods and time in producing them. In equilibrium, the low-wage spouse (i.e., typically the wife) specializes in providing relatively time-intensive household public goods. ${ }^{5}$

We then ask how a mandated wealth transfer from husband to wife (which is equivalent to the government re-directing a benefit that was previously paid out to the husband to the wife) affects the equilibrium allocation. Even though preferences are symmetric, mandated transfers affect male- and female-provided public goods differently, due to the endogenous specialization pattern in household production. In particular, a transfer to the wife increases the provision of female-provided, i.e. time-intensive, public goods. Given that child-related public goods tend to be time-intensive, the model is consistent with the observed positive effect of transfers targeted to women on spending on children. In addition, a mandated transfer also increases the wife's private consumption and lowers the husband's private consumption. Hence, the specialization hypothesis also rationalizes that transfers lead to more spending on female clothing (Phipps and Burton 1998; Lundberg, Pollak, and Wales 1997), while lowering spending on male clothing, alcohol, and tobacco (Hoddinott and Haddad 1995; Duflo and Udry 2004). ${ }^{6}$

Turning to implications for development, we find that the specialization hypothesis leads to a fundamentally different tradeoff than does the preference hypothesis. ${ }^{7}$ Under the preference hypothesis, i.e., women derive more utility from public goods and men more utility from private goods, when imposing a mandated transfer from men to women the resulting higher public-good spending (such as spending on children) comes

\footnotetext{
${ }^{5}$ Specialization within the household was first discussed in the literature on the sexual division of labor (Becker 1981). However, most of this literature employs unitary or collective models of the household, whereas we embed household production in a noncooperative model. A few authors have also explored a semi-cooperative approach, e.g., Gobbi (2018) and d'Aspremont and Ferreira (2014).

${ }^{6}$ Assuming, of course, that men are more likely to dress in male versus female clothing, and that they spend a greater share of their private consumption on alcohol and tobacco.

${ }^{7}$ Throughout this paper, we use the terms "preference hypothesis" and "preference-based mechanism" for the assumption that women intrinsically care more about children than men do.
} 
at the expense of male private consumption. In contrast, according to the specialization hypothesis the increase in the provision of female-provided public goods comes at least partly at the expense of male-provided public goods.

To spell out what this means for economic growth, we embed our model of household decision making into an endogenous growth model driven by the accumulation of human and physical capital. Parents care about their private consumption and their children's future income, which they can raise by investing in children's human capital (which is time-intensive) and by leaving bequests of physical capital. In equilibrium, bequests are provided by husbands, whereas wives play a large role in human capital accumulation. We show that a mandated transfer from husband to wife leads to an increase in children's human capital, but a decrease in the physical capital stock. Whether such a policy increases economic growth depends on the state of technology. In a setting where human capital is the main driver of growth, mandated transfers to women do promote development, but they slow down economic growth when the share of physical capital in production is large. Given that the human capital share tends to increase in the course of development, our results imply that mandated transfers to women may be beneficial in advanced, human capital-intensive countries, but are unlikely to promote growth in less developed economies.

Of course, the implications of female empowerment for economic development also depend on the relative importance of the specialization hypothesis developed here versus the preference hypothesis. It is not our intention to deny the possibility that men and women have different preferences, ${ }^{8}$ but it is not obvious how important such differences are for explaining the data. Experimental evidence shows that women are more risk-averse than men, but in regard to social preferences (which would be more relevant here) results are inconclusive (Croson and Gneezy 2009). ${ }^{9}$ We also do not claim that our theory accurately describes the behavior of all couples. For the specialization hypothesis to account for the data, we only need that there is a non-negligible fraction of couples who spend their money separately and act noncooperatively along the lines described by the model, while others may pool resources and hence do not respond to mandated transfers.

\footnotetext{
${ }^{8}$ In fact, we allow for a preference gap in our own previous work (Doepke and Tertilt 2009) and provide evolutionary justifications for why such a gap may exist.

${ }^{9}$ There is also evidence that women and men focus on different local public goods as policymakers (Chattopadhyay and Duflo 2004; Beath, Christia, and Enikolopov 2017; Miller 2008), but again such differences could be equally explained by preferences or by endogenous specialization.
} 
To assess the empirical relevance of the specialization hypothesis, we use data from the Mexican PROGRESA Program. This is a well-studied program that has been used before to document that higher female income shares lead to higher spending on children and lower spending on alcohol and tobacco (Attanasio and Lechene 2002). We expand the analysis of Attanasio and Lechene by focusing on total spending and the saving rate. In line with the mechanism of our model, we find that a rise in the female income share not only leads to higher expenditures on children, but also increases total spending and leaves less resources for saving.

Similar findings have been documented by other authors in the context of credit extension (Pitt and Khandker 1998; Khandker 2005) and transfers to small business owners (de Mel, McKenzie, and Woodruff 2009; Fafchamps et al. 2014). Additional relevant evidence is provided by the study of Haushofer and Shapiro (2016) of a field experiment in Kenya that randomized the gender of the recipient of a cash transfer. Once again in line with the specialization hypothesis, they find that ownership of metal roofs (an investment good) increases much more after a transfer if the recipient is male rather than female. In sum, there is by now sizeable empirical evidence supporting the implication of the specialization hypothesis that mandated transfers induce a reallocation from male- to female-provided public goods. We also describe additional empirical implications of the specialization hypothesis that could be tested in future research, such as that mandated transfers should have big effects only when women and men have sharply distinct roles and are specialized in providing different public goods.

Our overall conclusion is that there is good evidence that the specialization hypothesis is relevant. However, we also believe that more work is needed to quantify its importance relative to the preference hypothesis. More generally, to draw reliable conclusions about how household-level interventions will affect development, we need a better understanding of the process of household decision making in developing countries, which requires a back-and-forth between modeling and measurement. Without such an understanding, taking intuitions developed from one particular channel to policy interventions may be premature.

\section{Relationship to Literature}

Our analysis builds on the literature on the noncooperative model of the household, which in turn is closely related to the literature in public economics on the voluntary 
provision of public goods. ${ }^{10}$ Relative to these literatures, a novelty of our paper is that we consider a setting with a continuum of public goods that are distinguished by the time-intensity of production. Another branch of the literature on family decision making relies on cooperative models, where couples can commit to an efficient outcome rather than choosing a best-response strategy. ${ }^{11}$ We rely on a noncooperative model here, because our objective is to explore a channel that does not rely on women and men having different preferences, whereas under cooperative decision making the preference hypothesis turns out to be the only possible explanation for mandated transfers having effects. The reason for this is that in a cooperative model, resources are pooled in the budget constraint, so that mandated transfers cannot affect public-good spending through the constraint set. Rather, the only possibility is that mandated transfers shift the spouses' bargaining power. A shift in bargaining power, in turn, only affects the allocation if women and men have different preferences for public-good spending (at least on the margin). ${ }^{12}$

Another difference between noncooperative and cooperative models is that under noncooperative decision making, the equilibrium allocation is generally not fully efficient. A common argument in favor of efficiency in marriage is that couples are in a long-term relationship and often care about each other. However, to explain why mandated transfers affect outcomes, any model must include some source of inefficiency. The difference is one of degree: a cooperative model capturing the preference hypothesis would satisfy static efficiency but violate ex-ante efficiency (because bargaining power and allocations depending on whether some income is labeled as female or male is not ex-ante optimal), whereas our noncooperative model also allows for static inefficiency. Dynamic inefficiencies can arise from limited commitment (such as the possibility of unilateral divorce, see Mazzocco, Ruiz, and Yamaguchi 2013 and Voena 2015). ${ }^{13}$ A number of empirical papers fail to reject static efficiency, but Naidoo (2015) argues that such tests have

\footnotetext{
${ }^{10}$ See Lundberg and Pollak (1994) and Konrad and Lommerud (1995) for the noncooperative model of the household, and Bergstrom, Blume, and Varian (1986) for a discussion of the voluntary provision of public goods. Some of our theoretical results on the noncooperative model build on Browning, Chiappori, and Lechene (2010) and Lechene and Preston (2011), who work out the properties of noncooperative household demand under general conditions, but do not focus specifically on the issue of differences in the opportunity cost of time within the household. Heath and Tan (2019) provide another recent application of the noncooperative model in a developing-country setting.

${ }^{11}$ See, e.g., Manser and Brown (1980), McElroy and Horney (1981), and Chiappori $(1988,1992)$.

${ }^{12}$ See Blundell, Chiappori, and Meghir (2005) and Cherchye, De Rock, and Vermeulen (2012).

${ }^{13}$ Empirically, dynamic efficiency can be assessed by measuring couples' bargaining power over time. Lise and Yamada (2018) show that in Japanese data, bargaining power responds to relative wages, suggesting dynamic inefficiency.
} 
low power, and Dauphin, Fortin, and Lacroix (2018) find that a more demanding test does reject efficiency in a number of settings. Other authors provide direct evidence of significant static inefficiencies in family decision making in the developing-country context (Udry 1996; Duflo and Udry 2004; Goldstein and Udry 2008). The specialization hypothesis is relevant if at least a fraction of households fails to act cooperatively, which Del Boca and Flinn (2012) argue to be the case even in a rich-country setting. ${ }^{14}$

In our noncooperative model, each spouse has their own individual budget constraint. At first sight, this may appear to be an odd assumption, given that (especially in developed countries) many couples combine their finances. However, it has been documented that families throughout the world use various budgeting systems, and separate accounts are common (Pahl 1983; Pahl 1995; Kenney 2006). In the Western world, separate budgeting is often observed among younger and more affluent couples, couples where both spouses work, as well as cohabiting couples (Lauer and Yodanis 2014; Pahl 2008). Importantly for the purposes of our study, separate budgeting is also prevalent in many developing countries, notably in Sub-Saharan Africa (Pahl 2008). ${ }^{15}$

Our work also relates to a recent political-economy literature on the causal link from development to women's rights (Doepke and Tertilt 2009; Fernández 2014). In contrast to these papers, here we explore the reverse link from female empowerment to economic development. ${ }^{16}$

In the following section, we introduce our baseline model of household decision making and show how mandated transfers to women affect the supply of public goods. In Section 3, we embed this model in a macroeconomic model of endogenous growth, and demonstrate that the growth effect of mandated transfers hinges on the importance of physical versus human capital in production. In Section 4 we contrast the empirical implications of the specialization hypothesis to those of the preference hypothesis, and we provide empirical evidence from Mexico that supports the specialization hypothesis. Section 5 concludes. All proofs and extensions of the baseline model are contained in the online appendix.

\footnotetext{
${ }^{14}$ They estimate that about one-fourth of American couples behave in a noncooperative way. See Mazzocco (2007) for a related test of ex-ante efficiency, Ashraf (2009) for evidence on inefficiency concerning financial choices, and Iyigun and Walsh (2007) on inefficiencies arising from pre-marital investments.

${ }^{15}$ Caldwell (1976) writes about families in tropical Africa: "Husbands were not expected to provide for their wives. In recent years males [...] have continued to resist assuming economic responsibility for their wives."

${ }^{16}$ The role of gender equality for economic growth is also analyzed in Galor and Weil (1996), Lagerlöf (2003), and de la Croix and Vander Donckt (2010), but these papers do not analyze the effects of transfers, and instead focus on the link between gender equality and demographic change.
} 


\section{The Effect of Mandated Transfers on Public-Good Provision in a Noncooperative Model of the Household}

In this section, we describe our baseline model of household decision making, and analyze the implications of mandated transfers for the equilibrium allocation. We consider a couple consisting of a woman and a man who both derive utility from a set of public goods in the household. The two spouses have separate budget constraints, and (following the standard noncooperative model of the household) the provision of public goods is determined as a Nash equilibrium between the spouses.

\subsection{The Household Decision Problem}

Preferences are symmetric between women and men. In particular, the husband and wife have utility functions:

$$
\log \left(c_{g}\right)+\int_{0}^{1} \log \left(C_{i}\right) d i
$$

Here $c_{g}$ is the private-good consumption of the spouse of gender $g \in\{f, m\}$ (female and male), and the $\left\{C_{i}\right\}$ are a continuum of public goods for the household, indexed from 0 to 1 . The public goods represent all final or intermediate goods that the spouses jointly care about, such as shelter or goods related to children. In Section 3 below, we provide a concrete example where all public goods are intermediate goods that affect child quality, but the general analysis is equally applicable to other kinds of public goods. We use log utility to simplify the exposition; however, the main results carry over to more general settings. ${ }^{17}$

A key characteristic of the environment is that the public goods $C_{i}$ are produced within the household using household production functions that combine purchased inputs and time. The spouses split their time between household production and participating in the formal labor market. The only asymmetry between the spouses is a difference in their market wages $w_{g}$.

Different public goods are distinguished by the relative importance of goods and time in producing them. Specifically, each public good is produced using a Cobb-Douglas technology where the share of goods and time varies across goods. Public good $i$ has share parameter $\alpha(i) \in[0,1]$ for the time input and $1-\alpha(i)$ for goods. We assume (without loss of generality) that the function $\alpha(i)$ is such that the public goods are ordered

\footnotetext{
${ }^{17}$ Generalizations in terms of preferences and technologies are discussed in Appendix F.
} 
from the least to the most time-intensive, i.e., $\alpha(i)$ is non-decreasing, with $\alpha(0)=0$ and $\alpha(1)=1$. As we will see, the shape of the $\alpha(i)$ has important implications for the effects of mandated transfers on public-good provision.

Each public good can be produced by either spouse; however, each spouse has to combine labor with his or her own goods contribution. Thus, it is not possible to provide only the goods input for a particular $C_{i}$ and leave it to the spouse to provide the labor. This assumption captures that time and goods inputs often cannot be separated. For example, the public good "getting children fed" requires shopping for groceries first, which takes time and knowledge of what the children like to eat. The spouse who typically does not do the feeding may lack such knowledge. ${ }^{18}$ We show that our results are robust to relaxing this assumption in Section 2.3 below. The assumption that each public good can be produced with equal productivity by either spouse implies that male and female provision are perfect substitutes for a given good. However, the model still allows for complementarities between male and female provision given the way that male- and female-produced public goods enter the overall utility from public goods. Our results hold up as long as the overall substitution of female versus male provision of public goods is not frictionless. While in our model this friction exclusively stems from variation in comparative advantage across a variety of public goods, other mechanisms, such as more pervasive complementarities between female- and male-provided inputs, would yield similar results.

Each spouse maximizes utility, taking the other spouse's behavior (in particular, contributions to public goods, $C_{g, i}$ ) as given. In other words, the solution concept is a Nash equilibrium, which is the sense in which decision making is noncooperative. The problem of the spouse of gender $g \in\{f, m\}$ is to maximize (1) subject to the following constraints:

$$
\begin{aligned}
C_{i} & =C_{f, i}+C_{m, i} \quad \forall i, \\
C_{g, i} & =E_{g, i}^{1-\alpha(i)} T_{g, i}^{\alpha(i)} \quad \forall i, \\
c_{g}+\int_{0}^{1} E_{g, i} d i & =w_{g}\left(1-T_{g}\right)+x_{g},
\end{aligned}
$$

\footnotetext{
${ }^{18}$ The requirement for provision of goods and time by the same spouse can also be microfounded through a monitoring friction, i.e., spouses can provide cash to each other, but they cannot monitor how the cash is being spent. For evidence on asymmetric information and monitoring frictions in families see Chen (2006), Castilla and Walker (2013), de Laat (2014), and Hoel (2015). This still leaves open the possibility of general transfers between spouses that are not targeted towards specific public goods. Such general transfers are considered in Section 2.3 below.
} 


$$
\int_{0}^{1} T_{g, i} d i=T_{g} .
$$

Here $E_{g, i}$ is goods spending on good $i$ by spouse $g, T_{g, i}$ is the time input for good $i, T_{g}$ is the total amount of time spouse $g$ devotes to public goods production, $w_{g}$ is the market wage, and $x_{g}$ is wealth (e.g., an initial endowment or lump-sum transfer). Equation (2) states that the total provision $C_{i}$ of public good $i$ is the sum of the wife's and the husband's contributions. Equation (3) gives the household production function for good $i$, where the share parameters depend on $i$. Equation (4) is the budget constraint of spouse $g$. Each spouse has a time endowment of 1 , so that $1-T_{g}$ is the time supplied to the labor market. Equation (5) is the time constraint, which states that all time contributions to public goods add up to $T_{g} \cdot{ }^{19}$

Note that the maximization problem does not include a participation constraint (i.e., the requirement that each spouse should be better off with the partner compared to being single). The reason is that such constraints would never bind in our model, as each spouse is always at least weakly better off with a partner. This result follows from our assumption of public goods and voluntary contributions. In equilibrium, spouses receive non-negative contributions to public goods from their partner, and they are not giving anything up in order to be together.

Definition 2.1 (Noncooperative Equilibrium). An equilibrium for given wages and wealth levels $\left\{w_{g}, x_{g}\right\}$ for $g \in\{f, m\}$ consists of a consumption allocation $\left\{c_{g}, C_{i}\right\}$ for $g \in\{f, m\}$ and $i \in[0,1]$ and household production inputs and outputs $\left\{E_{g, i}, T_{g, i}, T_{g}, C_{g, i}\right\}$ for $g \in\{f, m\}$ and $i \in[0,1]$ such that for $g \in\{f, m\}$, the choices $c_{g}, E_{g, i}, T_{g, i}, T_{g}, C_{g, i}$, and $C_{i}$ maximize (1) subject to (2) to (5), taken the spouse's public good supplies as given.

We now show that the household bargaining game has a generically unique equilibrium. The reason is that as long as male and female wages are different, each spouse has a comparative advantage in providing either time- or goods-intensive public goods. Hence, the low-wage spouse provides a range of time-intensive goods, whereas the high-wage spouse provides goods-intensive goods. The following proposition summarizes the properties of the equilibrium. We focus on the case of the husband having a higher wage. The case where the wife has a higher wage is analogous.

\footnotetext{
${ }^{19}$ For simplicity, throughout the paper we do not impose a constraint requiring that time spent on market work has to be non-negative. This constraint is never binding if there is only wage income, and imposing the constraint leaves all results intact, while complicating the notation.
} 
Proposition 2.1 (Separate Spheres in Equilibrium). Assume $0<w_{f}<w_{m}$. There is a generically unique Nash equilibrium with the following features. There is a cutoff $\bar{i}$ such that all public goods in the interval $i \in[0, \bar{i}]$ are provided by the husband (i.e., the husband provides goods-intensive goods), while public goods in the range $i \in(\bar{i}, 1]$ are provided by the wife (the wife provides time-intensive goods). Private and public consumption satisfies

$$
C_{i}=\left\{\begin{array}{ccc}
(1-\alpha(i))^{1-\alpha(i)}\left(\frac{\alpha(i)}{w_{m}}\right)^{\alpha(i)} c_{m} & \text { for } i \in[0, \bar{i}], \\
(1-\alpha(i))^{1-\alpha(i)}\left(\frac{\alpha(i)}{w_{f}}\right)^{\alpha(i)} & c_{f} & \text { for } i \in(\bar{i}, 1] .
\end{array}\right.
$$

If the cutoff $\bar{i}$ is interior (i.e., neither spouse is fully specialized in public- or private-good production), it is determined such that female and male provision of public goods is equalized at the cutoff. Hence, if $\bar{i} \in(0,1)$, the cutoff and private consumption satisfy the condition:

$$
\left(\frac{w_{m}}{w_{f}}\right)^{\alpha(\bar{i})}=\frac{c_{m}}{c_{f}}
$$

While a positive gender wage gap is a key assumption throughout the paper, we do not take a stand on what the ultimate driving force behind the wage gap is. For our purposes, it is irrelevant whether it is due to intrinsic productivity differences between genders, discrimination, or a gap in education or experience..$^{20}$

Division of labor in household production is a result shared by many models of the household (see Becker 1981). A more specific feature of our noncooperative model is that there is a division not only in labor inputs but also in decision making. This implication is in line with an empirical literature that finds that many couples separate spheres of responsibility within the household. Such a division is particularly prevalent in Africa (Boserup 1985; Caldwell and Caldwell 1987). ${ }^{21}$ Pahl $(1983,2008)$ reports a sharp division of tasks in two separate studies of British couples. Husbands are often in charge of moving, finances, holidays, home repairs, eating out and the car, while women make decisions regarding interior decoration, food, child care and school expenses, and children's clothing. ${ }^{22}$ The phenomenon that husbands and wives are in charge of different

\footnotetext{
${ }^{20}$ It would be straightforward to derive an endogenous wage gap due to education decisions if one started with a small gender asymmetry, e.g. in time endowments due to pregnancy; see Echevarria and Merlo (1999) for such a model.

${ }^{21}$ Citing from Boserup (1985, p.388) "Even though African women often provide the primary or sole economic support of children, their husbands [...] have the right to decide on the living arrangements, education, future occupation, and marriage partners of their children."

${ }^{22}$ There is also evidence that the public goods provided by women are indeed more time intensive
} 
purchasing decisions is studied also in the marketing literature. ${ }^{23}$

The idea of separate spheres in decision making was first introduced into economics by Lundberg and Pollak (1993). However, Lundberg and Pollak assume an exogenous separation of spheres, whereas our model features an endogenous separation. ${ }^{24}$ This distinction is important, since the division of spheres may change in response to government policy, as we will see in the next section.

\subsection{Effect of Mandated Transfers on Public-Good Provision}

With the equilibrium characterization at hand, we can now ask how changes in relative female and male wealth affect outcomes. Specifically, we are interested in whether (and how) giving a government transfer to the woman instead of the man affects the allocation. We model this formally as a mandated wealth transfer from husband to wife. However, it should be easy to see that this results in the same comparison as giving a specified amount of aid to either one spouse or the other.

Consider a mandated wealth transfer from the husband to the wife, i.e., an increase $\epsilon>0$ in the wife's wealth $x_{f}$ and a corresponding decline in the husband's wealth $x_{m}$. Given (6), we see that any two public goods that are provided by the same spouse both before and after a change in transfers will still be provided in the same proportion, because public-good provision is proportional to private consumption. However, the wife's private consumption rises relative to the husband's private consumption after the transfer, which also implies that the transfer increases the provision of female-provided public goods relative to male-provided public goods.

Proposition 2.2 (Effect of Mandated Transfers on Public Good Provision). Assume $0<$ $w_{f}<w_{m}$ and that $\alpha(i)$ is strictly increasing in $i$. Consider the effects of a transfer $\epsilon>0$ from the husband to the wife, i.e., the wife's wealth increases from $x_{f}$ to $\tilde{x}_{f}=x_{f}+\epsilon$, and the husband's

than those that husbands are in charge of. Aguiar and Hurst (2007) show that in the United States, the most time intensive home production categories are cooking and cleaning, shopping, and child care, all of which are tasks that are predominantly done by women. The only category where men provide more time than women comprises home maintenance, outdoor cleaning, vehicle repair, gardening, and pet care. This is also the smallest category overall in terms of time use.

${ }^{23}$ For example, Wolgast (1958) finds that women are more likely to be in charge of general household goods, while husbands are often in charge of car purchase decisions. Green and Cunningham (1975) finds that groceries fall in the female sphere, whereas life insurance and car purchase decisions are typically in the male sphere. See also Davis (1976) for a survey.

${ }^{24}$ Browning, Chiappori, and Lechene (2010) derive a similar seperate-spheres result in a model with a finite number of public goods, but in their model specialization is driven by different preferences rather than different wages and home production. 
wealth decreases from $x_{m}$ to $\tilde{x}_{m}=x_{m}-\epsilon$. Let $\tilde{i}$ be the new cutoff between male and female provision, and let $\tilde{c_{f}}, \tilde{c}_{m}$, and $\tilde{C}_{i}$ denote the new equilibrium allocation. If the cutoff is interior both before and after the transfer, then the cutoff decreases, $\tilde{i}<\bar{i}$. The ratio of female private consumption to male private consumption $\tilde{c_{f}} / \tilde{c_{m}}$ increases after the transfer. The ratio of always female-provided public goods $(i \geq \bar{i})$ to always male-provided public goods $(i \leq \tilde{i})$ increases by the same percentage. Hence, a transfer to the low-wage spouse increases the relative provision of public goods provided by this spouse.

At first sight, the finding that a transfer to a spouse increases the public-good provision of this spouse may seem unsurprising. However, it stands in contrast to a well-known result in public economics on the private provision of public goods. The result states that when the equilibrium is interior in the sense that all providers make voluntary contributions (in this case, husband and wife), a redistribution of income between the providers leaves the equilibrium allocation unchanged, so that a (local) version of income pooling prevails. ${ }^{25}$

In our model, the income pooling result breaks down because of the continuum of public goods. It is well-known that income redistribution does matter in voluntary contribution games with a finite number of goods if the equilibrium is at a corner. ${ }^{26}$ Because of our continuum of goods, even though the allocation is interior in the sense that both spouses contribute to public goods, each good is provided by only one spouse, so that there is a corner solution for any given public good. In this setting, the key determinant of the new level of public-good provision after a transfer is the move in the cutoff between male and female provision of public goods. The force that increases female provision is that the wife receives the transfer; the force that lowers female provision is that in the new equilibrium, the wife provides a wider range of public goods. In the classic public-economics result, the increased contributions of one spouse are fully offset by a reduction in contributions of the other spouse. In contrast, in our model the move in the cutoff does not fully offset the direct effect of the transfer. When wealth is transferred to the wife, the provision cutoff moves towards public goods that are more goods-intensive, and hence public goods where the wife has a smaller comparative advantage. This unfavorable shift in comparative advantage slows down the adjustment of the provision cutoff compared to a setting where all public goods are produced with the same technology.

\footnotetext{
${ }^{25}$ See Warr (1983) and Bergstrom, Blume, and Varian (1986).

${ }^{26}$ Browning, Chiappori, and Lechene (2010) make this point in the context of a household bargaining model with a finite number of public goods.
} 
The model implications are consistent with the empirical evidence on the effects of targeted transfers described in the introduction. Notice that there are no empirical studies that have information on all public and private goods produced and consumed within a household. Rather, only a few spending categories can be assigned to a specific person or can be unambiguously considered public. Studies that point to an increase in publicgood spending after a mandated transfer to the wife often focus on food and children's clothing. To the extent that these goods are usually female-provided, our theory predicts that spending on these goods should rise after a transfer to the wife. ${ }^{27}$ Regarding private goods, empirical studies often consider male and female clothing and luxuries such as alcohol. Our theory predicts that after a mandated transfer, female private consumption should rise and male consumption should fall. Thus, the theory is consistent with the observation that after a transfer, female clothing purchases increase relative to male purchases, while spending on alcohol declines, as long as (realistically) men have a higher propensity to spend on alcohol than women do. ${ }^{28}$

We now illustrate these results with a computed example. The household production functions are parameterized by $\alpha(i)=i$, i.e., time intensity varies linearly with the index of the public good. This setting is of special interest, because it implies that the overall household production technology is symmetric in terms of time versus goods intensity. We also set the female wage to half the male wage, $w_{f}=0.5$ and $w_{m}=1$, and initial wealth is zero, $x_{f}=x_{m}=0$.

Figure 1 shows the preferred provision of each public good by the wife and husband, holding the marginal utility of wealth constant at its equilibrium level. The preferred provision curves of both spouses are U-shaped. This shape is due to the Cobb-Douglas production technology, which induces a U-shape in unit production costs of the public goods. More importantly, the wife's preferred provision curve has a uniformly larger slope than the husband's, i.e., the wife's preferred provision increases relative to the husband's as the index $i$ increases. This follows because time intensity is increasing in $i$, and the wife has a comparative advantage at providing time-intensive public goods because of her lower market wage $w_{f}$.

\footnotetext{
${ }^{27}$ One may also wonder how the time allocation shifts in response to a transfer. However, we are not aware of empirical studies that study shifts in time use in response to transfers. In the model, total female home production increases, whereas male home production time goes down. The effect on total home time is ambiguous and depends on parameters.

${ }^{28}$ Our model only allows for a single homogeneous private consumption good, but it is straightforward to reinterpret the findings in a setting where male and female private consumption correspond to different bundles of goods.
} 


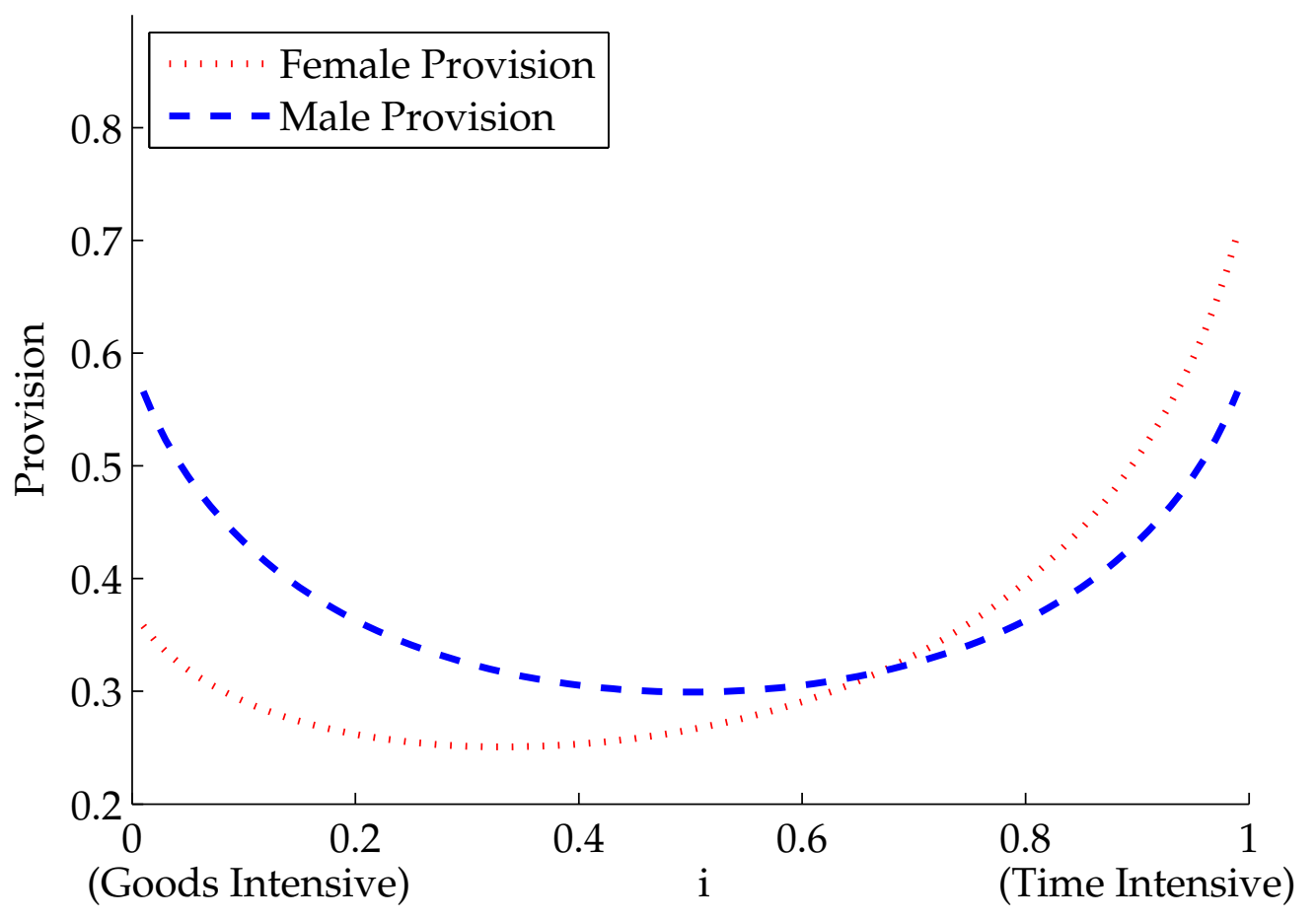

Figure 1: Preferred Provision of Each Public Good for $w^{f} / w^{m}=0.5$. Dotted line: Preferred Provision by Wife. Dashed Line: Preferred Provision by Husband.

In equilibrium, each public good is provided by the spouse with the higher preferred provision level. Hence, as displayed in Figure 2, the equilibrium provision curve is the upper envelope of the female- and male-preferred provision curves. The vertical line in Figure 2 denotes the cutoff $\bar{i}$ : to the left of this point, goods are provided by the husband, and to the right they are provided by the wife.

Next, consider how the equilibrium provision of public goods changes if a mandated wealth transfer from the husband to the wife is imposed. Figure 3 compares the baseline displayed in Figure 2 to the equilibrium outcome when the husband has to make a transfer of $\epsilon=0.3$ to the wife (given that initial wealth was set to zero, this implies that the new wealth levels are $x_{f}=0.3$ and $x_{m}=-0.3$ ). After the transfer, the equilibrium cutoff between male and female provision of public goods moves to the left, i.e., the wife (who now has higher wealth) provides a wider range of public goods. However, in line with Proposition 2.2, the move in the cutoff does not fully offset the impact of the wealth transfer: equilibrium provision of all public goods that were female-provided before the transfer goes up, and equilibrium provision of public goods that are always male- 


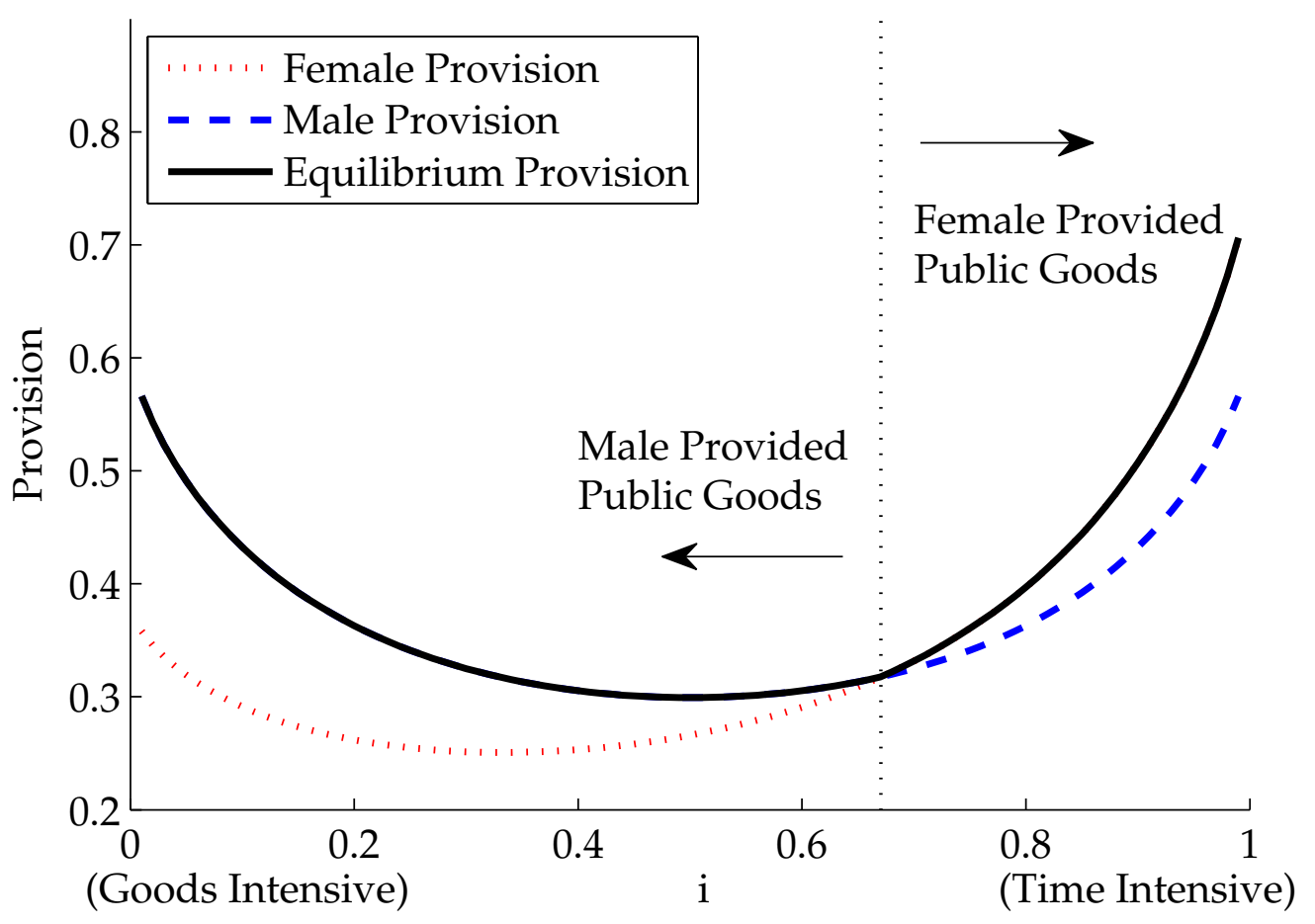

Figure 2: Provision of Each Public Good for $w^{f} / w^{m}=0.5$. Dotted line: Preferred Provision by Wife. Dashed Line: Preferred Provision by Husband. Solid Line: Actual Provision.

provided goes down. In between the old and the new cutoff, the equilibrium provider switches from husband to wife, implying that the new equilibrium provision curve has a larger slope after the transfer compared to the initial equilibrium.

Notice that the wife's comparative advantage in providing time-intensive goods (which follows from the lower female market wage) combined with the variation in the share parameter $\alpha(i)$ is the only force in our model that slows down the shift in the cutoff between male and female provision after a transfer, relative to a benchmark where there is no variation in the wife' comparative advantage across public goods. ${ }^{29}$ Any additional forces that also slow down the shift in the cutoff would further strengthen our results. The most extreme case would be a setting where the cutoff $\bar{i}$ is fixed and does not respond to transfers at all, perhaps because the division of labor is set by social norms. Alternatively, consider a setting with learning by doing, i.e., the spouses become more efficient over time at producing the public goods that they provide. In such a setting

\footnotetext{
${ }^{29}$ That is, in the benchmark we either have $w_{m}=w_{f}$ or $\alpha(i)$ constant, in which case the classic neutrality result in public good provision of Warr (1983) and Bergstrom, Blume, and Varian (1986) obtains.
} 


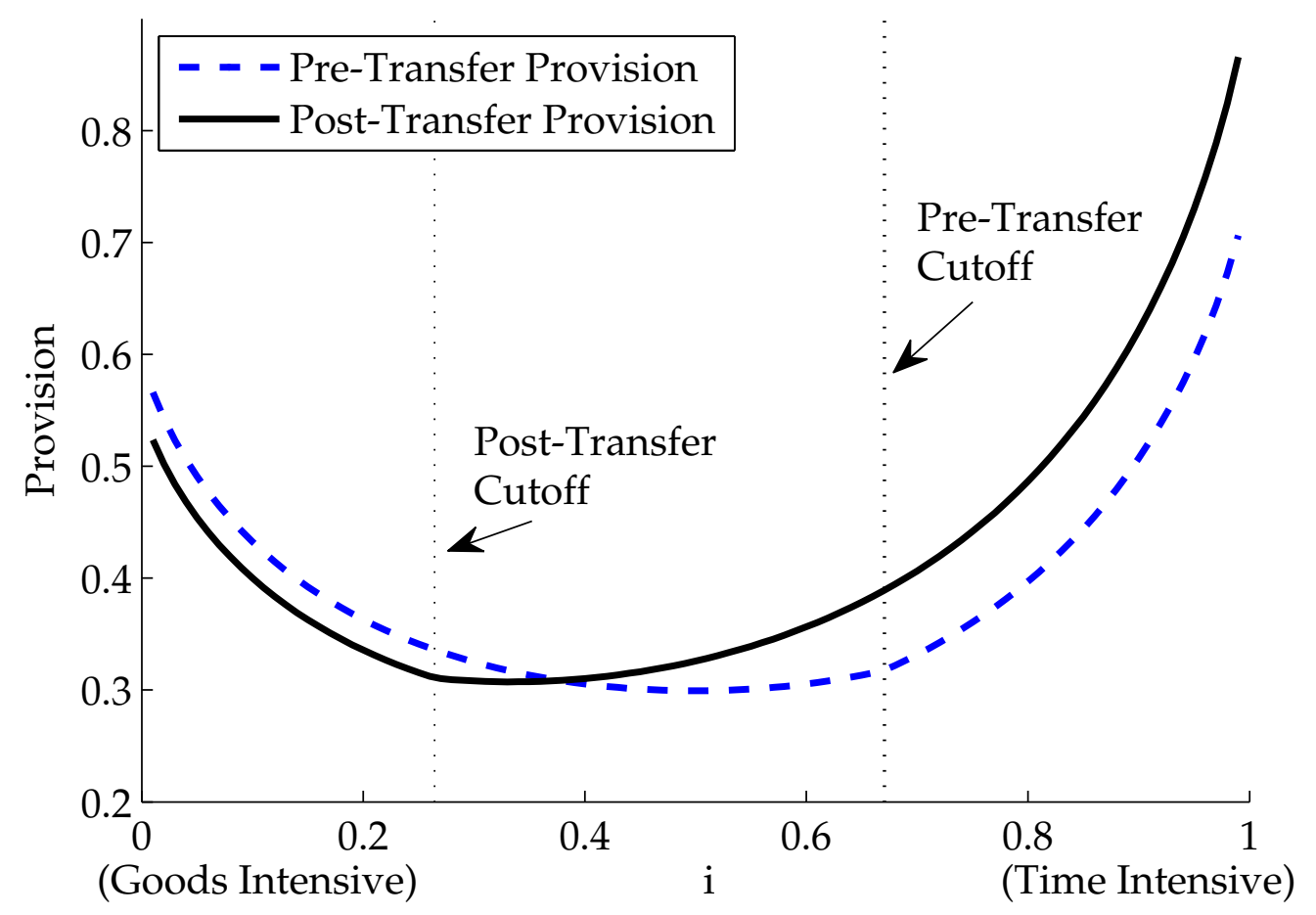

Figure 3: Provision of Each Public Good for $w^{f}=0.5, w^{m}=1$ Before and After Transfer of $\epsilon=0.3$ from Husband to Wife. Dashed Line: Pre-Transfer Equilibrium Provision. Solid Line: Post-Transfer Equilibrium Provision.

each spouse would gain an absolute advantage at providing a certain range of public goods, which would make the cutoff shift more slowly and result in larger effects of mandated transfers on public good provision. Another extension of the model that would strengthen our findings is one where the Inada condition for public goods provision does not hold, so that there can be cases where some public goods are not provided at all. An example is a variant of the baseline model with the utility function given by

$$
\log \left(c_{g}\right)+\int_{0}^{1} \log \left(C_{i}+\hat{C}\right) d i
$$

with the parameter $\hat{C}>0$. In this model there can be equilibria (depending on income and wages) where the woman provides time-intensive public goods, the man provides goods-intensive public goods, and there is an intermediate range which are provided by neither spouse. In such an equilibrium, there is no public good where the two spouses have the same preferred provision level, which has the effect of hindering the substitution between female and male provision of public goods. As a result, as in the baseline 
model a transfer from husband to wife increases the provision of female-provided public goods and lowers the provision of male-provided public goods. We focus on the case where the cutoff $\bar{i}$ is highly responsive to show that our mechanism is robust, but as this discussion shows, a number of arguably plausible model elements could be used to further strengthen the findings.

\subsection{Voluntary Transfers between the Spouses}

In our baseline model, the only way in which the spouses interact is through their provision of public goods. An additional interaction that we have not considered so far is voluntary transfers between the spouses. This is a potentially important limitation, because in reality transfers between spouses are frequently observed. In this section, we explore how results change if we allow for such transfers.

There are two different types of voluntary transfers that can be considered. The first possibility is a transfer for a specific use, namely, for buying the goods input for a specific public good, while prohibiting other uses (such as diverting the transfer to buy private goods). In our baseline model, such specific transfers are ruled out by the assumption that in the production of any given public good, the same spouse has to provide both the goods and the time input. The reason for this assumption is that we envision that time and goods components of a given public good are required at the same time, and the other spouse is not able to monitor ex post how funds were used. Direct monitoring would require time, which is a costly input by itself. Another way to monitor would be to ask the spouse to provide receipts to prove that certain expenses have been made, but this does not provide perfect monitoring either. ${ }^{30}$ However, one might argue that monitoring is possible in at least some cases, and hence we consider the possibility of specific transfers below.

For now, we consider the second possibility, namely a general transfer from one spouse to the other that can be used in any way the recipient sees fit. Even though the spouses

\footnotetext{
${ }^{30}$ Some evidence on this is provided by Zelizer (1989), who shows that it was common for American women around the turn of the twentieth century to gain private resources from husbands by padding bills. An example is given from a 1890 newspaper, where it was described that women routinely engaged in domestic fraud, e.g. by getting the hatmaker to send a bill for 40 dollars when the hat had cost only 30. A second example is given where a woman would regularly tell her husband that flour is out or sugar low (when it was not) to get cash to spend according to her own desires (p. 357-358). Zelizer also reports a similar type of deception by husbands who would misreport their paychecks. A study in Chicago from 1924 found that when asked about their husband's paycheck, over two-thirds of women reported an amount lower than the actual earnings. This was sometimes achieved by taking money out of the paycheck envelope before bringing it home (Zelizer 1989, p. 364).
} 
act noncooperatively, it may still be in the interest of the richer spouse to make such a voluntary transfer, because this may induce the other spouse to provide more public goods. To model this possibility, we extend our model by adding an initial stage in which the spouses can make voluntary transfers, followed by the noncooperative provision game as described above.

To simplify the analysis, we focus on a voluntary transfer from the high-wage spouse (the husband) to the low-wage spouse (the wife). A transfer in this direction is more likely to be attractive, because it allows the low-wage spouse to spend more time on home production, which increases overall efficiency and public good provision. The transfer takes the form of a lump sum payment (an "allowance"), which the receiving spouse is then able to use in her preferred way in the second stage. We start by formally defining an equilibrium with voluntary transfers.

Definition 2.2 (Equilibrium with Voluntary Transfer). Let $V_{m}\left(w_{f}, w_{m}, x_{f}, x_{m}\right)$ denote the equilibrium utility of the husband corresponding to the equilibrium in Definition 2.1, given wages $w_{f}, w_{m}$ and wealth levels $x_{f}, x_{m}$ (this utility is unique because of Proposition 2.1). An equilibrium of the model where voluntary transfers are allowed consists of an initial transfer $X$ and an equilibrium as defined in Definition 2.1 for wages $w_{f}, w_{m}$ and wealth levels $x_{f}+X, x_{m}-$ $X$ such that the transfer satisfies:

$$
X=\underset{0 \leq X \leq w_{m}+x_{m}}{\operatorname{argmax}}\left\{V_{m}\left(w_{f}, w_{m}, x_{f}+X, x_{m}-X\right)\right\} .
$$

That is, the husband picks a non-negative transfer to maximize his own ex-post utility.

The possibility of voluntary transfers is important, because if such transfers are present, mandated transfers imposed from the outside may no longer be effective. Intuitively, if the husband finds it optimal to transfer money to his wife, he can reduce his voluntary transfer by the amount of the mandated transfer, resulting in the same ultimate equilibrium. The following proposition makes this point precise.

Proposition 2.3 (Offsetting Voluntary and Mandated Transfers). Consider an equilibrium with transfers as defined in Definition 2.2 where the optimal transfer satisfies $X>0$. If before the voluntary transfer takes place a mandated transfer of $\epsilon \leq X$ to the wife is imposed on the husband, the husband will reduce the voluntary transfer to $X-\epsilon$, and the resulting equilibrium allocation will be unchanged. 
Hence, for our theory of the effects of mandated transfers to be viable, we need to check that it is not always in the husband's interest to make a voluntary transfer. The attraction of a voluntary transfer is that it allows the wife to spend more time on home production, from which the husband benefits. This motive for making transfers is especially pronounced if the wage gap between husband and wife is large. However, there is also a downside to making a transfer, which is that at least part of the transfer will be diverted for the wife's private consumption. We now establish that even if the wage gap between the spouses is arbitrarily large, the husband does not always want to make a transfer.

Proposition 2.4 (Non-Optimality of Voluntary Transfers). Consider the marginal impact of a voluntary transfer on the husband's utility. As the relative wealth of the spouses approaches the level at which $\bar{i}=0$ (all public goods are provided by the wife), this marginal impact is negative:

$$
\lim _{x_{f} \rightarrow 2\left(w_{m}+x_{m}\right)-w_{f}}\left\{\left.\frac{\partial V_{m}\left(w_{f}, w_{m}, x_{f}+X, x_{m}-X\right)}{\partial X}\right|_{X=0}\right\}<0 .
$$

Hence, the husband does not provide voluntary transfers if relative wealth is close to this level.

In practice, for realistic wage gaps the husband does not want to provide a voluntary transfer for most of the range of initial income distributions. Specifically, voluntary transfers do not arise for all numerical examples that we present. Also notice that for the specialization hypothesis to matter empirically, it is not necessary that voluntary transfers are absent in all families. Rather, it is sufficient that there are at least some families where such transfers do not take place, and where transfers mandated from the outside are therefore effective. Our theory should be thought of as modeling the lesscooperative couples who do not make voluntary transfers and who therefore account for the empirically observed effects of mandated transfers.

Our setting is even more plausible if we consider a dynamic extension with repeated interactions, where we interpret our model as describing decision making in a given period. If incomes fluctuate from period to period, husbands may make transfers in periods when they have high income but not in others. The specialization hypothesis is relevant as long as there are at least some couples who do not make transfers every single period. Even if there are occasional transfers in all couples (say, at the very beginning of the relationship), the mechanism still has bite.

We now turn to the second type of voluntary transfer, namely a transfer for the purchase of the goods input for a specific public good. In the baseline model, we motivated the 
absence of such transfers by a monitoring friction, which implies that goods and time inputs for any given public good have to be provided by the same spouse. In reality, this monitoring friction will likely not apply to all goods. For example, whereas some goods are consumed in the process of public good production (such as food for the children that has already been eaten), in other cases the richer spouse will be able to inspect that the required goods have been bought. To deal with this possibility, in Appendix E we develop an extension of our model by allowing for the existence of two types of public goods: those easy to monitor and those where monitoring is not possible. Concretely, in our model this means that in addition to the individually produced public goods as before, we now add jointly produced public goods where goods inputs provided by one spouse can be combined with time input of the other spouse. Combining goods from one spouse with time from the other is equivalent to providing a specific transfer to the spouse who is providing the time in order to buy the goods. In the appendix, we show that the main results still go through in this extended setting. Specifically, in equilibrium the richer spouse will provide the goods input for all public goods that can be monitored, and the poorer spouse will provide the time input for those goods. Regarding the non-monitored goods, the equilibrium characterization and the effect of mandated transfers are as in the baseline model. Hence, the extension shows that our setting is consistent with frequent (specific) transfers between spouses, yet mandated (general) transfers imposed from the outside still affect the equilibrium allocation.

\subsection{Do Mandated Transfers Increase the Total Provision of Public Goods?}

Our analysis so far provides a new rationale for why, empirically, mandated transfers to women have an impact on the household allocation that is different from the impact of transfers to men. From the perspective of policy implications, there is a central difference between our specialization hypothesis and the preference hypothesis. In a model where mandated transfers affect allocations because women value public goods more than men do, the increase in public-good spending brought about by a transfer comes exclusively at the expense of men's private consumption. In contrast, according to the specialization hypothesis an increase in public good spending by women comes at least partially at the expense of male-provided public goods. For this reason, whether mandated transfers to women are good policy is not obvious.

To assess the desirability of mandated transfers in our model, in Appendix C we examine the effect of transfers on the total utility derived from public goods, which is given 
by:

$$
\int_{0}^{1} \log \left(C_{i}\right) d i
$$

While maximizing the utility derived from public goods is not equivalent to maximizing welfare, public good provision is generally inefficiently low in our model (as shown in Appendix B), so that an increase in public good provision moves the economy closer to efficiency. Moreover, in the growth model developed in Section 3 maximizing utility derived from public goods corresponds to maximizing the growth rate of the economy. There, asking whether mandated transfers increase utility derived from public goods amounts to asking whether transfers promote economic development, which is the question that motivates this paper.

In the appendix, we show that there are three channels through which a mandated transfer affects the total provision of public goods. The expenditure-share channel implies that a transfer towards the spouse whose share in public-good provision exceeds his or her share in total income raises total public goods spending. This is particularly obvious in a corner solution where one spouse provides all of the public goods. At this corner, the non-providing spouse has a marginal propensity to spend on public goods of zero, implying that transferring funds from the non-provider to the provider (who has a positive propensity to spend on public goods) will increase total provision. The expenditure share channel is also the only channel at work if the cutoff $\bar{i}$ does not change in response to the transfer, say, because each spouse has a strong comparative advantage for a distinct range of public goods. More generally, if one spouse is responsible for providing most public goods, transfers to this spouse will tend to increase public-good provision.

The other two channels are generated by the change in the cutoff $\bar{i}$ between male and female public good provision brought about by a mandated transfer. The efficiency channel arises because the spouse with a lower market wage has a comparative advantage in household production. Hence, if the low-wage spouse substitutes into household production and the high-wage spouse into market production, the overall efficiency of time use in the household is improved. Finally, the change in the cutoff $\bar{i}$ also implies that the resources of the provider receiving the transfer are spread over more public goods, while the other spouse can focus on a smaller range, which gives rise to the reallocation channel.

In the appendix, we provide conditions under which the expenditure share channel dominates. If these conditions are satisfied, mandating a transfer from men to women 
will lower or increase public-good provision depending on which spouse provides most public goods. This finding is important because of the contrast it provides to a model that is based on the preference hypothesis. In a preference-based model, mandated transfers to the spouse who values public goods more always increase public good provision. In contrast, our household production model suggests that the effects of such a policy are not uniform, and may depend on the stage of development and on local economic conditions.

We now build on this analysis to ask under which conditions a mandated transfer is growth-enhancing within a growth model driven by the accumulation of physical and human capital.

\section{Growth Implications of Mandated Transfers}

The results of the analysis above suggest that the effects of gender-targeted transfers on development depend on the relative importance of male- versus female-provided public goods in production. In this section, we spell out this link using a simple growth model in which we identify male-provided public goods with household saving and investment. Buying land, farm animals, or physical capital involves mostly money and little time, and thus falls on the goods-intensive side of the range of public goods. In contrast, we identify time-intensive inputs in child rearing, which are predominantly femaleprovided, as being associated with the accumulation of human capital. In this framework, we show that the growth effect of mandated transfers that redistribute wealth from men to women switches signs as the economy becomes more intensive in human capital.

\subsection{A Growth Model with Physical and Human Capital}

We consider a model economy that is populated by successive generations of constant size. Thus, each couple has two children, one boy and one girl. There is measure one of couples in each generation. The preferences of a spouse of gender $g$ are given by the utility function:

$$
\log \left(c_{g}\right)+\log \left(y^{\prime}\right) .
$$

Here $c_{g}$ is the private consumption of spouse $g$, and $y^{\prime}$ is a measure of the full income of the children in the next period (i.e., when the children are adults). Thus, we capture altruism towards children in a warm-glow fashion. 
Output is produced using an aggregate production function that employs physical capital $K$ and human capital $H$ :

$$
Y=A K^{1-\theta} H^{\theta} .
$$

Below, we consider how the effects of mandated transfers depend on the share of human capital $\theta$. We denote the endowment of a specific couple with physical and human capital by $k$ and $h$.

Given the production function, parents can raise their children's future income in two different ways: by investing in their human capital, or by leaving them a bequest in the form of physical capital. Physical capital fully depreciates each generation. The children's physical capital $k^{\prime}$ is the sum of the bequests $b_{f}$ and $b_{m}$ left by the mother and father:

$$
k^{\prime}=b_{f}+b_{m} .
$$

The production of human capital, in contrast, is a more complex process that involves combining many different inputs in a household production function. The log of the children's human capital $h^{\prime}$ is given by:

$$
\log \left(h^{\prime}\right)=\int_{0}^{1} \log \left(C_{j}\right) d j
$$

where, as in the analysis in the preceding sections, $C_{j}$ is composed of the contributions of both spouses: $C_{j}=C_{f, j}+C_{m, j}$, and each spouse's contribution is produced with a CobbDouglas technology using expenditure inputs $E_{g, j}$ and time inputs $T_{g, j}$, the productivity of which depends on human capital $h$ :

$$
C_{g, i}=E_{g, j}^{1-j}\left(T_{g, j} h\right)^{j} .
$$

Hence, the various $C_{g, j}$ serve as intermediate inputs in the production of children's human capital. The interpretation is that the accumulation of human capital requires some relatively goods-intensive inputs such as food, clothing, shelter, and health investments, but also more time-intensive inputs such as child-rearing, education, and enrichment activities. The essential point here is that compared to physical capital (which consists entirely of goods), human capital is more intensive in parental time.

We assume that the production technology (9) for the final good (which can be used for consumption, for intermediate goods in the production of human capital, or for bequests) is operated by a competitive industry, so that the market wage $w$ and the return 
on capital $r$ are given by marginal products. The children's full income enters the parents' utility function in the following form:

$$
y^{\prime}=r^{\prime} k^{\prime}+w^{\prime} h^{\prime} .
$$

Here $r^{\prime}$ and $w^{\prime}$ denote the return to capital and the wage in the next period. Hence, the full income can be interpreted as the market value of the entire bequest absent frictions (such as gender discrimination). Given these preferences, parents are indifferent about the division of bequests between their children. We assume that the total amounts of physical and human capital given to the children are divided equally between the two, which would be the unique equilibrium if parents cared separately about the full income of sons and daughters, i.e., bequests entered as $\log \left(y_{f}^{\prime}\right)+\log \left(y_{m}^{\prime}\right)$.

So far, our setup does not feature any gender asymmetry. The only asymmetry that we introduce is an exogenous gender wage gap, in the sense that women's market productivity relative to men is given by $\delta<1$. That is, the female wage per unit of human capital supplied to the labor market is $w_{f}=\delta w$, whereas the male wage is $w_{m}=w$. Clearly, it would be interesting to endogenize the gender wage gap, and to consider the repercussions of the gender wage gap for differential investment in boys and girls (which we rule out be imposing an equal division of bequests). However, our focus is on the growth effect of mandated transfers for a given gender wage gap, and these results depend on the size but not the source of the gender gap. Hence, to isolate the effect of a single gender asymmetry (and also to simplify the following analysis) we impose the gender wage gap exogenously.

As in the preceding analysis, husband and wife individually decide on labor supply, household production inputs, and also on bequests. Each spouse thus maximizes (8) subject to (10)-(13) and the following budget constraint:

$$
c_{g}+b_{g}+\int_{0}^{1} E_{g, j} d j=w_{g} \frac{h}{2}\left(1-\int_{0}^{1} T_{g, j} d j\right)+r \frac{k}{2}+\tau_{g} .
$$

The factor of one-half on the right-hand side appears because each spouse controls only one-half of the total physical and human capital endowments provided by his or her respective parents (given two-child families). In addition to capital income, a spouse also receives the mandated wealth transfer $\tau_{g}$ where (to allow for market clearing) we impose:

$$
\tau_{f}+\tau_{m}=0
$$


We interpret the transfer as government-mandated redistribution of wealth between husbands and wives. Our aim is to consider how such transfers affect the growth rate of the economy. As in our discussion above, comparing different levels of transfers is equivalent to comparing economies where a given transfer (financed by lump-sum taxes) is paid out either to husbands or to wives.

To close the economy, we specify the market clearing conditions for physical and human capital, which (given measure one of identical families) are given by:

$$
\begin{gathered}
K=k \\
H=\frac{1}{2}\left[1-\int_{0}^{1} T_{m, j} d j+\delta\left(1-\int_{0}^{1} T_{f, j} d j\right)\right] h .
\end{gathered}
$$

We start our analysis of the growth model with a closer look at the household decision problem. First, we provide an alternative representation of the utility function (8).

Lemma 3.1 (Representation of Preferences). The preferences given by the utility function (8) can be represented equivalently by the utility function:

$$
U\left(c_{g}, k^{\prime}, h^{\prime}\right)=\log \left(c_{g}\right)+\beta_{k} \log \left(k^{\prime}\right)+\left(1-\beta_{k}\right) \log \left(h^{\prime}\right)
$$

where $\beta_{k}$ is given by:

$$
\beta_{k}=\frac{(1-\theta) \phi}{\theta+(1-\theta) \phi},
$$

and $\phi$ denotes the fraction of human capital employed in market production (which is taken as given by the individual).

Hence, the implicit weight $\beta_{k}$ on the bequest $k^{\prime}$ in utility is decreasing in the share $\theta$ of human capital in goods production (9), whereas the weight on the children's human capital $h^{\prime}$ is increasing in $\theta$.

Next, we show that the household decision problem in the growth model is a special case of the general noncooperative model analyzed in Section 2.

Lemma 3.2 (Relation to General Decision Problem). The individual decision problem in the growth model of maximizing (15) subject to (10) to (14) is a special case of the general decision problem in Section 2 of maximizing (1) subject to (2) to (5). Specifically, to map the problem in 
the growth model into the general decision problem, the function $\alpha(i)$ is set to:

$$
\alpha(i)=\left\{\begin{array}{ccc}
0 & \text { for } & 0 \leq i \leq \beta_{k}, \\
\frac{i-\beta_{k}}{1-\beta_{k}} & \text { for } & \beta_{k}<i \leq 1,
\end{array}\right.
$$

where $\beta_{k}$ is given by (16). Let $\tilde{w}_{g}$ and $\tilde{x}_{g}$ denote the wages and wealth levels pertaining to the general decision problem. These are set to:

$$
\begin{aligned}
& \tilde{w}_{g}=\frac{1}{2} w_{g} h, \\
& \tilde{x}_{g}=\frac{1}{2} r k+\tau_{g} .
\end{aligned}
$$

Let $\tilde{c}_{g}, \tilde{C}_{i}, \tilde{C}_{g, i}, \tilde{E}_{g, i}, \tilde{T}_{g, i}$ and $\tilde{T}_{g}$ denote the equilibrium choices in the general decision problem given $\alpha(i), \tilde{w}_{g}$, and $\tilde{x}_{g}$ as specified in (17) to (19). The equilibrium choices in the decision problem in the growth model can then be recovered as follows:

$$
\begin{aligned}
& c_{g}=\tilde{c}_{g}, \\
& b_{g}=\int_{0}^{\beta_{k}} \tilde{C}_{g, i} d i, \\
& E_{g, j}=\left(1-\beta_{k}\right) \tilde{E}_{g, \beta_{k}+j\left(1-\beta_{k}\right)} \quad \forall j \in[0,1], \\
& T_{g, j}=\left(1-\beta_{k}\right) \tilde{T}_{g, \beta_{k}+j\left(1-\beta_{k}\right)} \quad \forall j \in[0,1] .
\end{aligned}
$$

Intuitively, the bequest in the growth model corresponds to a range of household public goods in the general model for which we have $\alpha(i)=0$, i.e., the time component is zero and the goods component is one. The remaining public goods contribute to the production of human capital. The implicit weight of the bequest in the utility function depends on the weight of physical capital in the production function. The more important physical capital is for production, the more important the physical bequest becomes in the parent's utility function, and the more goods-intensive public goods are on average. Conversely, an increase in the human capital intensity of production also increases the implicit weight on children's human capital in parental preferences, which enhances the importance of time in producing public goods.

Lemma 3.2 implies that, given state variables $k$ and $h$, the results from Section 2 apply. Specifically, this means that in equilibrium only husbands provide bequests (because bequests are goods-intensive). Further, assuming the equilibrium is interior, there is a 
cutoff such that among the public goods that are inputs into human capital, the husband will be in charge of the less time-intensive inputs (such as shelter), while the wife specializes in time-intensive activities such as doing homework with the children. It follows that a mandated transfer to women will increase human capital, while a transfer to men will increase bequests and hence physical capital. This is consistent with the evidence, cited in the introduction, that transfers to women tend to increase total household spending (which by construction must lower savings).

\subsection{When Do Mandated Transfers Increase Growth?}

We now would like to assess the implications of these relationships for the effect of mandated transfers on economic growth. As a first step, the following proposition characterizes the equilibrium for the model economy in the case where mandated wealth transfers are proportional to output. The economy converges to a balanced growth path with a constant growth rate. Even during the transition to the growth path, the time allocation is constant, and consumption and bequests are constant fractions of income per capita.

Lemma 3.3 (Equilibrium Characterization). If mandated transfers are proportional to output, $\tau_{f}=-\tau_{m}=\gamma Y$ for some $\gamma \geq 0$, equilibrium consumption and bequests are a fixed fraction of output also, and the time allocation is constant, i.e. independent of the state variables $k$ and $h$.

Next, we establish the key result of this section: The effect of mandated transfers on growth rates depends on the share of human capital in production.

Proposition 3.1 (Growth Implications of Mandated Transfers). Let mandated transfers be proportional to output, $\tau_{f}=-\tau_{m}=\gamma Y$ for some fixed scalar $\gamma$. Consider a one-time increase in the transfer. There are thresholds $\tilde{\theta}, \hat{\theta}$ such that if both spouses contribute to human capital accumulation (i.e., the equilibrium is interior) and the share of human capital $\theta$ is sufficiently small $(\theta<\tilde{\theta})$, output $Y^{\prime}$ in the next period is decreasing in today's transfer $\gamma$ :

$$
\frac{\partial Y^{\prime}}{\partial \gamma}<0
$$

Conversely, if the share of human capital $\theta$ is sufficiently large $(\theta>\hat{\theta})$, future output is increasing in the transfer $\gamma$ :

$$
\frac{\partial Y^{\prime}}{\partial \gamma}>0
$$


The intuition for the proposition is that the share of human capital $\theta$ controls the extent to which male- versus female-provided public goods matter for economic growth. In the limit case $\theta=1$ (production linear in human capital only), the couple's bargaining problem is of the form analyzed in Proposition C.3, where transfers to women on the margin always increase public good provision (or, in this application, the rate of economic growth). The reason is that at $\theta=1$ time and money inputs are equally important, so that the efficiency channel dominates, which favors transfers to the low-wage spouse. Conversely, as $\theta$ tends to zero (production close to linear in physical capital), growth depends mostly on goods-only public goods provided by men, i.e., men provide most of the public goods. In this case the expenditure-share channel dominates, and transfers to women lower growth (following the intuition of the results in Propositions C.1 and C.2.). ${ }^{31}$

Within the model, the way output should be measured is not obvious, because in addition to physical production $Y$ there is also production of a public good (future human capital) within the household. However, the growth result is robust to alternative ways of measuring output, because Lemma 3.3 implies that all physical goods (private consumption, bequests, and goods inputs into the production of human capital) are proportional to $Y$ and thus all move in the same direction, whereas the time allocation is constant. Thus, if $Y$ increases in the next period, total private consumption and future physical and human capital also increase, and vice versa if $Y$ declines.

Figure 4 illustrates these results with a computed example. The gender gap is set to $\delta=0.5$; i.e., men are twice as productive as women in the market. The figure displays the effect of a mandated transfer from husband to wife, amounting to 10 percent of income per capita, on output in the children's generation as a function of the human capital share $\theta$. For low values of $\theta$, this transfer lowers future output. In this range men provide the majority of public goods. At a human capital share of $\theta=0.53$, the transfer leaves future output unchanged. For even higher levels of $\theta$, transfers to women increase future output. At $\theta=1$, the transfer increase future output in the children's generation by almost 2.9 percent.

Notice that even though for low $\theta$ a transfer to women lowers growth, it still increases the accumulation of human capital. Figure 5 breaks down the effect of the mandated

\footnotetext{
${ }^{31}$ The expenditure share channel also dominates in the case of a corner solution where only one spouse is contributing to public goods, i.e., a transfer to the spouse providing the public goods increases economic growth.
} 


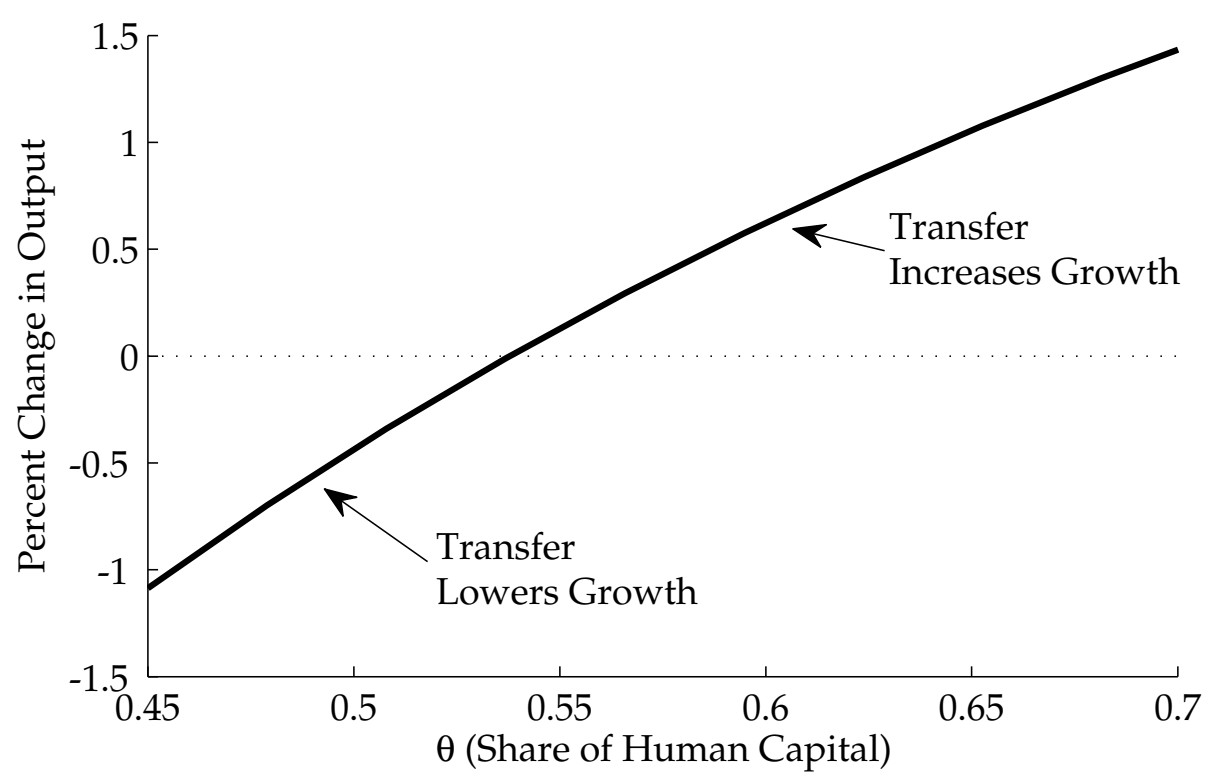

Figure 4: Effect of a Mandated Transfer of 10 percent of Income per Capita from Husband to Wife on Output in the Next Generation as a Function of Human Capital Share $\theta$

transfer on the accumulation of human and physical capital. Physical capital (the bequest) is always provided entirely by the husband in this range, whereas the wife provides most of the time-intensive inputs to human capital production. Hence, regardless of $\theta$ a transfer from husband to wife results in lower bequests, but more investment in children's human capital. Nevertheless, for low $\theta$ (production intensive in physical capital) the positive effect on human capital is insufficient to compensate for the lower bequest.

If the human capital share $\theta$ were to increase slowly in the course of development, our results imply that targeting transfers to women might be beneficial at an advanced, human capital-intensive production stage, but less so at an earlier stage when human capital plays a small role. Similarly, in a cross section of countries, targeting transfers to women may be counterproductive in less advanced economies where physical accumulation is still the main driver of growth.

In this section, we have focused on the role of the human capital share $\theta$. More generally, one may conjecture that the relative scarcity of human and physical capital, i.e., the ratio of the state variables $h$ and $k$, should also matter for growth effects of mandated transfers. In our model, however, this issue does not arise. Lemma 3.3 implies that all 


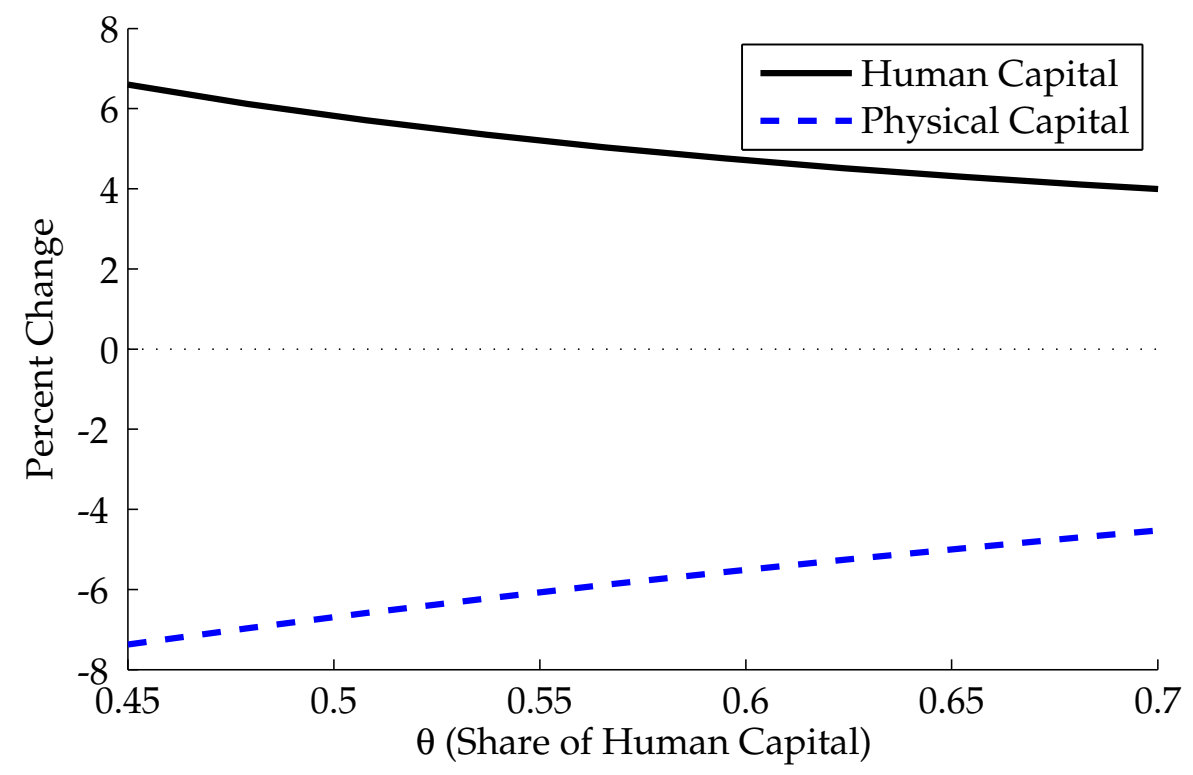

Figure 5: Effect of a Mandated Transfer of 10 percent of Income per Capita from Husband to Wife on Physical and Human Capital in the the Next Generation as a Function of Human Capital Share $\theta$

combinations of $h$ and $k$ that yield the same output today yield the same (current and future) allocation, so that the ratio of $h$ and $k$ does not matter for growth. This result is due to the Cobb-Douglas structure of production, which implies that labor income and capital income are fixed fractions of output. One could extend our model by introducing direct persistence in human capital across generations or additional human capital externalities, in which case the issue of whether physical or human capital is the main bottleneck for growth would become relevant. Such an extended model would imply that mandated transfers to women are more likely to increase growth when human capital scarcity is the bottleneck for growth. ${ }^{32}$

In our growth analysis, we have treated the gender wage gap parameter $\delta$ as exogenous, in line with our focus on the implications of mandated transfers in a given economic environment in terms of women's and men's economic opportunities. But in reality women's economic opportunities do vary systematically with development and economic growth (e.g., Galor and Weil 1996, de la Croix and Vander Donckt 2010, Goldin

\footnotetext{
${ }^{32}$ In the empirical literature, there is no clear consensus on whether scarcity of human or physical capital is a more important reason for underdevelopment. In their summary of the "development accounting" literature, Hsieh and Klenow (2010) argue that physical capital differences explain about 20 percent of cross country-income differences, with human capital differences accounting for 10-30 percent.
} 
2014). An interesting extension of our framework would be to let $\delta$ change with economic growth. A simple way to do this would be to conjecture a dependence of $\delta$ on total human capital, through a function $\delta_{t}=\Delta\left(H_{t}\right)$, with $\delta_{t}$ increasing in $H_{t}$. Such a setting would have interesting additional implications. If we continue to assume that the human capital share $\theta$ increases over time, mandated transfers would initially be detrimental to development (because physical capital drives growth), then they would promote development (once $\theta$ is sufficiently large), but they would ultimately cease to be effective at an advanced stage of development where $\delta$ approaches one (no gender wage gap). This is because once the gender wage gap disappears, women and men behave in the same way, and mandated transfers no longer change the public-goods allocation (see Appendix D). It would be interesting to explore such implications in future research.

\subsection{A Quantitative Assessment}

Our model is stylized and not designed for quantitative analysis. Indeed, the model has only two parameters: the human capital share, $\theta$, and the gender wage gap, $\delta$. Clearly it is impossible to closely match a lot of data moments without more degrees of freedom. Yet, to get some sense of the magnitudes, it is still interesting to ask what the model predictions are for empirically plausible choices for these parameters. In this section, we quantify the model predictions using a simple back-of-the envelope calculation for Mexico, the country for which we provide empirical evidence in the next section.

According to the ILO, the gender wage gap in Mexico was roughly 20 percent in 2000. ${ }^{33}$ Good data on labor earning shares for Mexico are hard to find. According to Frankema (2010), the labor income share was about 30 percent in 2000. Yet, as Gollin (2002) and others have argued, labor income shares in developing countries are often mismeasured. Thus, instead of taking $\theta$ directly from the data, we calibrate it to match the elasticity of children's clothing (a child-related public good in the empirical analysis below) with respect to the female income share. According to our findings in the next section this elasticity is $0.148 .{ }^{34}$ This number can be matched in the model by choosing $\theta=0.425$. Given this parametrization, a mandated transfer of 0.5 percent of GDP would decrease

\footnotetext{
${ }^{33}$ Note that this is the raw gap that combines all sources of wage disparities, including the education gap. Source: ILO, Annual Indicators, downloaded from www.ilo.org/ilostat, on November 18, 2015.

${ }^{34}$ This can be calculated using data from Tables 1 and 2: The derivative of children's clothing expenditure share with respect to female income share is the regression coefficient 0.058 . The ratio of the female income share to the expenditure share of children's clothing is 2.55. Multiplying these two numbers gives the elasticity 0.148 .
} 
the growth rate from 11.05 percent to 11.03 percent. At a lower labor income share, the transfer would lower growth even more. However, at a human capital share of 0.51 or higher, the growth implications flip-a transfer to women would increase growth. Further, as shown in the theoretical analysis, results are sensitive to the size of the gender wage gap. For a gender wage gap of 30 instead of 20 percent, the child expenditure elasticity would be 0.218 . Accordingly, the effect of a mandated transfer on growth would double in size. These results show that the growth implications of mandated transfers to women are sensitive to small changes in the share of human capital and the gender wage gap, suggesting that the sign of the effect may vary across developing countries.

\section{Empirical Assessment of the Specialization Hypothesis}

Our results on the growth effects of mandated transfers hinge on the assumption that the specialization hypothesis indeed plays an important role in explaining household expenditure patterns. In this section, we discuss how this assumption can be tested. We summarize testable implications generated by the specialization hypothesis, and we describe how these implications can be used to distinguish our theory from the alternative preference hypothesis. We also summarize evidence about these implications from the existing empirical literature, and we test one specific implication using data from Mexico.

\subsection{Testable Implications of the Specialization Hypothesis}

A robust implication of the specialization hypothesis is that the effect of a transfer to one spouse versus the other will depend on who is the equilibrium provider of a given good. Our model says that if you are in charge of buying a particular set of goods and you get more money, then you will spend more on those goods that you are already responsible for. Thus, if transfers are given to the spouse who is in charge of buying child-related goods, then child expenditures increase.

Implication 4.1 (Role of the provider). Mandated transfers from the other spouse to the equilibrium provider of child-related goods increase spending on children.

Note that a mandated transfer from husband to wife is equivalent to re-directing a benefit that was previously paid out to the husband to the wife. The implication is therefore 
applicable to any setting where the gender of the recipient of a given transfer is randomized. Another way of stating the implication is that a transfer to the equilibrium provider of child-related goods increases spending on children by more than the same transfer to the other spouse.

Also note that it is not gender per se that matters (as under the preference hypothesis), but the actual pattern of the division of labor in the household. Thus, if one had detailed time use data, a testable implication would be that among couples where men do a lot of the child care, the effect of transfers to women on spending on children should be smaller. In the extreme, among households where men do most of the child care, effects of mandated transfers should be reversed. The same logic could also be applied to same sex couples, on which the preference hypothesis is silent.

In our model the gender wage gap drives specialization in the household. If we had data with variation in the couple-specific gender wage gap, couples with a lower wage gap should have a less strict specialization, and hence the effects of targeted transfers on the allocation of spending should be smaller. If we observe couples with opposite specialization patterns (i.e. couples where the husband is a stay-at-home-dad and does most tasks associated with child care) the signs of the effects should reverse.

Implication 4.2 (Gender wage gap). The size of the effect of mandated transfers declines with the wage gap in the family.

Notice it is not the gender wage gap per se that drives the effects, but the resulting specialization pattern. In reality, specialization is not solely determined by relative wages, but also other factors such as social norms. Thus, the point at which the effects should go away entirely is not the point where male and female wages are equal, but the point at which specialization by gender disappears. Nevertheless, as long as specialization responds to relative wages, changes in relative wages will matter for the size of the effects.

In a preference-based model, in contrast, effects depend solely on gender, but not on who is the equilibrium provider. It is possible to get implications similar to ours in a variation of a preference-based model if we assume that women like human capital more, whereas men like physical capital more. Such a setting seems a bit implausible, because human and physical capital are inputs but not consumption goods in their own right. If women and men ultimately care about future consumption (whether their own or their children's), it would seem strange that women value one input more and men the other. Nevertheless, it is possible to construct such a case. However, with such 
preferences hard wired by gender, the effects would not depend on relative wages or specialization. Rather, we should expect to observe the same effects in households with sharply separated gender roles and in households where husband and wife have similar wages and share household responsibilities equally.

An implication specific to the preference hypothesis is that allocations change in response to a mandated transfer only if bargaining weights move. In a limited commitment model, bargaining weights move in response to outside options. There are cases where a change in transfer payments does not change the outside option, for example if divorce is the outside option and upon divorce transfers are always given to women. The preference hypothesis implies that what happens to outside options matters, whereas under the specialization hypothesis transfers move the allocation even if outside options do not change.

Implication 4.3 (Outside options). Mandated transfers affect the allocation even if they do not change outside options.

Another important feature of the specialization hypothesis is that the tradeoff is not so much between private versus public goods, but rather between different types of public goods. When transfers are given to women, the spending share on public goods provided by men should go down. If men are in charge of savings and investment (as they are in the growth model above, because these public goods require little time input), then relative spending on these will decline in response to mandated transfers from men to women.

Implication 4.4 (Savings). If men are in charge of savings, then mandated transfers from men to women will increase spending and decrease savings.

Note that this implication does not contradict evidence that spending on alcohol and tobacco (typically considered male private goods) goes down in response to mandated transfers. The specialization hypothesis implies that when transfers are given to the provider of child-related goods, spending on both private good consumed and public goods provided by the other spouse decline.

These implications suggest a number of possible tests of the specialization hypothesis. Some of these are difficult to implement with existing data, mainly because of a lack of data sets that include detailed information on wages and time use and that also exhibit significant variation in gender roles (specifically, a sizeable fraction of men providing 
more child care than their spouse). As more micro data becomes available and as gender roles continue to shift, it will be fruitful to test the related implications in future studies. For now, we focus on an implication that can be readily tested with existing data, namely the implications of mandated transfers for household savings.

\subsection{Empirical Evidence on the Effect of Mandated Transfers on Savings from PRO- GRESA}

To examine the implications of the specialization hypothesis for household savings, we use the same empirical setting that has produced the best-known evidence to date on the different spending patterns of women and men, namely the Mexican PROGRESA data. PROGRESA is a welfare program that was introduced in poor rural areas in Mexico starting in 1998. PROGRESA has two features that allow an evaluation of the effects of targeted transfers. First, all PROGRESA transfers are paid to women. Second, the timing of the introduction of PROGRESA was randomized across villages. This allows for a quasi-experimental evaluation by comparing households receiving the transfer with those that are eligible in principle but face a delayed start date. Attanasio and Lechene (2002) use the PROGRESA data to show that an exogenous increase in the income share of the wife in a household increases expenditures on children's clothing and food, and lowers expenditures on alcohol. Similar results are reported by Bobonis (2009). If most of alcohol is consumed by men, these results are consistent with a shift in spending from private spending by men towards more spending on public goods (i.e., children). However, the existing studies do not consider the impact of targeted transfers on savings behavior. Hence, we extend the research design of Attanasio and Lechene (2002) to also consider effects on savings.

Our sample consists of pooled data from the October 1998, March 1999, and November 1999 survey waves. We consider a sample of households consisting of a married couple and their children. As the earlier studies, we drop households containing additional adults (because our analysis focuses on marital bargaining, and bargaining in multi-generation households may be more complex) and also childless households (because PROGRESA transfers were conditional on having children). The data set contains demographic characteristics, education of husband and wife, separate income measures for husband and wife, transfer income from the PROGRESA program, measures of total household expenditure, and measures of expenditures on specific categories such as alcohol/tobacco and children's clothing. Our specific interest is in measuring the impact 
of the female income share on household savings. Our savings measure is computed as the difference between total income and self-reported total expenditures. We report robustness to alternative measures of saving below.

Table 1 provides summary statistics for our sample. The typical household contains five people, and husbands are on average four years older than their wife. Household income is about 1,600 Pesos, and the average PROGRESA transfer amounts to a little over 5 percent of average income (and a substantially larger fraction for those households who actually receive a transfer). The wife's income share averages 10 percent of household income, and households save about a quarter of their income.

Our main results are contained in Table 2. Our objective is to measure the impact of variations in the female share in household income on spending on different types of public and private goods in the household. We focus on alcohol/tobacco and men's clothing as measures of men's private goods, women's clothing as a measure of women's private goods, and children's clothing as a measure of a public good that is often femaleprovided. In line with our theory, we focus on savings as a public good that is more likely to be male-provided.

Column (1) of Table 2 shows results for our most basic setup, where the left-hand side variable is regressed on only three variables: log household income, log household income squared, and the female income share. These regressions answer the question whether, controlling for overall income, households where women earn a large fraction of income have different spending patterns than households where women contribute less. The regressions in column (1) are estimated via OLS, and hence document basic correlations without addressing causality. Each entry in the column represents the estimated coefficient on the female income share in a separate regression for a specific left-hand-side variable. The results show that households where women earn a large fraction of income spend substantially less on alcohol and tobacco, and substantially more on children's clothing. In addition, such households also have significantly larger overall expenditures and, correspondingly, save a smaller share of their income. The effect on savings is quantitatively large, with a one-standard deviation in the female income share corresponding to a savings rate that is lower by 10 percentage points.

The correlations documented in column (1) are consistent with the main results of our theoretical analysis, namely that a higher female income share corresponds to more spending on female-provided public goods, and less spending on male private goods 
Table 1: Summary Statistics of the PROGRESA Sample

\begin{tabular}{lrr}
\hline \hline Variable & Mean & Std. Dev. \\
\hline \multicolumn{3}{c}{ Demographics: } \\
Wife's Age & 33.6 & 13.1 \\
Husband's Age & 37.6 & 13.6 \\
Household Size & 5.04 & 2.03 \\
Children in School & 1.58 & 1.45 \\
Children in Primary School & 1.42 & 1.3 \\
Female Children & 0.93 & 1.27 \\
Wife's Schooling & 6.27 & 3.98 \\
Husband's Schooling & 6.49 & 3.89 \\
\hline
\end{tabular}

Income and Savings:

\begin{tabular}{lrr} 
Household Income & $1,584.6$ & $10,184.3$ \\
PROGRESA Income & 82.0 & 142.1 \\
Wife's Income Share & 10.5 & 21.2 \\
Savings Share & 23.2 & 76.8 \\
\hline
\end{tabular}

Expenditure Shares:

$\begin{array}{lll}\text { Alcohol/Tobacco } & 0.48 & 2.80 \\ \text { Women's Clothing } & 1.32 & 2.72 \\ \text { Men's Clothing } & 1.42 & 3.05 \\ \text { Children's Clothing } & 4.12 & 5.59\end{array}$

Notes: The estimation sample contains 9,506 observations. The sample is winsorized to omit observations with a savings rate of more than 100 percent or less than -500 percent, which are most likely generated by mismeasurement in income or expenditure. 
Table 2: Impact of Female Income Share on Expenditure Shares and Savings

\begin{tabular}{lcccc}
\hline \hline & $(1)$ & $(2)$ & $(3)$ & $(4)$ \\
\hline \multirow{4}{*}{ Alcohol/Tobacco } & \multicolumn{5}{c}{ Expenditure Shares } \\
\cline { 2 - 5 } & $-0.426^{* * *}$ & $-0.284^{* *}$ & $-0.742^{* * *}$ & $-0.530^{* *}$ \\
Men's Clothing & $(0.110)$ & $(0.122)$ & $(0.175)$ & $(0.217)$ \\
& -0.245 & 0.091 & $-0.908^{* * *}$ & -0.236 \\
Women's Clothing & $-0.144)$ & $(0.154)$ & $(0.194)$ & $(0.227)$ \\
& $(0.136)$ & $(0.144)$ & $(0.189)$ & $(0.215)$ \\
Children's Clothing & $5.068^{* * *}$ & $2.774^{* * *}$ & $9.932^{* * *}$ & $5.800^{* * *}$ \\
& $(0.357)$ & $(0.339)$ & $(0.580)$ & $(0.632)$ \\
\hline \multirow{5}{*}{ Expenditure versus Savings } \\
\cline { 2 - 5 } Log(Expenditures) & $0.314^{* * *}$ & $0.241^{* * *}$ & $0.422^{* * *}$ & $0.299^{* * *}$ \\
& $(0.027)$ & $(0.028)$ & $(0.039)$ & $(0.046)$ \\
Savings Share & $-0.431^{* * *}$ & $-0.391^{* * *}$ & $-0.404^{* * *}$ & $-0.315^{* * *}$ \\
& $(0.045)$ & $(0.048)$ & $(0.035)$ & $(0.041)$ \\
\hline Estimation Method & OLS & OLS & IV & IV \\
Additional Controls & No & Yes & No & Yes \\
\hline
\end{tabular}

Notes: Robust standard errors (in parentheses) are adjusted for clusters by household. Stars denote significance at 10 percent, 5 percent, and 1 percent level, respectively. The number of observations is 9,506. Each estimate displayed is the estimated coefficient on the female income share in a linear regression for the left-hand side variable displayed in the first column. Coefficient estimates and standard errors for expenditure shares are multiplied by 100 (i.e., expressed in percent). All regressions include log household income and log household income squared. Regressions (2) and (4) include the following additional controls: household size, number of children in school, number of children in primary school, number of girls, eligibility for the PROGRESA program, the wife's and husband's education, and the ages of wife and husband. In Regressions (3) and (4) the female income share is instrumented with PROGRESA income (estimation via two-stage least squares). 
and male-provided public goods. ${ }^{35}$ Of course, given that we estimate a basic regression using OLS, it is possible that these correlations do not represent a causal relationship, but are due to omitted variables. This concern is particularly salient here because of the conditionality of the program on school attendance. School attendance is directly related to expenditure shares as it involves direct costs and because school attendance may reduce household income (if labor supply of children falls). A failure to control properly for schooling could thus severely threaten the interpretation. Following Attanasio and Lechene (2002), we pursue two strategies for dealing with these problems. First, we include a large set of controls that are available in the data set in our regressions. These additional variables consist of household size, the number of children in school, the number of children in primary school, the number of girls, eligibility for the PROGRESA program, the wife's and husband's education, and the ages of wife and husband. By including these controls, the conditionality of the program should largely be dealt with.

Results with the full set of additional controls using OLS regression are displayed in column (2) of Table 2. The patterns in these regressions are very similar to those in column (1). Even after allowing for additional controls, households with a higher female income share spend more on children's clothing, less on alcohol/tobacco, and save less. The impact on savings is only slightly lower compared to column (1). In this regression we now also a get positive coefficient estimate for women's clothing that is close to being significant. Hence, the results line up even better with the theory compared to the most basic regressions.

The second strategy for addressing omitted-variable bias is to exploit the exogenous variation in female income generated by the staggered rollout of the PROGRESA program. We do this (in line with the existing literature) by using the income received from the PROGRESA program (which goes entirely to women) as an instrument for the female income share. Column (3) of Table 2 displays two-stage least squares results for the regression that controls only for log of income and log of income squared in addition to the female income share. Once again, the basic patterns are confirmed, with the exception that there is now a negative impact of a rise in the female income share on spending on women's clothing. The impact on savings is slightly reduced in size, but

\footnotetext{
${ }^{35}$ We do not find significant effects on male and female clothing, although here it should be kept in mind that the spending shares of these categories are low to begin with (a little over 1 percent of total spending in both cases) with many households spending nothing on these items in a given period, which may make it difficult to pick up significant effects.
} 
still large in economic terms.

Column (4) of Table 2 presents results for our preferred specification, which includes the full control set and also instruments the female income share with PROGRESA income. In these regressions, all coefficient estimates confirm the predictions of the theory, and all estimates except those on male and female clothing are highly significant. The negative impact of the female income share on savings continues to be large, with a one standard deviation in the female income share corresponding to a drop in savings of 6.5 percentage points.

A potential concern about these results is that our savings measure may not fully capture all forms of saving and investment. In particular, we compute savings as the difference between income and expenditure, but there are some types of expenditures (such as purchases of livestock) that may also play the role of investment. If the rise in expenditure and the drop in measured savings corresponding to a rise in the female income share were due to higher expenditure on such investment goods, our results would be misleading. To deal with this concern, in Appendix G we present results for alternative measures of savings that correct for spending on investment goods, and show that our findings are robust.

Our results are consistent with studies that have analyzed the effects of the PROGRESA program on investment and savings more generally. Gertler, Martinez, and RubioCodina (2012) analyze the long-run impact of the PROGRESA program on the ownership of productive agricultural assets and other forms of saving and investment. They find a positive effect on overall investment, suggesting that about a quarter of PROGRESA transfers are saved or invested. Whereas Gertler, Martinez, and Rubio-Codina (2012) focus on the question of whether the propensity to save out of PROGRESA income is positive, our results address the question of whether the propensity to save out of female income is lower than the propensity to save out of male income. In combination, our results and the results of Gertler, Martinez, and Rubio-Codina (2012) suggest that the propensity to save is positive for both women and men, but lower for women (implying that targeted transfers to women lower the share of income saved), which is exactly what our theory predicts.

Rubalcava, Teruel, and Thomas (2009) focus on investments in livestock, and show that households receiving PROGRESA income are more likely to own small livestock such as chickens, turkeys, and pigs. Given that PROGRESA transfers are given to women, the authors interpret this as evidence that women favor future investments more than 
men do. In our theory, a given spending category reacts positively to female income if the spending category is within the "female sphere" within the household. Given that the traditional division of labor in agricultural households is that women are in charge of small livestock whereas men deal with large animals, a positive effect on small livestock is also what our theory would predict. Notably, Rubalcava, Teruel, and Thomas (2009) also document that PROGRESA income has no discernable effect on ownership of large animals (cows, donkeys, and horses), which is supportive of a separate-spheres interpretation rather than an overall gender difference in time preferences. For our own analysis, we use a broader measure of investment, and (as already mentioned) we show in Appendix $G$ that our results are robust to treating livestock purchases as a part of investment.

Our finding that the propensity to save and invest out of female income is lower than that out of male income is also confirmed by other studies. Woolley (2004) surveyed Canadian couples. When asked how to spend a windfall transfer, women emphasized spending on children and the household, while men were more likely to plan to save or to pay down debt. Haushofer and Shapiro (2016) conducted a field experiment in Kenya where they randomized the gender of the recipient of a cash transfer. An important and expensive durable in Kenya is a metal roof. They find that in response to a cash transfer to men, ownership of metal roofs increased by 24 percentage points. The effect is only about half as large for female recipients. The gender difference is significant at the five percent level. ${ }^{36}$ Akresh, Walque, and Kazianga (2016) conducted a field experiment in Burkina Faso that involved cash transfers to fathers and mothers. They find that cash transfers to fathers lead to relatively more household investment in livestock, relatively more investment in household equipment (specifically electricity and metal roofs), and higher agricultural production of cash crops. Similarly, Robinson (2012) relies on a field experiment in Kenya to document that men have a substantially higher propensity to save out of transfers. The study by de Mel, McKenzie, and Woodruff (2009) examines the impact of transfers to micro entrepreneurs in Sri Lanka. They find that for men both business and household assets increase after a transfer, but not for women. Accordingly, profits increase for men but not for women. Fafchamps et al. (2014) find a similar result in Ghana, where female entrepreneurs appear to spend relatively more of a cash grant on household expenditures. Bernhardt et al. (2019) propose that the higher profitability

\footnotetext{
${ }^{36}$ The paper also analyzes the effect on other asset categories and finds smaller treatment effects for females for essentially all asset classes. While the gender differences for these other assets are not significant, the authors speculate that this is likely due to small sample sizes.
} 
of male-owned micro-enterprises arises because couples are more likely to invest in the husband's rather than the wife's enterprise. All of these studies are consistent with the predictions of the specialization hypothesis.

\section{Conclusions and Outlook}

In this paper we have addressed the economic implications of the empirical observation that money in the hands of women leads to higher spending on children. This observation has already fueled a trend in development policy to channel more resources towards women and, more generally, to envision female empowerment as a conduit to economic development. If we are to fully understand the effects of such genderbased development policies, however, we must first pin down the mechanism that generates the observed empirical findings. The conventional interpretation of the facts is that women and men have different preferences, in the sense that women attach more weight to children's welfare. However, in this paper we show that the facts can be explained also by an alternative hypothesis that relies on the endogenous division of labor in household production.

Under the specialization hypothesis, it is not obvious whether targeting transfers to women is good policy. In particular, we show that targeting transfers to women increases the growth rate of an economy only if human capital is the key engine of growth. Moreover, we show that the effects of targeted transfers disappear when the wage gap between women and men approaches zero. In other words, if women are fully empowered in the labor market, then further empowering them through transfers has no effect on the provision of public goods in the household.

The links among the effects of targeted transfers, the share of human capital, and the degree of labor-market discrimination suggest that there is no fixed relationship between female empowerment and economic development, but rather that the effectiveness of empowerment policies depends on the stage of development. The theory suggests that mandating wealth transfers from men to women lowers economic growth at an early stage of development, when there is little demand for human capital and instead physical capital accumulation drives growth. At a highly advanced stage of development there tends to be little gender discrimination, so that women and men earn similar wages and thus transfers would have little effect. The best case for these kinds of targeted transfers could be made for countries at an intermediate stage of development, 
when human capital is already a key driver of growth, but women's labor market opportunities still lag behind men's.

We have limited our attention here to the implications of a narrow concept of female empowerment, namely the transfer of resources from husbands to wives. In reality, of course, female empowerment can take other forms. For example, there are many facets of discrimination against women, not just in labor markets but also in consumption markets, some of which may lead men and women to act as if they had different preferences. ${ }^{37}$ That is, if women had access to a more limited set of private goods than men do, they would endogenously place less weight on their private consumption compared to spending on public goods. Such a mechanism might be relevant in countries like Saudi Arabia where until recently laws prohibited certain activities for women, such as driving. Female empowerment that reduces such consumption discrimination would lead to lower child expenditure shares. Another important dimension of female empowerment concerns access to education, which could be analyzed in the context of our growth model with human capital accumulation. Reducing discrimination against women in terms of education is more likely to promote economic development, but even here there are potential effects going in the opposite direction (such as repercussions on the time spent educating children).

The bottom line is that female empowerment cannot be regarded as a generic concept that has uniform effects at all stages of development. Rather, the effects of female empowerment depend both on the specific form that an empowerment policy takes, and on the nature of the economy where the policy is implemented. While many of these interdependencies remain to be disentangled in future research, we see our analysis as a step towards a more differentiated view.

\section{References}

Aguiar, Mark, and Erik Hurst. 2007. "Measuring Trends in Leisure: The Allocation of Time Over Five Decades." Quarterly Journal of Economics 122 (3): 969-1006.

Akresh, Richard, Damien de Walque, and Harounan Kazianga. 2016. "Evidence from a Randomized Evaluation of the Household Welfare Impacts of Conditional and Unconditional Cash Transfers Given to Mothers or Fathers." World Bank, Policy Research Working Paper 7730.

\footnotetext{
${ }^{37}$ In Doepke and Tertilt (2011) we analyze simple examples of this kind, but do not pursue them in the context of a growth model.
} 
Anderson, Siwan, and Jean-Marie Baland. 2002. "The Economics of Roscas and Intrahousehold Resource Allocation." Quarterly Journal of Economics 117 (3): 963-995.

Ashraf, Nava. 2009. "Spousal Control and Intra-Household Decision Making: An Experimental Study in the Philippines." American Economic Review 99 (4): 12451277.

Atkin, David. 2009. "Working for the Future: Female Factory Work and Child Health in Mexico." Unpublished Manuscript, Yale University.

Attanasio, Orazio, and Valérie Lechene. 2002. "Tests of Income Pooling in Household Decisions." Review of Economic Dynamics 5 (4): 720-748.

- 2014. "Efficient Responses to Targeted Cash Transfers." Journal of Political Economy 122 (1): 178-222.

Basu, Kaushik. 2006. "Gender and Say: A Model of Household Behaviour with Endogenously Determined Balance of Power." Economic Journal 116 (511): 558-580.

Beath, Andrew, Fotini Christia, and Ruben Enikolopov. 2017. "Direct Democracy and Resource Allocation: Experimental Evidence from Afghanistan." Journal of Development Economics 124:199-213.

Becker, Gary S. 1981. A Treatise on the Family. Cambridge: Harvard University Press.

Bergstrom, Theodore, Lawrence Blume, and Hal Varian. 1986. “On the Private Provision of Public Goods." Journal of Public Economics 29 (1): 25-49.

Bernhardt, Arielle, Erica Field, Rohini Pande, and Natalia Rigol. 2019. "Household Matters: Revisiting the Returns to Capital among Female Micro-Entrepreneurs." Forthcoming, American Economic Review: Insights.

Blundell, Richard, Pierre-André Chiappori, and Costas Meghir. 2005. "Collective Labor Supply with Children." Journal of Political Economy 113 (6): 1277-306.

Bobonis, Gustavo J. 2009. "Is the Allocation of Resources within the Household Efficient? New Evidence from a Randomized Experiment." Journal of Political Economy 117 (3): 453-503.

Boserup, Ester. 1985. "Economic and Demographic Interrelationships in sub-Saharan Africa." Population and Development Review 11 (3): 383-397.

Browning, Martin. 2000. “The Saving Behaviour of a Two-Person Household." Scandinavian Journal of Economics 102 (2): 235-51.

Browning, Martin, Pierre-André Chiappori, and Valérie Lechene. 2010. "Distributional Effects in Household Models: Separate Spheres and Income Pooling." Economic Journal 120 (545): 786-799.

Caldwell, John C., and Pat Caldwell. 1987. "The Cultural Context of High Fertility in Sub-Saharan Africa." Population and Development Review 13:40937.

Caldwell, Pat. 1976. "Issues of Marriage and Marital Change: Tropical Africa and the Middle East." Chapter 16 of Family and Marriage in Some African Countries, edited by 
S.A. Huzayyin and G.T. Acsadi, Research Monograph Series no. 6, 325-335. Cairo: Cairo Demographic Centre.

Castilla, Carolina, and Thomas Walker. 2013. "Is Ignorance Bliss? The Effect of Asymmetric Information between Spouses on Intra-Household Allocations." American Economic Review 103 (3): 263-268.

Chattopadhyay, Raghabendra, and Esther Duflo. 2004. "Women as Policy Makers: Evidence from a Randomized Policy Experiment in India." Econometrica 72 (5): 14091443.

Chen, Joyce J. 2006. "Migration and Imperfect Monitoring: Implications for IntraHousehold Allocation." The American Economic Review 96 (2): pp. 227-231.

Cherchye, Laurens, Bram De Rock, and Frederic Vermeulen. 2012. "Married with Children: A Collective Labor Supply Model with Detailed Time Use and Intrahousehold Expenditure Information." American Economic Review 102 (7): 3377-405.

Chiappori, Pierre-André. 1988. "Rational Household Labor Supply." Econometrica 56 (1): 63-90.

. 1992. "Collective Labor Supply and Welfare." Journal of Political Economy 100 (3): 437-467.

Croson, Rachel, and Uri Gneezy. 2009. "Gender Differences in Preferences." Journal of Economic Literature 47 (2): 448-474.

d'Aspremont, Claude, and Rodolphe Dos Santos Ferreira. 2014. "Household Behavior and Individual Autonomy: an Extended Lindahl Mechanism." Economic Theory 55 (3): 643-664.

Dauphin, Anyck, Bernard Fortin, and Guy Lacroix. 2018. "Is Consumption Efficiency within Households Falsifiable?" Review of Economics of the Household 16 (3): 737-66.

Davis, Harry L. 1976. "Decision Making within the Household." Journal of Consumer Research 2 (4): 241-260.

de Laat, Joost. 2014. "Household Allocations and Endogenous Information: The case of Split Migrants in Kenya." Journal of Development Economics 106:108-117.

de la Croix, David, and Marie Vander Donckt. 2010. "Would Empowering Women Initiate the Demographic Transition in Least Developed Countries?" Journal of Human Capital 4 (2): 85-129.

Del Boca, Daniela, and Chris Flinn. 2012. "Endogenous Household Interaction." Journal of Econometrics 166 (1): 49-65.

de Mel, Suresh, David McKenzie, and Christopher Woodruff. 2009. "Are Women More Credit Constrained? Experimental Evidence on Gender and Microenterprise Returns." American Economic Journal: Applied Economics 1 (3): 1-32.

Doepke, Matthias, and Michèle Tertilt. 2009. “Women's Liberation: What's in It for Men?" Quarterly Journal of Economics 124 (4): 1541-1591. 
_ 2011. "Does Female Empowerment Promote Economic Development?" CEPR Discussion Paper 8441.

Doepke, Matthias, Michèle Tertilt, and Alessandra Voena. 2012. "The Economics and Politics of Women's Rights." Annual Review of Economics 4:339-372.

Duflo, Esther. 2003. "Grandmothers and Granddaughters: Old-Age Pensions and Intrahousehold Allocation in South Africa." World Bank Economic Review 17 (1): 125.

—. 2012. "Women Empowerment and Economic Development." Journal of Economic Literature 50 (4): 1051-1079.

Duflo, Esther, and Christopher Udry. 2004. "Intrahousehold Resource Allocation in Cote d'Ivoire: Social Norms, Separate Accounts and Consumption Choices." NBER Working Paper 10498.

Echevarria, Cristina, and Antonio Merlo. 1999. "Gender Differences in Education in a Dynamic Household Bargaining Model." International Economic Review 40 (2): 265286.

Fafchamps, Marcel, D. McKenzie, Simon Quinn, and Christopher Woodruff. 2014. “Microenterprise Growth and the Flypaper Effect: Evidence from a Randomized Experiment in Ghana." Journal of Development Economics 106:211-226.

Fernández, Raquel. 2014. “Women's Rights and Development." Journal of Economic Growth 19 (1): 37-80.

Frankema, Ewout. 2010. “Reconstructing Labor Income Shares in Argentina, Brazil and Mexico,1870-2000." Journal of Iberian and Latin American Economic History 28 (02): 343-374.

Galor, Oded, and David N. Weil. 1996. "The Gender Gap, Fertility, and Growth." American Economic Review 86 (3): 374-87.

Gertler, Paul J., Sebastian W. Martinez, and Marta Rubio-Codina. 2012. "Investing Cash Transfers to Raise Long-Term Living Standards." American Economic Journal: Applied Economics 4 (1): 164-92.

Gobbi, Paula. 2018. "Childcare and Commitment within Households." Journal of Economic Theory 176:503-551.

Goldin, Claudia. 2014. "A Grand Gender Convergence: Its Last Chapter." American Economic Review 104 (4): 1091-1119.

Goldstein, Markus, and Christopher Udry. 2008. "The Profits of Power: Land Rights and Agricultural Investment in Ghana." Journal of Political Economy 116 (6): 9811022.

Gollin, Douglas. 2002. "Getting Income Shares Right." Journal of Political Economy 110 (2): 458-474.

Green, Robert T., and Isabella C. Cunningham. 1975. "Feminine Role Perception and Family Purchasing Decisions." Journal of Marketing Research 12 (3): 325-332. 
Haddad, Lawrence, John Hoddinot, and Harold Alderman, eds. 1997. Intra-Household Resource Allocation in Developing Countries: Models, Methods, and Policy. Baltimore and London: Johns Hopkins University Press.

Haushofer, Johannes, and Jeremy Shapiro. 2016. "The Short-term Impact of Unconditional Cash Transfers to the Poor: Experimental Evidence from Kenya." Quarterly Journal of Economics 131 (4): 1973-2042.

Heath, Rachel, and Xu Tan. 2019. "Intrahousehold Bargaining, Female Autonomy, and Labor Supply: Theory and Evidence from India." Forthcoming, Journal of the European Economic Association.

Hoddinott, John, and Lawrence Haddad. 1995. "Does Female Income Share Influence Household Expenditures? Evidence From Côte D'Ivoire." Oxford Bulletin of Economics and Statistics 57 (1): 77-96.

Hoel, Jessica B. 2015. “Heterogeneous Households: A Within-subject Test of Asymmetric Information between Spouses in Kenya." Journal of Economic Behavior and Organization 118:123-135.

Hsieh, Chang-Tai, and Peter J. Klenow. 2010. "Development Accounting." American Economic Journal: Macroeconomics 2 (1): 207-23.

Iyigun, Murat, and Randall P. Walsh. 2007. “Endogenous Gender Power, Household Labor Supply, and the Quantity-Quality Tradeoff." Journal of Development Economics 82 (1): 138-155.

Kenney, C.T. 2006. "The Power of the Purse: Allocative Systems and Inequality in Couple Households." Gender and Society 20:354-381.

Khandker, Shahidur R. 2005. "Microfinance and Poverty: Evidence Using Panel Data from Bangladesh." World Bank Economic Review 19 (2): 263-286.

Konrad, Kai A., and Kjell Erik Lommerud. 1995. "Family Policy with Non-cooperative Families." Scandinavian Journal of Economics 97 (4): 581-601.

Lagerlöf, Nils-Petter. 2003. "Gender Equality and Long-Run Growth." Journal of Economic Growth 8 (4): 403-426.

Lauer, Sean R., and Carrie Yodanis. 2014. "Money Management, Gender and Households." In The Wiley Blackwell Companion of the Sociology of Families, edited by Judith Treas, Jacqueline Scott, and Martin Richards, 344-360. John Wiley \& Sons, Ltd.

Lechene, Valérie, and Ian Preston. 2011. “Noncooperative Household Demand." Journal of Economic Theory 146:504-27.

Lise, Jeremy, and Ken Yamada. 2018. "Household Sharing and Commitment: Evidence from Panel Data on Individual Expenditures and Time Use." Forthcoming, Review of Economic Studies.

Lundberg, Shelly, and Robert A. Pollak. 1993. "Separate Spheres Bargaining and the Marriage Market." Journal of Political Economy 101 (6): 988-1010. 
_. 1994. "Noncooperative Bargaining Models of Marriage." American Economic Review 84 (2): 132-137.

Lundberg, Shelly J., Robert A. Pollak, and Terence J. Wales. 1997. "Do Husbands and Wives Pool Their Resources? Evidence from the United Kingdom Child Benefit." Journal of Human Resources 32 (3): 463-480.

Manser, Marilyn, and Murray Brown. 1980. "Marriage and Household DecisionMaking: A Bargaining Analysis." International Economic Review 21 (1): 31-44.

Mazzocco, Maurizio. 2007. "Household Intertemporal Behaviour: A Collective Characterization and a Test of Commitment." Review of Economic Studies 74 (3): 857-895.

Mazzocco, Maurizio, Claudia Ruiz, and Shintaro Yamaguchi. 2013. "Labor Supply, Wealth Dynamics, and Marriage Decisions." Unpublished Manuscript, UCLA.

McElroy, Marjorie B., and Mary Jean Horney. 1981. “Nash-Bargained Household Decisions: Toward a Generalization of the Theory of Demand." International Economic Review 22 (2): 333-49.

Miller, Grant. 2008. “Women's Suffrage, Political Responsiveness, and Child Survival in American History." Quarterly Journal of Economics 123 (3): 1287-1327.

Naidoo, Jesse. 2015. "The Power of Tests for Pareto Efficiency Within the Family." Unpublished Manuscript, University of Chicago.

Pahl, Jan. 1983. "The Allocation of Money and the Structuring of Inequality within Marriage." Sociological Review 31 (2): 237-263.

. 1995. "His Money, her Money: Recent Research on Financial Organisation in Marriage." Journal of Economic Psychology 16:361-376.

- 2008. “Family Finances, Individualisation, Spending Patterns and Access to Credit." The Journal of Socio-Economics 37:577591.

Phipps, Shelley A., and Peter S. Burton. 1998. "What's Mine is Yours? The Influence of Male and Female Incomes on Patterns of Household Expenditure." Economica 65 (260): 599-613.

Pitt, Mark M., and Shahidur R. Khandker. 1998. “The Impact of Group-Based Credit Programs on Poor Households in Bangladesh: Does the Gender of Participants Matter?" Journal of Political Economy 106 (5): 958-996.

Qian, Nancy. 2008. "Missing Women and the Price of Tea in China: The Effect of Sex-Specific Earnings on Sex Imbalance." Quarterly Journal of Economics 123 (3): 1251-1285.

Robinson, Jonathan. 2012. "Limited Insurance within the Household: Evidence from a Field Experiment in Kenya." American Economic Journal: Applied Economics 4 (4): $140-64$.

Rubalcava, Luis, Graciela Teruel, and Duncan Thomas. 2009. "Investments, Time Preferences, and Public Transfers Paid to Women." Economic Development and Cultural Change 57 (3): 507-538. 
Thomas, Duncan. 1993. "The Distribution of Income and Expenditure within the Household." Annals of Economics and Statistics 29:109-135.

Udry, Christopher. 1996. "Gender, Agricultural Production, and the Theory of the Household." Journal of Political Economy 104 (5): 1010-46.

Voena, Alessandra. 2015. "Yours, Mine, and Ours: Do Divorce Laws Affect the Intertemporal Behavior of Married Couples?" American Economic Review 105 (8): 22952332.

Warr, Peter G. 1983. "The Private Provision of a Public Good is Independent of the Distribution of Income." Economics Letters 13 (2-3): 207-211.

Wolgast, Elizabeth H. 1958. "Do Husbands or Wives Make the Purchasing Decisions?" Journal of Marketing 23 (2): 151-158.

Woolley, Frances. 2004. "Why Pay Child Benefits to Mothers?" Canadian Public Policy/Analyse de Politiques 30 (1): 47-69.

Zelizer, Viviana A. 1989. "The Social Meaning of Money: "Special Monies"." American Journal of Sociology 95:342-377. 


\title{
Does Female Empowerment Promote Economic Development?
}

\author{
Appendix for Online Publication
}

\section{Matthias Doepke and Michèle Tertilt}

\section{A Proofs for Propositions and Lemmas}

Proof of Proposition 2.1: We start by showing that the equilibrium satisfies the cutoff rule. The first-order conditions characterizing the wife's optimization problem are given by:

$$
\begin{aligned}
c_{f} & =\frac{1}{\lambda_{f}}, \\
E_{f, i} & \leq \frac{1-\alpha(i)}{\lambda_{f}}, \\
T_{f, i} & \leq \frac{\alpha(i)}{w_{f} \lambda_{f}},
\end{aligned}
$$

where (25) and (26) hold with equality for all public goods $i$ for which the wife is the sole provider, and $\lambda_{f}$ denotes the multiplier on the budget constraint. The corresponding optimality conditions for the husband are:

$$
\begin{aligned}
c_{m} & =\frac{1}{\lambda_{m}}, \\
E_{m, i} & \leq \frac{1-\alpha(i)}{\lambda_{m}}, \\
T_{m, i} & \leq \frac{\alpha(i)}{w_{m} \lambda_{m}} .
\end{aligned}
$$

In Nash equilibrium, each spouse contributes only to those public goods for which she or he has a higher willingness to pay. To show that there is an equilibrium that satisfies the cutoff rule, we therefore have to show that the wife's relative willingness to pay increases with $i$. Given the first-order conditions, the ratio of female to male preferred public-good provision for good $i$ (in each case assuming that each spouse would be the sole provider) is:

$$
\frac{C_{f, i}}{C_{m, i}}=\frac{E_{f, i}^{1-\alpha(i)} T_{f, i}^{\alpha(i)}}{E_{m, i}^{1-\alpha(i)} T_{m, i}^{\alpha(i)}}=\left(\frac{w_{m}}{w_{f}}\right)^{\alpha(i)} \frac{\lambda_{m}}{\lambda_{f}} .
$$

This expression is increasing in $i$ (given the assumption $w_{f}<w_{m}$ ), which implies that there is an equilibrium that satisfies the cutoff rule. Intuitively, women provide public goods using 
relatively more time compared to goods because of their low wages, which induces them to provide relatively more of the time-intensive goods. Given the cutoff rule, (6) follows from substituting the expressions for $E_{g, i}$ and $T_{g, i}$ from the first-order conditions into the production function for public goods, and (7) follows from equating male and female contributions at the cutoff.

To establish generic uniqueness of the equilibrium, we need to characterize the cutoff $\bar{i}$ more sharply by solving for the multipliers on the budget constraint. Plugging the first-order conditions for the wife back into the budget constraint and using the cutoff rule gives:

$$
\frac{1}{\lambda_{f}}+\int_{\bar{i}}^{1} \frac{1-\alpha(i)}{\lambda_{f}} d i=w_{f}-w_{f} \int_{\bar{i}}^{1} \frac{\alpha(i)}{w_{f} \lambda_{f}} d i+x_{f} .
$$

Canceling terms we get:

$$
\frac{1}{\lambda_{f}}+\int_{\bar{i}}^{1} \frac{1}{\lambda_{f}} d i=w_{f}+x_{f}
$$

which gives:

$$
\lambda_{f}=\frac{2-\bar{i}}{w_{f}+x_{f}} .
$$

Proceeding along the same lines with the male budget constraint gives:

$$
\lambda_{m}=\frac{1+\bar{i}}{w_{m}+x_{m}} .
$$

If the cutoff $\bar{i}$ is interior, it is characterized by the condition that at $\bar{i}$ female- and male-preferred provision of the public good is equal. Using (30), this can be written as:

$$
\left(\frac{2-\bar{i}}{1+\bar{i}}\right)\left(\frac{w_{m}+x_{m}}{w_{f}+x_{f}}\right)=\left(\frac{w_{m}}{w_{f}}\right)^{\alpha(\bar{i})} .
$$

Notice that the left-hand side is strictly decreasing in $\bar{i}$ while the right-hand side is increasing. Hence, there can be at most one solution to the equation. When the equation does not have a solution the equilibrium is a corner. Specifically, if:

$$
2\left(\frac{w_{m}+x_{m}}{w_{f}+x_{f}}\right)<1
$$

holds we have $\bar{i}=0$ (the wife is sufficiently rich to provide all public goods). Conversely, if:

$$
\frac{1}{2}\left(\frac{w_{m}+x_{m}}{w_{f}+x_{f}}\right)>\frac{w_{m}}{w_{f}}
$$

holds, we have $\bar{i}=1$, and the husband provides all public goods.

The equilibrium is only generically unique because we allow for the possibility that $\alpha(i)$ is constant over some range. If the equilibrium cutoff $\bar{i}$ falls into such a constant range, there is indeterminacy in terms of which spouse is providing which goods in this range. However, the private consumption and equilibrium provision of public goods is independent of who provides which 
goods in this range, so that there is no loss in generality from restricting attention to equilibria that satisfy the cutoff rule.

Proof of Proposition 2.2: The equilibrium cutoff conditions (33) before and after the transfer $\epsilon$ read:

$$
\begin{aligned}
\left(\frac{2-\bar{i}}{1+\bar{i}}\right)\left(\frac{w_{m}+x_{m}}{w_{f}+x_{f}}\right) & =\left(\frac{w_{m}}{w_{f}}\right)^{\alpha(\bar{i})}, \\
\left(\frac{2-\tilde{i}}{1+\tilde{i}}\right)\left(\frac{w_{m}+x_{m}-\epsilon}{w_{f}+x_{f}+\epsilon}\right) & =\left(\frac{w_{m}}{w_{f}}\right)^{\alpha(\tilde{i})} .
\end{aligned}
$$

Since $\epsilon>0$, the second term on the left-hand side is smaller in the second equation, implying that we must have $\tilde{i}<\bar{i}$. It then follows from (7) that the ratio $\tilde{c}_{f} / \tilde{c}_{m}$ has to increase after the transfer. Moreover, due to (6) the provision of public goods is proportional to the private consumption of the spouse providing the good. For public goods that have the same provider both before and after the change, the ratio of provision therefore changes by the same amount as the ratio of private consumption.

Proof of Proposition 2.3: From Definition 2.2, $X$ satisfies:

$$
X=\underset{0 \leq X \leq w_{m}+x_{m}}{\operatorname{argmax}}\left\{V_{m}\left(w_{f}, w_{m}, x_{f}+X, x_{m}-X\right)\right\} .
$$

Now define $X^{\star}=X-\epsilon$. Substituting into the last expression we get:

$$
X^{\star}=\underset{0 \leq X^{\star}+\epsilon \leq w_{m}+x_{m}}{\operatorname{argmax}}\left\{V_{m}\left(w_{f}, w_{m}, x_{f}+\epsilon+X^{\star}, x_{m}-\epsilon-X^{\star}\right)\right\} .
$$

or:

$$
X^{\star}=\underset{-\epsilon \leq X^{\star} \leq w_{m}+x_{m}-\epsilon}{\operatorname{argmax}}\left\{V_{m}\left(w_{f}, w_{m}, x_{f}+\epsilon+X^{\star}, x_{m}-\epsilon-X^{\star}\right)\right\} .
$$

Thus, $X^{\star}$ is the optimal voluntary transfer if an initial transfer of $\epsilon$ is imposed and negative transfers up to $\epsilon$ are allowed. Moreover, because $\epsilon \leq X$ we have $X^{\star} \geq 0$, so that $X^{\star}$ also satisfies:

$$
X^{\star}=\underset{0 \leq X^{\star} \leq w_{m}+x_{m}-\epsilon}{\operatorname{argmax}}\left\{V_{m}\left(w_{f}, w_{m}, x_{f}+\epsilon+X^{\star}, x_{m}-\epsilon-X^{\star}\right)\right\},
$$

implying that $X^{\star}$ is indeed the optimal transfer after the initial transfer is imposed, leading to identical post-transfer wealth and hence an identical ex-post equilibrium.

Proof of Proposition 2.4: We start by rewriting the husband's utility derived from the provision of public goods. In the case of an interior $\bar{i}$ (which we focus on here) this is given by:

$$
\begin{aligned}
& \int_{0}^{1} \log \left(C_{i}\right) d i \\
& \quad=\int_{0}^{1} \log \left(E_{i}^{1-\alpha(i)} T_{i}^{\alpha(i)}\right) d i \\
& =\int_{0}^{\bar{i}}\left[(1-\alpha(i)) \log \left(E_{m, i}\right)+\alpha(i) \log \left(T_{i, m}\right)\right] d i
\end{aligned}
$$




$$
\begin{gathered}
+\int_{\bar{i}}^{1}\left[(1-\alpha(i)) \log \left(E_{f, i}\right)+\alpha(i) \log \left(T_{i, f}\right)\right] d i \\
=\int_{0}^{\bar{i}}\left[(1-\alpha(i)) \log \left(\frac{1-\alpha(i)}{\lambda_{m}}\right)+\alpha(i) \log \left(\frac{\alpha(i)}{w_{m} \lambda_{m}}\right)\right] d i \\
\quad+\int_{\bar{i}}^{1}\left[(1-\alpha(i)) \log \left(\frac{1-\alpha(i)}{\lambda_{f}}\right)+\alpha(i) \log \left(\frac{\alpha(i)}{w_{f} \lambda_{f}}\right)\right] d i .
\end{gathered}
$$

Denote as $B$ the constant that does not depend on wages or multipliers. Then the expression can be written as:

$$
\begin{aligned}
\int_{0}^{1} \log \left(C_{i}\right) d i \\
=B-\int_{0}^{\bar{i}}\left[\log \left(\lambda_{m}\right)+\alpha(i) \log \left(w_{m}\right)\right] d i-\int_{\bar{i}}^{1}\left[\log \left(\lambda_{f}\right)+\alpha(i) \log \left(w_{f}\right)\right] d i \\
=B-\bar{i} \log \left(\lambda_{m}\right)-(1-\bar{i}) \log \left(\lambda_{f}\right) \\
\quad-\int_{0}^{\bar{i}} \alpha(i) d i \log \left(w_{m}\right)-\int_{\bar{i}}^{1} \alpha(i) d i \log \left(w_{f}\right)
\end{aligned}
$$

Hence, noting that $c_{m}=1 / \lambda_{m}$ from (27), total male utility is given by:

$$
\begin{aligned}
& V_{m}\left(w_{f}, w_{m}, x_{f}+X, x_{m}-X\right)= \\
& B-(1+\bar{i}) \log \left(\lambda_{m}\right)-(1-\bar{i}) \log \left(\lambda_{f}\right)-\int_{0}^{\bar{i}} \alpha(i) d i \log \left(w_{m}\right)-\int_{\bar{i}}^{1} \alpha(i) d i \log \left(w_{f}\right) .
\end{aligned}
$$

From (31) and (32), the multipliers $\lambda_{f}$ and $\lambda_{m}$ are given by:

$$
\begin{aligned}
\lambda_{f} & =\frac{2-\bar{i}}{w_{f}+x_{f}+X}, \\
\lambda_{m} & =\frac{1+\bar{i}}{w_{m}+x_{m}-X} .
\end{aligned}
$$

Plugging these into (35) and taking a derivative with respect to $X$ yields:

$$
\begin{aligned}
\left.\frac{\partial V_{m}\left(w_{f}, w_{m}, x_{f}+X, x_{m}-X\right)}{\partial X}\right|_{X=0}= & -\frac{1+\bar{i}}{w_{m}+x_{m}}+\frac{1-\bar{i}}{w_{f}+x_{f}} \\
& +\left[\log \left(\frac{(2-\bar{i})\left(w_{m}+x_{m}\right)}{(1+\bar{i})\left(w_{f}+x_{f}\right)}\right)+\frac{1-\bar{i}}{2-\bar{i}}-1\right] \frac{\partial \bar{i}}{\partial X} \\
& -\alpha(\bar{i}) \log \left(\frac{w_{m}}{w_{f}}\right) \frac{\partial \bar{i}}{\partial X} .
\end{aligned}
$$

Now taking the desired limit and recognizing that in the limit we have $\bar{i}=0$ gives:

$$
\lim _{x_{f} \rightarrow 2\left(w_{m}+x_{m}\right)-w_{f}}\left\{\left.\frac{\partial V_{m}\left(w_{f}, w_{m}, x_{f}+X, x_{m}-X\right)}{\partial X}\right|_{X=0}\right\}
$$




$$
\begin{aligned}
& =\lim _{x_{f} \rightarrow 2\left(w_{m}+x_{m}\right)-w_{f}}\left\{-\frac{1}{w_{m}+x_{m}}+\frac{1}{w_{f}+x_{f}}+\left[\log \left(\frac{2\left(w_{m}+x_{m}\right)}{w_{f}+x_{f}}\right)-\frac{1}{2}\right] \frac{\partial \bar{i}}{\partial X}\right\} \\
& =-\frac{1}{2}\left[\frac{1}{w_{m}+x_{m}}+\lim _{x_{f} \rightarrow 2\left(w_{m}+x_{m}\right)-w_{f}}\left\{\frac{\partial \bar{i}}{\partial X}\right\}\right] .
\end{aligned}
$$

Consider two cases: if $x_{f}$ converges to $2\left(w_{m}+x_{m}\right)-w_{f}$ from above, then there is no change in $\bar{i}$ in the limit since the equilibrium remains at a corner. Thus,

$$
\lim _{x_{f} \searrow 2\left(w_{m}+x_{m}\right)-w_{f}}\left\{\left.\frac{\partial V_{m}\left(w_{f}, w_{m}, x_{f}+X, x_{m}-X\right)}{\partial X}\right|_{X=0}\right\}=-\frac{1}{2} \frac{1}{w_{m}+x_{m}}<0 .
$$

The more interesting case happens when $x_{f}$ converges to $2\left(w_{m}+x_{m}\right)-w_{f}$ from below. For this case there is a negative change in $\bar{i}$ on the margin. We now show that even taking this into account, the overall expression in (36) is still negative. Using the multipliers (31) and (32) in the cutoff condition (7) for $\bar{i}$ and taking logs yields:

$$
\log \left(\frac{2-\bar{i}}{w_{f}+x_{f}+X}\right)-\log \left(\frac{1+\bar{i}}{w_{m}+x_{m}-X}\right)=\alpha(\bar{i}) \log \left(\frac{w_{m}}{w_{f}}\right) .
$$

Taking a derivative on both sides with respect to $X$ and evaluating the expression at $X=0$ leads to:

$$
\frac{\partial \bar{i}}{\partial X}=-\frac{\frac{1}{w_{f}+x_{f}}+\frac{1}{w_{m}+x_{m}}}{\alpha^{\prime}(\bar{i}) \log \left(\frac{w_{m}}{w_{f}}\right)+\frac{1}{2-i}+\frac{1}{1+i}},
$$

We therefore have:

$$
\lim _{x_{f} \nearrow 2\left(w_{m}+x_{m}\right)-w_{f}}\left\{\frac{\partial \bar{i}}{\partial X}\right\}=-\frac{\frac{3}{2} \frac{1}{w_{m}+x_{m}}}{\alpha^{\prime}(0) \log \left(\frac{w_{m}}{w_{f}}\right)+\frac{3}{2}} .
$$

Using this in (36) gives the desired result:

$$
\begin{aligned}
& \lim _{x_{f} \nearrow 2\left(w_{m}+x_{m}\right)-w_{f}}\left\{\left.\frac{\partial V_{m}\left(w_{f}, w_{m}, x_{f}+X, x_{m}-X\right)}{\partial X}\right|_{X=0}\right\}= \\
& -\frac{1}{2} \frac{1}{w_{m}+x_{m}}\left(1-\frac{1}{\frac{2}{3} \alpha^{\prime}(0) \log \left(\frac{w_{m}}{w_{f}}\right)+1}\right)<0 .
\end{aligned}
$$

Intuitively, at $\bar{i}=0$, on the margin a transfer leads the wife to replace the husband as the provider of a public good that only requires a goods input, so that the wife does not have a comparative advantage as the provider.

Proof of Lemma 3.1: Substituting (13) into the utility function (8) gives:

$$
U\left(c_{g}, k^{\prime}, h^{\prime}\right)=\log \left(c_{g}\right)+\log \left(r^{\prime} k^{\prime}+w^{\prime} h^{\prime}\right) .
$$


The derivatives of (37) with respect to $k^{\prime}$ and $h^{\prime}$ are given by:

$$
\begin{aligned}
& \frac{\partial U}{\partial k^{\prime}}=\frac{r^{\prime}}{r^{\prime} k^{\prime}+w^{\prime} h^{\prime}}=\frac{(1-\theta)\left(\frac{\phi h^{\prime}}{k^{\prime}}\right)^{\theta}}{(1-\theta)\left(\frac{\phi h^{\prime}}{k^{\prime}}\right)^{\theta} k^{\prime}+\theta\left(\frac{k^{\prime}}{\phi h^{\prime}}\right)^{1-\theta} h^{\prime}}=\frac{(1-\theta) \phi}{(1-\theta) \phi+\theta} \frac{1}{k^{\prime}}, \\
& \frac{\partial U}{\partial h^{\prime}}=\frac{w^{\prime}}{r^{\prime} k^{\prime}+w^{\prime} h^{\prime}}=\frac{\theta}{(1-\theta) \phi+\theta} \frac{1}{h^{\prime}} .
\end{aligned}
$$

Here the prices $r^{\prime}$ and $w^{\prime}$ were replaced by marginal products given technology (9), and $\phi$ denotes the fraction of human capital employed in market production, which is taken as given by the individual. Since only marginal utilities matter for choices, preferences (37) can be expressed as:

$$
U\left(c_{g}, k^{\prime}, h^{\prime}\right)=\log \left(c_{g}\right)+\frac{\partial U}{\partial k^{\prime}} k^{\prime}+\frac{\partial U}{\partial h^{\prime}} h^{\prime}=\log \left(c_{g}\right)+\beta_{k} \log \left(k^{\prime}\right)+\left(1-\beta_{k}\right) \log \left(h^{\prime}\right),
$$

which is (15).

Proof of Lemma 3.2: Start with the original formulation of maximizing (1) subject to (2) to (5), where we denote all variables with a tilde to distinguish them from the ones used in the growth formulation:

$$
\max \left\{\log \left(\tilde{c}_{g}\right)+\int_{0}^{1} \log \left(\tilde{C}_{i}\right) d i\right\}
$$

subject to:

$$
\begin{aligned}
\tilde{C}_{i} & =\tilde{C}_{f, i}+\tilde{C}_{m, i} \quad \forall i \\
\tilde{C}_{g, i} & =\tilde{E}_{g, i}^{1-\alpha(i)} \tilde{T}_{g, i}^{\alpha(i)} \quad \forall i \\
\tilde{c}_{g}+\int_{0}^{1} \tilde{E}_{g, i} d i & =\tilde{w}_{g}\left(1-\int_{0}^{1} \tilde{T}_{g, i} d i\right)+\tilde{x}_{g} .
\end{aligned}
$$

Here have already substituted the time constraint into the budget constraint. Substituting (18) and (19) into the budget constraint (42) gives:

$$
\tilde{c}_{g}+\int_{0}^{1} \tilde{E}_{g, i} d i=\frac{1}{2}\left[w_{g} h\left(1-\int_{0}^{1} \tilde{T}_{g, i} d i\right)+r k\right]+\tau_{k} .
$$

For $i$ such that $0 \leq i \leq \beta_{k}$, we have $\alpha(i)=0$, so that it is optimal to set $\tilde{T}_{g, i}=0$ and $\tilde{C}_{g, i}=\tilde{E}_{g, i}$ to a constant $\tilde{C}_{g}$. Noting this fact, we can substitute (20) to (23) into the budget constraint (43) to get:

$$
c_{g}+b_{g}+\int_{\beta_{k}}^{1} \frac{E_{g,\left(i-\beta_{k}\right) /\left(1-\beta_{k}\right)}}{1-\beta_{k}} d i=\frac{1}{2}\left[w_{g} h\left(1-\int_{\beta_{k}}^{1} \frac{T_{g,\left(i-\beta_{k}\right) /\left(1-\beta_{k}\right)}}{1-\beta_{k}} d i\right)+r k\right]+\tau_{k} .
$$

Notice that in equation 44 the inputs corresponding to human capital are indexed from $\beta_{k}$ to 1 (index $i$ ), whereas in the growth model the index runs from 0 to 1 (index $j$ ). Applying the change 
of variables $i=\beta_{k}+j\left(1-\beta_{k}\right)$ to the two integrals gives:

$$
c_{g}+b_{g}+\int_{0}^{1} E_{g, j} d j=\frac{1}{2}\left[w_{g} h\left(1-\int_{0}^{1} T_{g, j} d j\right)+r k\right]+\tau_{k},
$$

which is the budget constraint (14) of the decision problem in the growth model. The equivalence of the remaining constraints is immediate.

Thus, we have shown that the set of constraints of the decision problem in the growth model is equivalent to the set of constraints for a special case of the general decision problem. What remains to be shown is that the objective functions are equivalent as well. To this end, given (21) and (10) we have:

$$
\int_{0}^{\beta_{k}} \log \left(\tilde{C}_{i}\right) d i=\beta_{k} \log \left(\frac{b_{f}+b_{m}}{\beta_{k}}\right)=\beta_{k} \log \left(\frac{k^{\prime}}{\beta_{k}}\right)
$$

Similarly, using (22), (23), and (11) and applying a change of variables as above gives:

$$
\begin{aligned}
\int_{\beta_{k}}^{1} \log \left(\tilde{C}_{i}\right) d i & =\int_{\beta_{k}}^{1} \log \left(\sum_{g \in\{f, m\}} \tilde{E}_{g, i}^{1-\alpha(i)} \tilde{T}_{g, i}^{\alpha(i)}\right) d i \\
& =\int_{\beta_{k}}^{1} \log \left(\sum_{g \in\{f, m\}} \frac{E_{g,\left(i-\beta_{k}\right) /\left(1-\beta_{k}\right)}^{1-\alpha,(i)} T_{g,(i) /\left(1-\beta_{k}\right)}^{\alpha(i)}}{1-\beta_{k}}\right) d i \\
& =\left(1-\beta_{k}\right) \int_{0}^{1} \log \left(\sum_{g \in\{f, m\}} \frac{E_{g, j}^{1-j} T_{g, j}^{j}}{1-\beta_{k}}\right) d j \\
& =\left(1-\beta_{k}\right)\left(\log \left(h^{\prime}\right)-\log \left(1-\beta_{k}\right)\right) .
\end{aligned}
$$

Using (20), (46), and (47), the objective function (39) can be written as:

$$
\log \left(c_{g}\right)+\beta_{k} \log \left(k^{\prime}\right)+\left(1-\beta_{k}\right) \log \left(h^{\prime}\right)-\beta_{k} \log \left(\beta_{k}\right)-\left(1-\beta_{k}\right) \log \left(1-\beta_{k}\right) .
$$

This is (15) up to an additive constant. The utility function in the special case of the general decision problem therefore induces the same preferences as the utility function of the decision problem in the growth model, which completes the proof.

Proof of Lemma 3.3: Fix the state variables $k>0$ and $h>0$, and let $c_{g}, k^{\prime}=b_{m}, E_{g, i}, T_{g, i}$, and $\bar{i}$ denote the equilibrium choices in the current generation given $k$ and $h$. Now consider alternative state variables $\tilde{k}>0$ and $\tilde{h}>0$. Define $\xi$ as the ratio of output under these and the original state variables: ${ }^{38}$

$$
\xi=\frac{\tilde{k}^{1-\theta} \tilde{h}^{\theta}}{k^{1-\theta} h^{\theta}} .
$$

We would like to show the following are equilibrium choices given $\tilde{k}$ and $\tilde{h}: \tilde{c}_{g}=\xi c_{g}, \tilde{k}^{\prime}=\xi k^{\prime}$, $\tilde{E}_{g, i}=\xi E_{g, i}, T_{g, i}$, and $\bar{i}$. We will show this by showing that given these choices, the decision

\footnotetext{
${ }^{38}$ The ratio of output takes this form because the time allocation is the same for the original and the new state variables, which will be verified below.
} 
problem at state variables $\tilde{k}$ and $\tilde{h}$ can be reduced to the decision problem at state variables $k$ and $h$. Recall that the decision problem of spouse $g$ is to maximize (8) subject to constraints (10)-(14).

The budget constraint (14) for spouse $g$ at state variables $\tilde{k}$ and $\tilde{h}$ is given by:

$$
\tilde{c}_{g}+\tilde{b}_{g}+\int_{0}^{1} \tilde{E}_{g, i} d i=\frac{1}{2}\left[\tilde{w}_{g} \tilde{h}\left(1-\int_{0}^{1} T_{g, i} d i\right)+\tilde{r} \tilde{k}\right]+\tilde{\tau}_{g}
$$

where $\tilde{w}_{g}$ and $\tilde{r}$ are factor prices at state variables $\tilde{k}$ and $\tilde{h}$. Given our conjecture, this can be written as:

$$
\xi c_{g}+\xi b_{g}+\int_{0}^{1} \xi E_{g, i} d i=\frac{1}{2}\left[\tilde{w}_{g} \tilde{h}\left(1-\int_{0}^{1} T_{g, i} d i\right)+\tilde{r} \tilde{k}\right]+\xi \tau_{g},
$$

Next, notice that given our conjecture we have $\tilde{w}_{g} \tilde{h}=\xi w_{g} h$ and $\tilde{r} \tilde{k}=\xi r k$. Substituting these expressions and dividing by $\xi$ gives:

$$
c_{g}+b_{g}+\int_{0}^{1} E_{g, i} d i=\frac{1}{2}\left[w_{g} h\left(1-\int_{0}^{1} T_{g, i} d i\right)+r k\right]+\tau_{g},
$$

which is the budget constraint for the state variables $k, h$. Similarly, we can plug the conjectured values into the constraints (10)-(13), and in each case reduce the constraint for $\tilde{k}, \tilde{h}$ to the original constraint for $k, h$ by dividing by $\xi$ or, in the case of constraint (11), by subtracting $\log (\xi)$ on both sides.

Hence, we have found so far that the constraint set for $\xi c_{g}, \xi k^{\prime}$ etc. at state variables $\tilde{k}, \tilde{h}$ is the same as the constraints set for $c_{g}, k^{\prime}$ etc. at state variables $k, h$. To show that the conjectured choices at $\tilde{k}, \tilde{h}$ are indeed optimal, we still need to show that the preferences over $\xi c_{g}, \xi k^{\prime}$ and $\tilde{h}^{\prime}$ given state variables $\tilde{k}, \tilde{h}$ are equivalent to the preferences over $c_{g}, k$, and $h$ given state variables $k$ and $h$. Here $\tilde{h}^{\prime}$ the children's human capital at current state variables $\tilde{k}, \tilde{h}$ given the conjectured choices, which is given by:

$$
\tilde{h}^{\prime}=\exp \left(\int_{0}^{1} \log \left(\left(\xi E_{i}\right)^{1-i}\left(T_{i} \tilde{h}\right)^{i}\right) d i\right) .
$$

Here $E_{i}=E_{m, i}$ and $T_{i}=T_{m, i}$ for $i<\bar{i}$ and $E_{i}=E_{f, i}$ and $T_{i}=T_{f, i}$ for $i \geq \bar{i}$. To simplify notation, let $\phi$ denote the fraction of human capital used for production:

$$
\phi=\frac{1}{2}\left[1-\int_{0}^{1} T_{m, i} d i+\delta\left(1-\int_{0}^{1} T_{f, i} d i\right)\right] .
$$

Note that under our conjecture, $\phi$ is a constant that does not depend on current state variables. We can now write the objective function (15) at state variables $\tilde{k}, \tilde{h}$ as:

$$
\begin{aligned}
\log \left(\tilde{c}_{g}\right) & +\beta_{k} \log \left(\tilde{k}^{\prime}\right)+\left(1-\beta_{k}\right) \log \left(\tilde{h}^{\prime}\right) \\
& =\log \left(\xi c_{g}\right)+\beta_{k} \log \left(\xi k^{\prime}\right)+\left(1-\beta_{k}\right) \int_{0}^{1} \log \left(\left(\xi E_{i}\right)^{1-i}\left(T_{i} \tilde{h}\right)^{i}\right) d i \\
& =\log \left(c_{g}\right)+\beta_{k} \log \left(k^{\prime}\right)+\left(1-\beta_{k}\right) \int_{0}^{1} \log \left(\left(E_{i}\right)^{1-i}\left(T_{i} h\right)^{i}\right) d i
\end{aligned}
$$




$$
+\left(1+\beta_{k}+\frac{1-\beta_{k}}{2}\right) \log (\xi)+\frac{1-\beta_{k}}{2}(\log (\tilde{h})-\log (h)) .
$$

This is the objective function at state variables $k, h$ plus a constant that does not depend on choices. The objective function thus induces the same preferences, which completes the proof.

Proof of Proposition 3.1: It will be useful to first characterize the equilibrium choices. Define $\beta_{h}=1-\beta_{k}$. Using Lemma 3.1, the first-order conditions characterizing the wife's optimization problem are given by:

$$
\begin{aligned}
c_{f} & =\frac{1}{\lambda_{f}}, \\
E_{f, i} & \leq \frac{(1-i) \beta_{h}}{\lambda_{f}}, \\
T_{f, i} & \leq \frac{i \beta_{h}}{w_{f} \frac{h}{2} \lambda_{f}}, \\
b_{f} & \leq \frac{\beta_{k}}{\lambda_{f}},
\end{aligned}
$$

where (51) and (52) hold with equality for all public goods $i$ that the wife contributes to, and $\lambda_{f}$ denotes the multiplier on the budget constraint. The corresponding optimality conditions for the husband are:

$$
\begin{aligned}
c_{m} & =\frac{1}{\lambda_{m}}, \\
E_{m, i} & \leq \frac{(1-i) \beta_{h}}{\lambda_{m}}, \\
T_{m, i} & \leq \frac{i \beta_{h}}{w_{m} \frac{h}{2} \lambda_{m}}, \\
b_{m} & \leq \frac{\beta_{k}}{\lambda_{m}} .
\end{aligned}
$$

We can now solve for the multipliers on the budget constraint. Plugging the first-order conditions for the wife back into the budget constraint and using the cutoff rule gives:

$$
\begin{aligned}
c_{f}+\int_{\bar{i}}^{1} E_{f, i} d i & =\frac{1}{2}\left[w_{f} h\left(1-\int_{\bar{i}}^{1} T_{f, i} d i\right)+r k\right]+\tau_{f}, \\
\frac{1}{\lambda_{f}}+\int_{\bar{i}}^{1} \frac{(1-i) \beta_{h}}{\lambda_{f}} d i & =\frac{1}{2}\left[w_{f} h\left(1-\int_{\bar{i}}^{1} \frac{i \beta_{h}}{w_{f} \frac{h}{2} \lambda_{f}} d i\right)+r k\right]+\tau_{f}, \\
\frac{1}{\lambda_{f}}+\int_{\bar{i}}^{1} \frac{(1-i) \beta_{h}}{\lambda_{f}} d i & =w_{f} \frac{h}{2}-\int_{\bar{i}}^{1} \frac{i \beta_{h}}{\lambda_{f}} d i+r \frac{k}{2}+\tau_{f}, \\
\frac{1}{\lambda_{f}}+\int_{\bar{i}}^{1} \frac{\beta_{h}}{\lambda_{f}} d i & =\frac{w_{f} h+r k}{2}+\tau_{f} .
\end{aligned}
$$


Solving for $\lambda_{f}$ yields:

$$
\lambda_{f}=\frac{1+\beta_{h}(1-\bar{i})}{\frac{w_{f} h+r k}{2}+\tau_{f}} .
$$

Proceeding along the same lines with the male budget constraint (but noting that he will provide the bequests in equilibrium) gives:

$$
\lambda_{m}=\frac{1+\beta_{k}+\beta_{h} \bar{i}}{\frac{w_{m} h+r k}{2}+\tau_{m}}
$$

Next, we characterize the cutoff rule for an interior solution. We focus on interior equilibria in which each spouse provides at least part of the human capital input, which implies that the husband (who has the higher wage) provides all of the bequest. Given the first-order conditions, the ratio of female to male preferred public-good provision for human capital good $i$ is:

$$
\frac{C_{f, i}}{C_{m, i}}=\frac{E_{f, i}^{1-i}\left(T_{f, i} h\right)^{i}}{E_{m, i}^{1-i}\left(T_{m, i} h\right)^{i}}=\left(\frac{w_{m}}{w_{f}}\right)^{i} \frac{\lambda_{m}}{\lambda_{f}} .
$$

The condition for the cutoff $\bar{i}$ is therefore:

$$
\frac{\lambda_{f}}{\lambda_{m}}=\left(\frac{w_{m}}{w_{f}}\right)^{\bar{i}}=\delta^{-\bar{i}}
$$

where $\delta<1$ is the gender gap. The cutoff $\bar{i}$ is characterized by the condition that at $\bar{i}$ female- and male-preferred provision of the public good is equal. Using (60) and the computed multipliers, we can write the cutoff condition as:

$$
\left(\frac{1+\beta_{h}(1-\bar{i})}{1+\beta_{k}+\beta_{h} \bar{i}}\right)\left(\frac{\frac{w_{m} h+r k}{2}+\tau_{m}}{\frac{w_{f} h+r k}{2}+\tau_{f}}\right)=\left(\frac{1}{\delta}\right)^{\bar{i}} .
$$

Now, express the transfers as a fraction of output (or output per capita, population size is normalized to one):

$$
\tau_{f}=-\tau_{m}=\gamma Y
$$

and factor prices as:

$$
\begin{gathered}
w_{m}=\delta^{-1} w_{f}=\frac{\theta Y}{\phi h}, \\
r_{t}=\frac{(1-\theta) Y}{k},
\end{gathered}
$$

where $\phi$ is defined in (49) from Lemma 3.3. The cutoff condition can then be written as:

$$
\left(\frac{1+\beta_{h}(1-\bar{i})}{1+\beta_{k}+\beta_{h} \bar{i}}\right)\left(\frac{\frac{\theta}{\phi}+1-\theta-2 \gamma}{\frac{\delta \theta}{\phi}+1-\theta+2 \gamma}\right)=\left(\frac{1}{\delta}\right)^{\bar{i}} .
$$

Notice that the left-hand side is strictly decreasing in $\bar{i}$ while the right-hand side is strictly increasing, implying that there is a unique equilibrium. When the equation does not have a so- 
lution, the equilibrium is a corner where either husband or wife provide all of the public goods that involve time inputs.

We are now ready to address the issue of the effect of a transfer on growth. The log of output in the next generation is:

$$
\begin{aligned}
\log \left(Y^{\prime}\right)= & \log (A)+(1-\theta) \log \left(k^{\prime}\right)+\theta \log \left(\phi h^{\prime}\right) \\
= & \log (A)+(1-\theta) \log \left(k^{\prime}\right)+\theta \int_{0}^{1}\left[(1-i) \log \left(E_{i, t}\right)+i \log \left(T_{i, t}\right)\right] d i \\
& +\frac{\theta}{2} \log (h)+\theta \log (\phi) \\
= & \log (A)+(1-\theta) \log \left(k^{\prime}\right)+\theta \int_{0}^{\bar{i}}\left[(1-i) \log \left(E_{m, i}\right)+i \log \left(T_{m, i}\right)\right] d i \\
& +\theta \int_{\bar{i}}^{1}\left[(1-i) \log \left(E_{f, i}\right)+i \log \left(T_{f, i}\right)\right] d i+\frac{\theta}{2} \log (h)+\theta \log (\phi) .
\end{aligned}
$$

Plugging in the solutions from the first-order conditions this is:

$$
\begin{aligned}
\log \left(Y^{\prime}\right)=\log (A)+ & (1-\theta) \log \left(\frac{\beta_{k}}{\lambda_{m}}\right) \\
& +\theta \int_{0}^{\bar{i}}\left[(1-i) \log \left(\frac{(1-i) \beta_{h}}{\lambda_{m}}\right)+i \log \left(\frac{i \beta_{h}}{w_{m} \frac{h}{2} \lambda_{m}}\right)\right] d i \\
& +\theta \int_{\bar{i}}^{1}\left[(1-i) \log \left(\frac{(1-i) \beta_{h}}{\lambda_{f}}\right)+i \log \left(\frac{i \beta_{h}}{w_{f} \frac{h}{2} \lambda_{f}}\right)\right] d i \\
& +\frac{\theta}{2} \log (h)+\theta \log (\phi) .
\end{aligned}
$$

Denote by B the constant that does not depend on current prices or multipliers (and thus not on transfers) to get:

$$
\begin{aligned}
\log \left(Y^{\prime}\right)=B-(1-\theta) & \log \left(\lambda_{m}\right) \\
& -\theta\left[\bar{i} \log \left(\lambda_{m}\right)+(1-\bar{i}) \log \left(\lambda_{f}\right)+\frac{1}{2}\left[\bar{i}^{2} \log \left(w_{m}\right)+\left(1-\bar{i}^{2}\right) \log \left(w_{f}\right)\right]\right] .
\end{aligned}
$$

Given that $w_{f}=\delta w_{m}$, we can further simplify to:

$$
\begin{aligned}
& \log \left(Y^{\prime}\right)=B-(1-\theta) \log \left(\lambda_{m}\right) \\
&-\theta\left[\bar{i} \log \left(\lambda_{m}\right)+(1-\bar{i}) \log \left(\lambda_{f}\right)+\frac{1}{2}\left[\log \left(w_{m}\right)+\left(1-\bar{i}^{2}\right) \log (\delta)\right]\right]
\end{aligned}
$$

Now consider the effect of a marginal change in the transfer $\epsilon$ from husband to wife on output in the next period (i.e., on growth). The derivative of $Y^{\prime}$ with respect to $\epsilon$ is given by:

$$
\frac{\partial \log \left(Y^{\prime}\right)}{\partial \epsilon}=-(1-\theta(1-\bar{i})) \frac{1}{\lambda_{m}} \frac{\partial \lambda_{m}}{\partial \epsilon}-\theta(1-\bar{i}) \frac{1}{\lambda_{f}} \frac{\partial \lambda_{f}}{\partial \epsilon}-\frac{\theta}{2} \frac{1}{w_{m}} \frac{\partial w_{m}}{\partial \epsilon}
$$




$$
-\theta\left[\log \left(\lambda_{m}\right)-\log \left(\lambda_{f}\right)-\bar{i} \log (\delta)\right] \frac{\partial \bar{i}}{\partial \epsilon}
$$

The cutoff condition (61) implies that the term involving $\frac{\partial \bar{i}}{\partial \epsilon}$ cancels, leaving us with:

$$
\frac{\partial \log \left(Y^{\prime}\right)}{\partial \epsilon}=-(1-\theta(1-\bar{i})) \frac{1}{\lambda_{m}} \frac{\partial \lambda_{m}}{\partial \epsilon}-\theta(1-\bar{i}) \frac{1}{\lambda_{f}} \frac{\partial \lambda_{f}}{\partial \epsilon}-\frac{\theta}{2} \frac{1}{w_{m}} \frac{\partial w_{m}}{\partial \epsilon} .
$$

Now consider the limit cases when the share of human capital goes to either zero or one. When $\theta$ approaches zero, only the first term remains. This term is negative in the limit (an increase in $\epsilon$ lowers male consumption, and hence increases $\lambda_{m}$ ). Hence, when physical capital is the main factor of production, a transfer from husband to wife lowers growth. Next, consider the limit case $\theta=1$, i.e., human capital is the only factor of production. Totally differentiating the cutoff condition (61) yields:

$$
\frac{\partial \bar{i}}{\partial \epsilon} \log (1 / \delta)=\frac{1}{\lambda_{f}} \frac{\partial \lambda_{f}}{\partial \epsilon}-\frac{1}{\lambda_{m}} \frac{\partial \lambda_{m}}{\partial \epsilon} .
$$

Using this in (64) together with $\theta=1$ gives:

$$
\frac{\partial \log \left(Y^{\prime}\right)}{\partial \epsilon}=-\frac{1}{\lambda_{f}} \frac{\partial \lambda_{f}}{\partial \epsilon}+\bar{i} \frac{\partial \bar{i}}{\partial \epsilon} \log (1 / \delta)-\frac{1}{2} \frac{1}{w_{m}} \frac{\partial w_{m}}{\partial \epsilon} .
$$

This expression is identical to equation (76) in the proof of Proposition C.3 except for the last term. In Proposition C.3 (which applies here because of Lemma 3.2), we showed that the first two terms combine to be positive, and the last term is positive as well. Hence, the entire derivative is positive: If human capital accounts for all of production, a transfer to the wife increases growth.

\section{B Equilibrium versus Efficient Public Good Provision}

Given that the spouses in our model act noncooperatively, equilibrium allocations generally fail to be efficient. To highlight the sources of inefficiency in the model, we now contrast the equilibrium outcome to efficient (i.e., Pareto optimal) allocations. Efficient allocations are defined as follows:

Definition B.1 (Efficient Allocation). An efficient allocation is a solution to a social planning problem with a Pareto weight for the wife of $\mu$, where $0 \leq \mu \leq 1$. The social planning problem is to maximize:

$$
\mu \log \left(c_{f}\right)+(1-\mu) \log \left(c_{m}\right)+\int_{0}^{1} \log \left(C_{i}\right) d i
$$

subject to the following constraints:

$$
\begin{aligned}
C_{i} & =C_{f, i}+C_{m, i}, \\
C_{g, i} & =E_{g, i}^{1-\alpha(i)} T_{g, i}^{\alpha(i)}, \\
\sum_{g \in\{f, m\}}\left(c_{g}+\int_{0}^{1} E_{g, i} d i\right) & =\sum_{g \in\{f, m\}} w_{g}\left(1-\int_{0}^{1} T_{g, i} d i\right)+x_{f}+x_{m} .
\end{aligned}
$$


That is, the efficient allocation is constrained by the same technological constraints as is the equilibrium, but there is a joint budget constraint for the household, as opposed to separate budget constraints for the two spouses. The presence of a joint budget constraint immediately implies that mandated transfers between the spouses do not affect efficient allocations, because only the couple's total wealth enters the constraint. The following proposition characterizes efficient allocations in more detail.

Proposition B.1 (Efficient Specialization). Efficient allocations are characterized by a Pareto weight $\mu$, where $0 \leq \mu \leq 1$, such that:

$$
\begin{aligned}
c_{f} & =\frac{1}{2} \mu\left(w_{f}+x_{f}+w_{m}+x_{m}\right), \\
c_{m} & =\frac{1}{2}(1-\mu)\left(w_{f}+x_{f}+w_{m}+x_{m}\right), \\
C_{i} & =\frac{1}{2}(1-\alpha(i))^{1-\alpha(i)} \alpha(i)^{\alpha(i)} w_{f}^{-\alpha(i)}\left(w_{f}+x_{f}+w_{m}+x_{m}\right) .
\end{aligned}
$$

Hence, the provision of public goods is independent of the Pareto weight $\mu$, which only matters for the allocation of private consumption between wife and husband. All home production is carried out by the wife. For given wages and wealth levels, the provision of public goods $C_{i}$ that are provided by the wife in equilibrium is always higher in the efficient allocation compared to the equilibrium allocation.

Proof of Proposition B.1: Let $\lambda$ denote the multiplier on the budget constraint. Given $w_{m}>w_{f}$, the cost of female time is strictly lower than the cost of male time, implying $T_{m, i}=0$ and $T_{f, i}>0$ for all $i$. Moreover, since in producing a given public good the time and goods contributions have to come from the same spouse, this also implies $E_{m, i}=0$ and $E_{f, i}>0$ for all $i$. Taking these features into account, the first-order conditions for the social planning problem are:

$$
\begin{aligned}
c_{f} & =\frac{\mu}{\lambda}, \\
c_{m} & =\frac{1-\mu}{\lambda}, \\
E_{f, i} & =\frac{1-\alpha(i)}{\lambda}, \\
T_{f, i} & \leq \frac{\alpha(i)}{w_{f} \lambda} .
\end{aligned}
$$

Plugging these expressions into the budget constraint and solving for the multiplier yields:

$$
\lambda=\frac{2}{w_{f}+x_{f}+w_{m}+x_{m}} .
$$

Using this to solve for the efficient allocation yields:

$$
\begin{aligned}
c_{f} & =\frac{1}{2} \mu\left(w_{f}+x_{f}+w_{m}+x_{m}\right), \\
c_{m} & =\frac{1}{2}(1-\mu)\left(w_{f}+x_{f}+w_{m}+x_{m}\right), \\
C_{i} & =\frac{1}{2}(1-\alpha(i))^{1-\alpha(i)} \alpha(i)^{\alpha(i)} w_{f}^{-\alpha(i)}\left(w_{f}+x_{f}+w_{m}+x_{m}\right),
\end{aligned}
$$


as stated in the proposition.

Regarding the relative provision of public goods in the equilibrium and in the efficient allocation, notice that the multiplier $\lambda$ enters (65) and (66) in the same way as the multiplier $\lambda_{f}$ enters (25) and (26) in the characterization of the equilibrium allocation. To show that for an $i$ where the wife is the equilibrium provider, the efficient provision of $C_{i}$ is higher than the equilibrium provision, it is therefore sufficient to show that $\lambda<\lambda_{f}$, or, using (31):

$$
\frac{2}{w_{f}+x_{f}+w_{m}+x_{m}}<\frac{2-\bar{i}}{w_{f}+x_{f}} .
$$

In the case of a corner solution with $\bar{i}=0$ the required inequality is immediate, and if $\bar{i}=1$ there are no female-provided public goods in equilibrium. For interior solutions, the cutoff condition (33) yields the following inequality:

$$
w_{m}+x_{m} \geq \frac{1+\bar{i}}{2-\bar{i}}\left(w_{f}+x_{f}\right) .
$$

Using this inequality, we get:

$$
\begin{aligned}
\frac{2}{w_{f}+x_{f}+w_{m}+x_{m}} & \leq \frac{2}{\left(1+\frac{1+\bar{i}}{2-i}\right)\left(w_{f}+x_{f}\right)} \\
& =\frac{2}{3} \frac{2-\bar{i}}{w_{f}+x_{f}} \\
& <\frac{2-\bar{i}}{w_{f}+x_{f}},
\end{aligned}
$$

as required.

Efficient allocations and equilibrium allocations differ for two reasons. First, efficient allocations feature full specialization, in the sense that only the wife is engaged in home production. This is because the wife has a comparative advantage in home production given her lower wage. In contrast, full specialization is not observed in the equilibrium allocation, unless the wife has at least twice as much total income as the husband has. As we will see below, this feature of efficient allocations provides one reason for why a mandated transfer from husband to wife may move the equilibrium closer to efficiency.

There is a second distinction between efficient and equilibrium allocations, related to the weight attached to public goods in the objective function. In the social planning problem, the planner takes into account the utility that both spouses derive from public goods. In contrast, in the equilibrium allocation the provider of a given public good takes into account only his or her own utility, and not that of the spouse. This is the well-known problem of the underprovision of voluntarily provided public goods, and explains why in the efficient allocation public good provision is usually higher. This source of inefficiency would be less important if we allowed for some altruism between the spouses, because then each provider would take into account at least some of the benefit of public good provision for the other spouse. Such an extension would be straightforward, as it amounts solely to a higher relative weight for public goods in the utility function, while leaving the analysis otherwise unchanged. For simplicity, we abstract 
from altruism in our exposition, but it should be kept in mind that none of our results relies on the absence of altruism. We show this formally in an earlier version of this paper, Doepke and Tertilt (2011).

\section{Do Mandated Transfers Increase the Total Provision of Public Goods?}

In this section we examine the effect of transfers on the total utility derived from public goods, which is given by:

$$
\int_{0}^{1} \log \left(C_{i}\right) d i
$$

We start by providing a decomposition of the effect of a mandated transfer into the expenditure share channel, the efficiency channel, and the reallocation

Proposition C.1 (Decomposition of Effect of Mandated Transfers on Total Public Good Provision). Let $\epsilon \geq 0$ denote a mandated transfer from husband to wife, at given wages $w_{f}, w_{m}$ and pretransfer wealth $x_{f}, x_{m}$. If there is an interior equilibrium with $0<\bar{i}<1$, the total provision of public goods is given by:

$$
\begin{aligned}
\int_{0}^{1} \log \left(C_{i}\right) d i=B-\bar{i} \log \left(\frac{1+\bar{i}}{w_{m}+x_{m}-\epsilon}\right)-(1-\bar{i}) \log \left(\frac{2-\bar{i}}{w_{f}+x_{f}+\epsilon}\right)- & \\
& \int_{0}^{\bar{i}} \alpha(i) d i \log \left(w_{m}\right)-\int_{\bar{i}}^{1} \alpha(i) d i \log \left(w_{f}\right),
\end{aligned}
$$

where $B$ is a constant and $\bar{i}$ is the equilibrium cutoff between male and female provision of public goods. Consequently, the derivative of total public goods provision with respect to $\epsilon$ evaluated at $\epsilon=0$ can be expressed as:

$$
\begin{aligned}
\frac{d \int_{0}^{1} \log \left(C_{i}\right) d i}{d \epsilon}= & -\underbrace{\frac{\bar{i}}{w_{m}+x_{m}}+\frac{1-\bar{i}}{w_{f}+x_{f}}}_{\text {Expenditure Share Channel }} \\
& +\underbrace{\left[\log \left(\frac{(2-\bar{i})\left(w_{m}+x_{m}\right)}{(1+\bar{i})\left(w_{f}+x_{f}\right)}\right)+\frac{1-\bar{i}}{2-\bar{i}}-\frac{\bar{i}}{1+\bar{i}}\right] \frac{\partial \bar{i}}{\partial \epsilon}}_{\text {Efficiency Channel }} \\
& -\underbrace{\alpha(\bar{i}) \log \left(\frac{w_{m}}{w_{f}}\right) \frac{\partial \bar{i}}{\partial \epsilon}}_{\text {Reallocation Channel }} .
\end{aligned}
$$

Proof of Proposition C.1: Recall from (34) that the total provision of public goods can be written as:

$$
\begin{aligned}
\int_{0}^{1} \log \left(C_{i}\right) d i=B-\bar{i} \log \left(\lambda_{m}\right)-(1-\bar{i}) \log \left(\lambda_{f}\right) & \\
& -\int_{0}^{\bar{i}} \alpha(i) d i \log \left(w_{m}\right)-\int_{\bar{i}}^{1} \alpha(i) d i \log \left(w_{f}\right),
\end{aligned}
$$


where $B$ is a constant. From (31) and (32), the multipliers $\lambda_{f}$ and $\lambda_{m}$ are given by:

$$
\begin{aligned}
\lambda_{f} & =\frac{2-\bar{i}}{w_{f}+x_{f}+\epsilon}, \\
\lambda_{m} & =\frac{1+\bar{i}}{w_{m}+x_{m}-\epsilon} .
\end{aligned}
$$

Plugging these into (68) yields the first expression stated in the proposition. Further, differentiating with respect to $\epsilon$ and evaluating at $\epsilon=0$ gives equation (67).

Note that $\frac{\partial \bar{i}}{\partial \epsilon} \leq 0$, that is, a transfer to the wife increases the range of public goods provided by the wife. Hence, when $w_{m}>w_{f}$ the efficiency channel is always positive. However, this does not imply that a mandated transfer to the wife always increases the provision of public goods overall, because the sign of the other channels is ambiguous. Indeed, we can establish that depending on the shape of the $\alpha(i)$ function, a transfer from husband to wife may either lower or raise total public good provision. To work towards this result, we first characterize the expenditure share channel in more detail.

Lemma C.1 (Expenditure Share Channel). Assume $0<w_{f}<w_{m}$. For given initial wealth $x_{f}$ and $x_{m}$, consider the marginal effect of a wealth transfer $\epsilon$ from the husband to the wife, holding constant the equilibrium cutoff $\bar{i}$ (as if each spouse had zero productivity in providing public goods provided by the other spouse). Notably, this implies that only the expenditure share channel is present. The transfer increases the total utility derived from public goods if and only if:

$$
\frac{1-\bar{i}}{\bar{i}}>\frac{w_{f}+x_{f}}{w_{m}+x_{m}}
$$

That is, holding $\bar{i}$ constant, transferring resources to the wife increases the total provision of public goods if and only if the share of public goods provided by the wife exceeds the wife's share in total resources of the couple.

Proof of Lemma C.1: The derivative of (34) with respect to $\epsilon$ for $\bar{i}$ held constant is:

$$
\frac{\partial \int_{0}^{1} \log \left(C_{i}\right) d i}{\partial \epsilon}=-\bar{i} \frac{\frac{\partial \lambda_{m}}{\partial \epsilon}}{\lambda_{m}}-(1-\bar{i}) \frac{\frac{\partial \lambda_{f}}{\partial \epsilon}}{\lambda_{f}} .
$$

From (31) and (32), the multipliers $\lambda_{f}$ and $\lambda_{m}$ are given by:

$$
\begin{aligned}
\lambda_{f} & =\frac{2-\bar{i}}{w_{f}+x_{f}+\epsilon}, \\
\lambda_{m} & =\frac{1+\bar{i}}{w_{m}+x_{m}-\epsilon},
\end{aligned}
$$

and the derivatives with respect to $\epsilon$ evaluated at $\epsilon=0$ are:

$$
\begin{aligned}
\frac{\partial \lambda_{f}}{\partial \epsilon} & =-\frac{2-\bar{i}}{\left(w_{f}+x_{f}\right)^{2}}, \\
\frac{\partial \lambda_{m}}{\partial \epsilon} & =\frac{1+\bar{i}}{\left(w_{m}+x_{m}\right)^{2}} .
\end{aligned}
$$


Plugging these expressions into (69) gives:

$$
\frac{\partial \int_{0}^{1} \log \left(C_{i}\right) d i}{\partial \epsilon}=-\frac{\bar{i}}{w_{m}+x_{m}}+\frac{1-\bar{i}}{w_{f}+x_{f}} .
$$

We therefore have:

$$
\frac{\partial \int_{0}^{1} \log \left(C_{i}\right) d i}{\partial \epsilon}>0
$$

if and only if:

$$
\frac{1-\bar{i}}{\bar{i}}>\frac{w_{f}+x_{f}}{w_{m}+x_{m}}
$$

That is, holding $\bar{i}$ constant, transferring resources to the wife increases the total provision of public goods if and only if the share of public goods provided by the wife exceeds the wife's share in total resources of the couple.

Depending on the shape of the $\alpha(i)$ function and the overall distribution of resources, the expenditure share channel can therefore favor making transfers to either spouse. In particular, transferring resources to the husband may increase the overall provision of public goods if a wide range of public goods are goods-intensive, which tends to increase the share of public goods provided by the husband.

We now build on the decomposition into efficiency, expenditure share, and reallocation channel to formally establish that the overall effect of mandated transfers on public-good provision is indeed ambiguous: depending on parameters, a mandated transfer can either lower or raise public good provision. The decomposition also clarifies the conditions under which a positive or a negative effect is likely to arise; in Section 3 in the main text, we build on this analysis to ask under which conditions a mandated transfer is growth enhancing in the context of a growth model driven by the accumulation of physical and human capital.

We formally establish that the overall effect of a mandated transfer on public-good provision is ambiguous by showing that the expenditure share can dominate the other channels. Given that the expenditure share channel itself can favor making transfers to either spouse, this implies that the overall effect on public-good provision is ambiguous also. For the expenditure channel to dominate, the remaining channels have to be sufficiently weak. The next proposition demonstrates that depending on the shape of the $\alpha(i)$ function, the other channels can be arbitrarily weak.

Proposition C.2 (Expenditure Share Channel Can Dominate). Assume $0<w_{f}<w_{m}$ and that $\alpha(i)$ is continuously differentiable. For given initial wealth $x_{f}$ and $x_{m}$, consider the marginal effect of $a$ mandated transfer $\epsilon$ from the husband to the wife on the equilibrium cutoff $\bar{i}$. The derivative $\frac{\partial \bar{i}}{\partial \epsilon}$ is declining in $\alpha^{\prime}(\bar{i})$ and can thus be arbitrarily small if $\alpha^{\prime}(\bar{i})$ is arbitrarily large. Given that $\frac{\partial \bar{i}}{\partial \epsilon}$ appears in both the reallocation channel and the efficiency channel, this implies that by choosing $\alpha(i)$ these channels can be arbitrarily weakened, so that the expenditure share channel dominates.

Proof of Proposition C.2: The cutoff condition (7) characterizing $\bar{i}$ can be written as:

$$
\frac{\lambda_{f}}{\lambda_{m}}=\left(\frac{w_{m}}{w_{f}}\right)^{\alpha(\bar{i})}
$$


Taking logs yields:

$$
\log \left(\frac{\lambda_{f}}{\lambda_{m}}\right)=\alpha(\bar{i}) \log \left(\frac{w_{m}}{w_{f}}\right) .
$$

For varying $\epsilon$, this equation is an identity, with $\lambda_{f}, \lambda_{m}$, and $\bar{i}$ all being functions of $\epsilon$. Differentiating both sides of the identity with respect to $\epsilon$ and solving for $\frac{\partial \bar{i}}{\partial \epsilon}$ yields:

$$
\frac{\partial \bar{i}}{\partial \epsilon}=\frac{1}{\alpha^{\prime}(\bar{i}) \log \left(\frac{w_{m}}{w_{f}}\right)}\left[\frac{1}{\lambda_{f}} \frac{\partial \lambda_{f}}{\partial \epsilon}-\frac{1}{\lambda_{m}} \frac{\partial \lambda_{m}}{\partial \epsilon}\right] .
$$

Thus, the derivative becomes arbitrarily small as $\alpha^{\prime}(\bar{i})$ becomes arbitrarily large.

An even simpler case obtains when $\alpha(i)$ has a discontinuity at $\bar{i}$, in which case $\bar{i}$ can be constant for a range of $\epsilon$.

Lemma C.1 and Proposition C.2 together imply that the question of whether mandated transfers from husbands to wives increase public good provision has no clear-cut answer. Instead, the effect of such transfers depends on the specifics of the technology for producing public goods and on the initial distribution of wealth and relative wages.

Even though these results show that the effects of mandated transfers on public good provision are generally ambiguous, it is also true that the efficiency channel always favors transfers to the low-wage spouse. Thus, one may conjecture that if the environment is symmetric apart from the wage gap between women and men (so that the expenditure share and reallocation channel do not strongly favor redistribution to either spouse), mandated transfers to women should increase public good provision. This turns out to be true in the case when $\alpha(i)=i$, i.e., time intensity varies linearly with the index of the public good. In this setting the overall household production technology is symmetric in terms of time versus goods intensity. It can indeed be shown that if there is an interior solution, the total provision of public goods is increased if wealth is transferred to the low-wage spouse.

Proposition C.3 (Transfer to Wife Increases Public-Good Provision if $\alpha(i)=i)$. Assume $0<w_{f}<$ $w_{m}$ and $\alpha(i)=i$. For given initial wealth $x_{f}$ and $x_{m}$, consider the effects of a mandated transfer $\epsilon$ from the husband to the wife, so that the new wealth levels are $x_{f}+\epsilon$ and $x_{m}-\epsilon$. If for given $x_{f}$ and $x_{m}$ the equilibrium is interior, i.e., the cutoff $\bar{i}$ between male and female provision of public goods satisfies $0<\bar{i}<1$, a marginal increase in the transfer from husband to wife increases the total provision of public goods. Formally, we have:

$$
\frac{\partial \int_{0}^{1} \log \left(C_{i}\right) d i}{\partial \epsilon}>0
$$

Proof of Proposition C.3: From (34), the total provision of public goods can be written as:

$$
\begin{aligned}
\int_{0}^{1} \log \left(C_{i}\right) d i=B & -\bar{i} \log \left(\lambda_{m}\right)-(1-\bar{i}) \log \left(\lambda_{f}\right) \\
& -\int_{0}^{\bar{i}} \alpha(i) d i \log \left(w_{m}\right)-\int_{\bar{i}}^{1} \alpha(i) d i \log \left(w_{f}\right) .
\end{aligned}
$$


For the case $\alpha(i)=i$ considered here this can be further simplified:

$$
\int_{0}^{1} \log \left(C_{i}\right) d i=B-\bar{i} \log \left(\lambda_{m}\right)-(1-\bar{i}) \log \left(\lambda_{f}\right)-\frac{1}{2}\left[\bar{i}^{2} \log \left(\frac{w_{m}}{w_{f}}\right)+\log \left(w_{f}\right)\right] .
$$

Next, combining the cutoff condition (7) with the first-order conditions (24) and (27) gives:

$$
\left(\frac{w_{m}}{w_{f}}\right)^{\bar{i}}=\frac{\lambda_{f}}{\lambda_{m}}
$$

Taking logs and solving for $\log \left(\lambda_{m}\right)$ gives:

$$
\log \left(\lambda_{m}\right)=\log \left(\lambda_{f}\right)-\bar{i} \log \left(\frac{w_{m}}{w_{f}}\right) .
$$

Using the expression to replace $\lambda_{m}$ in (72) gives:

$$
\int_{0}^{1} \log \left(C_{i}\right) d i=B-\log \left(\lambda_{f}\right)+\frac{1}{2} \bar{i}^{2} \log \left(\frac{w_{m}}{w_{f}}\right)-\frac{1}{2} \log \left(w_{f}\right) .
$$

We would like to characterize the derivative of this expression with respect to $\epsilon$. The only variables that depend on $\epsilon$ are $\bar{i}$ and $\lambda_{f}$. The derivative can therefore be written as:

$$
\frac{\partial \int_{0}^{1} \log \left(C_{i}\right) d i}{\partial \epsilon}=-\frac{1}{\lambda_{f}} \frac{\partial \lambda_{f}}{\partial \epsilon}+\bar{i} \frac{\partial \bar{i}}{\partial \epsilon} \log \left(\frac{w_{m}}{w_{f}}\right) .
$$

Given (70), at $\epsilon=0$ we have:

$$
\begin{aligned}
\lambda_{f} & =\frac{2-\bar{i}}{w_{f}+x_{f}}, \\
\frac{\partial \lambda_{f}}{\partial \epsilon} & =-\frac{2-\bar{i}}{\left(w_{f}+x_{f}\right)^{2}}-\frac{1}{w_{f}+x_{f}} \frac{\partial \bar{i}}{\partial \epsilon} .
\end{aligned}
$$

Plugging these expressions into (76) gives:

$$
\frac{\partial \int_{0}^{1} \log \left(C_{i}\right) d i}{\partial \epsilon}=\frac{1}{w_{f}+x_{f}}+\left(\frac{1}{2-\bar{i}}+\bar{i} \log \left(\frac{w_{m}}{w_{f}}\right)\right) \frac{\partial \bar{i}}{\partial \epsilon} .
$$

Totally differentiating (74) leads to:

$$
\frac{\partial \bar{i}}{\partial \epsilon}=-\frac{\frac{1}{w_{f}+x_{f}}+\frac{1}{w_{m}+x_{m}}}{\log \left(\frac{w_{m}}{w_{f}}\right)+\frac{1}{2-i}+\frac{1}{1+i}} .
$$

Plugging this into (77) gives:

$$
\frac{\partial \int_{0}^{1} \log \left(C_{i}\right) d i}{\partial \epsilon}=\frac{\log \left(\frac{w_{m}}{w_{f}}\right)+\frac{1}{2-i}+\frac{1}{1+i}-\left(\frac{1}{2-i}+\bar{i} \log \left(\frac{w_{m}}{w_{f}}\right)\right)\left(1+\frac{w_{f}+x_{f}}{w_{m}+x_{m}}\right)}{\left(w_{f}+x_{f}\right)\left(\log \left(\frac{w_{m}}{w_{f}}\right)+\frac{1}{2-\bar{i}}+\frac{1}{1+i}\right)}
$$


The denominator is positive. To prove the claim, we need to show that the numerator is positive as well. Using the cutoff condition (73) combined with the multipliers (70) and (71) to replace the term $\left(w_{f}+x_{f}\right) /\left(w_{m}+x_{m}\right)$, we need to establish the following inequality:

$$
\log \left(\frac{w_{m}}{w_{f}}\right)+\frac{1}{2-\bar{i}}+\frac{1}{1+\bar{i}}-\left(\frac{1}{2-\bar{i}}+\bar{i} \log \left(\frac{w_{m}}{w_{f}}\right)\right)\left(1+\frac{2-\bar{i}}{1+\bar{i}}\left(\frac{w_{f}}{w_{m}}\right)^{\bar{i}}\right)>0
$$

It can be verified numerically that the expression on the left-hand side is decreasing in $\bar{i}$ for all $w_{m} / w_{f}>1$. It is therefore sufficient to check the inequality at the point $\bar{i}=1$, i.e., at the point where the husband is providing all public goods and, therefore, the expenditure-share channel favors transfers to the husband. Plugging in $\bar{i}=1$ yields:

$$
\log \left(\frac{w_{m}}{w_{f}}\right)+\frac{3}{2}-\left(1+\log \left(\frac{w_{m}}{w_{f}}\right)\right)\left(1+\frac{w_{f}}{2 w_{m}}\right)>0 .
$$

Simplifying the expression yields:

$$
1-\left(1+\log \left(\frac{w_{m}}{w_{f}}\right)\right) \frac{w_{f}}{w_{m}}>0
$$

or:

$$
\frac{w_{m}}{w_{f}}>1+\log \left(\frac{w_{m}}{w_{f}}\right)
$$

which is satisfied because we assume $w_{m}>w_{f}$.

However, symmetry is not sufficient for a transfer from husband to wife to increase provision. For example the case $\alpha(i)=0.5$ for all $i$ is also symmetric, yet in this case transfers do not affect the total provision of public goods as long as equilibria are interior.

\section{The Effectiveness of Transfers When the Wage Gap Shrinks}

One determinant of the effect of transfers on public good provision is the wage gap between men and women. The wage gap is an essential ingredient in the household production mechanism, because it is what leads the two spouses to specialize in providing different types of public goods. In this appendix, we show that when the size of the wage gap approaches zero, the effect of mandated transfers (whichever the sign) also goes to zero. Intuitively, given that the wage gap is the only difference between the sexes in our model, when the wage gap disappears so does the distinction between women and men. In that case, it no longer matters much who controls resources.

Proposition D.1 (Role of Wage Gap). Assume $0<w_{f} \leq w_{m}$. For given initial wealth $x_{f}$ and $x_{m}$, consider the effects of a wealth transfer $\epsilon$ from the husband to the wife on public good provision. When the female wage converges to the male wage, the marginal effect of a transfer $\epsilon$ on the total provision of public goods converges to zero:

$$
\lim _{w_{f} \rightarrow w_{m}} \frac{\partial \int_{0}^{1} \log \left(C_{i}\right) d i}{\partial \epsilon}=0 .
$$


Proof of Proposition D.1: From (67), the derivative of the total provision of public goods with respect to the transfer $\epsilon$ (evaluated at $\epsilon=0$ ) is given by:

$$
\begin{aligned}
\frac{\partial \int_{0}^{1} \log \left(C_{i}\right) d i}{\partial \epsilon}= & -\frac{\bar{i}}{w_{m}+x_{m}}+\frac{1-\bar{i}}{w_{f}+x_{f}} \\
& +\left[\log \left(\frac{(2-\bar{i})\left(w_{m}+x_{m}\right)}{(1+\bar{i})\left(w_{f}+x_{f}\right)}\right)+\frac{1-\bar{i}}{2-\bar{i}}-\frac{\bar{i}}{1+\bar{i}}\right] \frac{\partial \bar{i}}{\partial \epsilon} \\
& -\alpha(\bar{i}) \log \left(\frac{w_{m}}{w_{f}}\right) \frac{\partial \bar{i}}{\partial \epsilon} .
\end{aligned}
$$

Using the multipliers (31) and (32) in the cutoff condition (7) for $\bar{i}$ yields:

$$
\left(\frac{w_{m}}{w_{f}}\right)^{\alpha(\bar{i})}=\frac{(2-\bar{i})\left(w_{m}+x_{m}-\epsilon\right)}{(1+\bar{i})\left(w_{f}+x_{f}+\epsilon\right)} .
$$

In the limit as $w_{f} \rightarrow w_{m}$, the left hand side converges to 1 and thus we have (evaluated at $\epsilon=0$ ):

$$
\frac{2-\bar{i}}{w_{f}+x_{f}}=\frac{1+\bar{i}}{w_{m}+x_{m}} \text {. }
$$

Solving this expression for $\bar{i}$, we get:

$$
\lim _{w_{f} \rightarrow w_{m}} \bar{i}=\lim _{w_{f} \rightarrow w_{m}} \frac{2\left(w_{m}+x_{m}\right)-\left(w_{f}+x_{f}\right)}{w_{f}+x_{f}+w_{m}+x_{m}} .
$$

The derivative $\frac{\partial \bar{i}}{\partial \epsilon}$ can be derived from (79) by taking logs, then differentiating both sides with respect to $\epsilon$, and collecting terms. Evaluated at $\epsilon=0$ the derivative is:

$$
\frac{\partial \bar{i}}{\partial \epsilon}=-\frac{\frac{1}{w_{f}+x_{f}}+\frac{1}{w_{m}+x_{m}}}{\alpha^{\prime}(\bar{i}) \log \left(\frac{w_{m}}{w_{f}}\right)+\frac{1}{2-\bar{i}}+\frac{1}{1+\bar{i}}},
$$

In the limit $w_{f} \rightarrow w_{m}$, the first term in the denominator disappears. Then, using (80), the derivative simplifies to:

$$
\lim _{w_{f} \rightarrow w_{m}} \frac{\partial \bar{i}}{\partial \epsilon}=-\frac{\frac{1}{w_{f}+x_{f}}+\frac{1}{w_{m}+x_{m}}}{\frac{1}{2-\bar{i}}+\frac{1}{1+\bar{i}}}=-\frac{3}{2 w_{m}+x_{f}+x_{m}} .
$$

Now plugging the derived limits for $\bar{i}$ and $\frac{\partial \bar{i}}{\partial \epsilon}$ into the expression for the total provision of public goods and simplifying, we get:

$$
\begin{aligned}
\lim _{w_{f} \rightarrow w_{m}} \frac{d \int_{0}^{1} \log \left(C_{i}\right) d i}{d \epsilon} & =\lim _{w_{f} \rightarrow w_{m}}\left\{-\frac{\bar{i}}{w_{m}+x_{m}}+\frac{1-\bar{i}}{w_{f}+x_{f}}+\left[\frac{1-\bar{i}}{2-\bar{i}}-\frac{\bar{i}}{1+\bar{i}}\right] \frac{\partial \bar{i}}{\partial \epsilon}\right\} \\
& =\frac{1}{w_{m}+x_{m}}-\frac{1}{w_{m}+x_{f}}-\frac{1}{w_{m}+x_{m}}+\frac{1}{w_{m}+x_{f}} \\
& =0
\end{aligned}
$$

which completes the proof. 


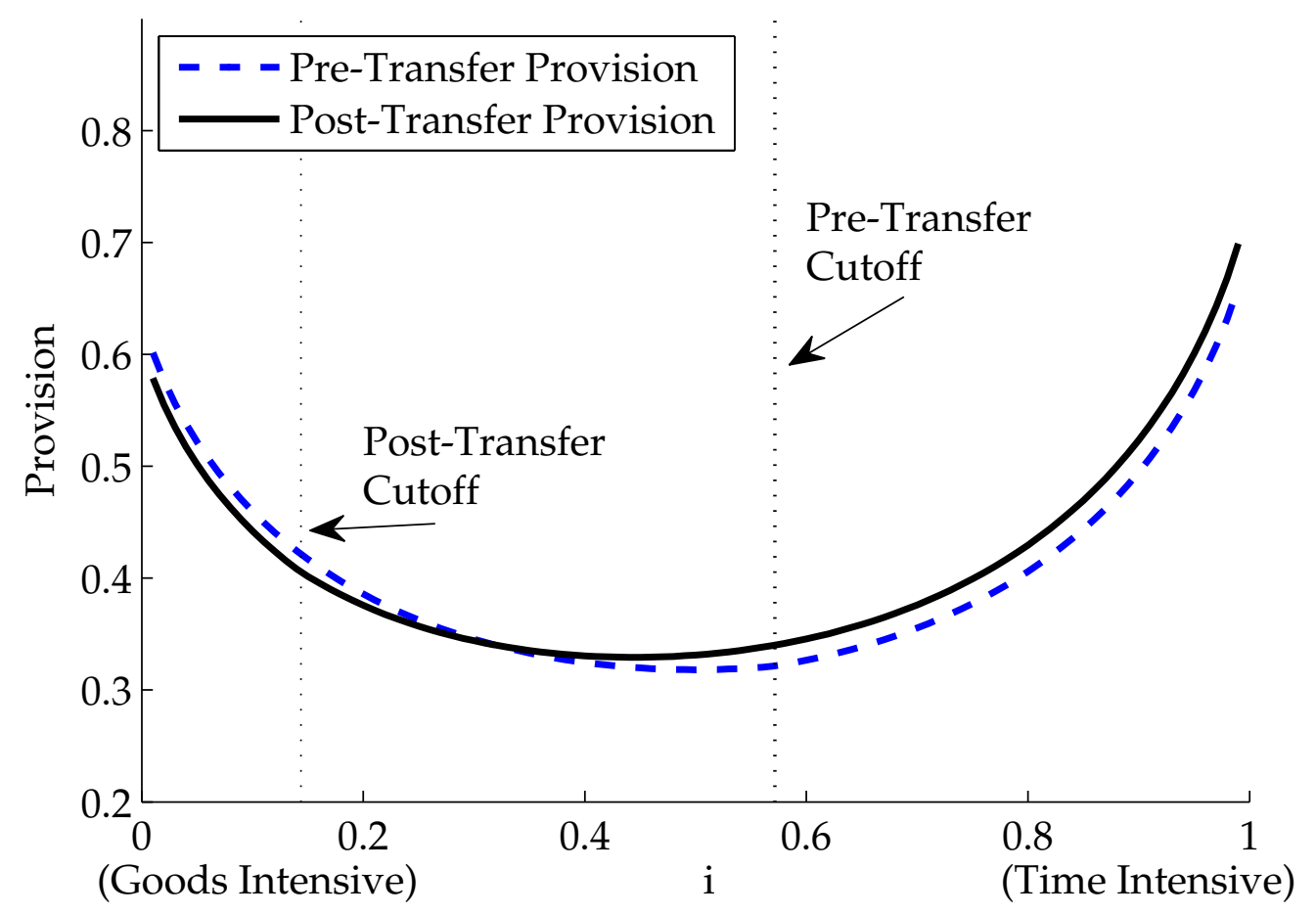

Figure 6: Provision of Each Public Good for $w^{f}=0.8, w^{m}=1$ Before and After Transfer of $\epsilon=0.3$ from Husband to Wife. Dashed Line: Pre-Transfer Equilibrium Provision. Solid Line: Post-Transfer Equilibrium Provision.

Thus, the model yields the testable prediction that the effects of mandated transfers should be large in places where women earn very little, and small in places where equality in the workplace has been nearly achieved.

To illustrate the workings of this mechanism, Figure 6 displays the impact on public good provision of a mandated transfer of $\epsilon=0.3$ from husband to wife when the wages are $w_{f}=0.8$, $w_{m}=1$. Compared to the case of a larger wage gap $\left(w_{f}=0.5, w_{m}=1\right)$ shown in Figure 3, the quantitative impact on the relative provision of female- and male-provided public goods is much smaller. Indeed, the impact on equilibrium public good provision is related directly to the difference in the slope between the female and male preferred provision curve, and this difference converges to zero as the wage gap disappears. Once the female wage exceeds about 90 percent of the male wage, the impact of a mandated transfer on equilibrium provision is barely discernible.

\section{E Extended Model with Joint Production}

Our baseline model relies on the assumption that in the production of any given public good, the same spouse has to provide the goods input and the time input. We had justified this assumption with the lack of monitoring between spouses. It is often difficult for a spouse to tell whether a transfer to the partner is spent in the intended way or diverted for other public goods or private 
consumption. In reality, this monitoring friction will likely not apply to all goods. There are ways to check receipts or actual goods inputs (e.g. whether a particular item has actually been bought). We thus now relax the assumption by assuming that there are two types of public goods: those easy to monitor and those where monitoring is not possible. Concretely, in our model this means that in addition to the individually produced public goods as before, we now add jointly produced public goods where goods inputs provided by one spouse can be combined with time input of the other spouse. In this appendix we show that our main results still go through in this extended setting.

In the extended model, as before there is a range of public goods $C_{i}$ that have to be produced by the spouses individually (i.e., a given spouse provides both goods and time), but there are additional public goods $C_{i}^{J}$ where joint production is possible, in the sense that the time of one spouse can be combined with goods provided by the other. To simplify the analysis we focus on the case where $\alpha(i)=i$ for both types of goods, but this is easy to generalize. The overall weight on the individually produced public goods is $\psi$, with the remaining weight $1-\psi$ applying to the jointly produced goods, so that preferences of spouse $g$ are:

$$
\log \left(c_{g}\right)+\psi \int_{0}^{1} \log \left(C_{i}\right) d i+(1-\psi) \int_{0}^{1} \log \left(C_{i}^{J}\right) d i
$$

The constraints faced by spouse $g$, corresponding to (2)-(5) in the baseline problem, are:

$$
\begin{aligned}
C_{i} & =C_{f, i}+C_{m, i} \quad \forall i, \\
C_{g, i} & =E_{g, i}^{1-i} T_{g, i}^{i} \quad \forall i, \\
C_{i}^{J} & =\left(E_{f, i}^{J}+E_{m, i}^{J}\right)^{1-i}\left(T_{f, i}^{J}+T_{m, i}^{J}\right)^{i} \quad \forall i, \\
c_{g}+\int_{0}^{1}\left(E_{g, i}+E_{g, i}^{J}\right) d i & =w_{g}\left(1-T_{g}\right)+x_{g}, \\
\int_{0}^{1}\left(T_{g, i}+T_{g, i}^{J}\right) d i & =T_{g} .
\end{aligned}
$$

The new constraint is (85); for the joint-production goods, each spouse can contribute either goods or time, and the goods provided by one spouse can be provided with time of the other.

We now show that the equilibrium in the extended setting inherits the main features of our baseline setting. In particular, in an interior equilibrium, for the individually produced public goods there is still a cutoff where the low-wage spouse specializes in time-intensive goods. For the joint production public goods, in an interior equilibrium the goods component is provided entirely by the high-wage spouse, and the time component is provided by the low-wage spouse. Hence, if we interpret the goods spending by the high-wage spouse as a transfer to the other spouse, the extended model allows for transfers between the spouses even in an interior equilibrium.

Proposition E.1 (Separate Spheres Equilibrium with Joint Production). Assume that wages satisfy $0<w_{f}<w_{m}$. There is a generically unique Nash equilibrium with the following features. There is a cutoff $\bar{i}$ such that all regular (i.e., not involving joint production) public goods in the interval $i \in[0, \bar{i}]$ are provided by the husband (i.e., the husband provides goods-intensive goods), while public goods in the range $i \in(\bar{i}, 1]$ are provided by the wife (the wife provides time-intensive goods). Private and public 
consumption satisfies

$$
\begin{gathered}
C_{i}=\left\{\begin{array}{c}
\psi(1-i)^{1-i}\left(\frac{i}{w_{m}}\right)^{i} c_{m} \quad \text { for } i \in[0, \bar{i}], \\
\psi(1-i)^{1-i}\left(\frac{i}{w_{f}}\right)^{i} c_{f} \quad \text { for } i \in(\bar{i}, 1],
\end{array}\right. \\
C_{i}^{J}=(1-\psi)(1-i)^{1-i}\left(\frac{i}{w_{f}}\right)^{i} c_{m}^{1-i} c_{f}^{i} \text { for all } i .
\end{gathered}
$$

If the cutoff $\bar{i}$ is interior, the husband provides all goods inputs for joint-production public goods, and the wife provides all time inputs for such goods. The cutoff $\bar{i}$ is determined such that female and male provision of regular public goods is equalized at the cutoff. Hence, if $\bar{i} \in(0,1)$, the cutoff and private consumption satisfy the condition:

$$
\left(\frac{w_{m}}{w_{f}}\right)^{\bar{i}}=\frac{c_{m}}{c_{f}} .
$$

That is, the characterization of the equilibrium is identical to that of the baseline model characterized in Proposition 2.1, except that there is now an additional category of public goods. The proof for the proposition is given below.

The intuition for the result is that for joint production goods, goods and time can be supplied by separate spouses, so that an equilibrium each input is supplied by the spouse who has a comparative advantage at supplying that input. This means that in an interior equilibrium where both spouses provide at least some individual-production goods, all goods inputs are supplied by the high-wage spouse, and all time inputs are supplied by the low-wage spouse. The baseline model is a special case of this model when $\psi$ goes to one. Moreover, even for $0<\psi<1$ the extended model turns out to be isomorphic to the baseline model for an appropriate choice of the function $\alpha(i)$ in the baseline model. This is because the goods component of joint-production goods is supplied in the same manner as standard public goods with $\alpha(i)=0$ (i.e., pure goods case), whereas the time component is supplied as standard public goods with $\alpha(i)=1$ (i.e., pure time goods). Thus, the model with joint-production public goods behaves as the standard model with additional weight on pure-goods and pure-time public goods (of course, the distinction between the model still matters if one wants to map specific public goods into observables).

The extended model also modifies our results on voluntary transfers in Section 2.3. There, we found that if spouses make voluntary transfers, mandated transfers have no effects on the margin, because the voluntary transfer would be adjusted to offset the mandated transfer. This result still holds in the extended model as far as general transfers are concerned, i.e., one spouse gives a lump sum of cash to the other. However, the extended model now includes an additional form of transfer, namely the goods contribution of one spouse to a public good produced with the time of the other. If a spouse is able to make a contribution to a specific public good (say, by checking receipts after a purchase carried out by the other spouse), this leaves the impact of mandated transfers on public goods provision intact. Hence, the extended model can rationalize that some voluntary specific-purpose transfers take place between spouses, yet mandated general transfers still affect the household allocation.

Proof of Proposition E.1: It is without loss of generality to focus on equilibria where each regular public good/each input into a specific joint public good is provided by only one of the spouses. For regular public goods this is as in the baseline model. For joint production goods, in equilibrium either one of the spouses has a higher willingness to provide a given input than the other 
(in which case this spouse is the sole provider), or the two spouses have the same willingness to provide one of the inputs (goods or time). If the willingness to provide a given input is the same, the couple is indifferent with regards to the which one of them provides the input for a specific good (holding fixed the equilibrium provision), so that (given that there is a continuum of joint production public goods) provision can always be arranged that for any given good-input combination one spouse is the sole provider. This allows us to express the first-order conditions characterizing the optimization problem of spouse $g \in\{f, m\}$ as:

$$
\begin{aligned}
c_{g} & =\frac{1}{\lambda_{g}}, \\
E_{g, i} & \leq \psi \frac{1-i}{\lambda_{g}}, \\
T_{g, i} & \leq \psi \frac{i}{w_{g} \lambda_{g}} \\
E_{g, i}^{J} & \leq(1-\psi) \frac{1-i}{\lambda_{g}}, \\
T_{g, i}^{J} & \leq(1-\psi) \frac{i}{w_{g} \lambda_{g}},
\end{aligned}
$$

where (92) to (95) hold with equality for all public goods that spouse $g$ contributes to, and $\lambda_{g}$ denotes the multiplier on the budget constraint.

In the Nash equilibrium, each spouse contributes only to those public goods for which she or he has a higher willingness to provide. For joint production goods, the willingness to provide applies separately for the two inputs, because providing money does not require also providing time for the same public good. Hence, the husband will provide the goods component of all joint production goods if we have $\lambda_{m}<\lambda_{f}$ (the husband has a lower marginal utility of wealth), and vice versa for the wife. Only when we have $\lambda_{m}=\lambda_{f}$ (and hence $c_{m}=c_{f}$ ) can we have provision of the goods component by both spouses. Similarly, the wife will provide all time inputs if $w_{f} \lambda_{f}<w_{m} \lambda_{m}$, and vice versa for the husband. Note that since we have $w_{f}<w_{m}$, in equilibrium it cannot be the case that both spouses make contributions to both inputs.

Moving on to individual production goods, because here it is not possible to combine inputs from the two spouses, what matters is the overall willingness to provide the good. As in the baseline model, the ratio of female to male preferred provision for individual-production public $\operatorname{good} i$ is:

$$
\frac{C_{f, i}}{C_{m, i}}=\frac{E_{f, i}^{1-i} T_{f, i}^{i}}{E_{m, i}^{1-i} T_{m, i}^{i}}=\left(\frac{w_{m}}{w_{f}}\right)^{i} \frac{\lambda_{m}}{\lambda_{f}} .
$$

This expression is increasing in $i$ (given the assumption $w_{f}<w_{m}$ ), which implies that there is an equilibrium that satisfies the cutoff rule. Intuitively, women provide public goods using relatively more time compared to goods because of their low wages, which induces them to provide relatively more of the time-intensive goods. Given the cutoff rule, (88) and (89) follows from substituting the expressions for $E_{g, i}, T_{g, i}, E_{g, i}^{J}, T_{g, i}^{J}$ from the first-order conditions into the production, and (90) follows from equating male and female contributions at the cutoff between female and male provision of individually-produced public goods.

We can characterize the cutoff $\bar{i}$ more sharply by solving for the multipliers on the budget con- 
straint. Consider first the case where $0<\bar{i}<1$, so that the wife provides all time inputs for joint production goods and the husband provides all goods inputs. Plugging the first-order conditions for the wife back into the budget constraint and using the cutoff rule gives:

$$
\frac{1}{\lambda_{f}}+\psi \int_{\bar{i}}^{1} \frac{1-i}{\lambda_{f}} d i=w_{f}-\psi w_{f} \int_{\bar{i}}^{1} \frac{i}{w_{f} \lambda_{f}} d i-(1-\psi) w_{f} \int_{0}^{1} \frac{i}{w_{f} \lambda_{f}} d i+x_{f} .
$$

Canceling terms we get:

$$
\frac{1}{\lambda_{f}}+\psi \int_{\bar{i}}^{1} \frac{1}{\lambda_{f}} d i+(1-\psi) \frac{1}{2} \frac{1}{\lambda_{f}}=w_{f}+x_{f}
$$

which gives:

$$
\lambda_{f}=\frac{3+\phi-2 \phi \bar{i}}{2\left(w_{f}+x_{f}\right)}
$$

Proceeding along the same lines with the male budget constraint gives:

$$
\lambda_{m}=\frac{3-\phi+2 \phi \bar{i}}{2\left(w_{m}+x_{m}\right)} .
$$

If the cutoff $\bar{i}$ indeed satisfies $0<\bar{i}<1$, it is characterized by the condition that at $\bar{i}$ female- and male-preferred provision of the individual-production public good is equal. Using (96), this can be written as:

$$
\left(\frac{3+\phi-2 \phi \bar{i}}{3-\phi+2 \phi \bar{i}}\right)\left(\frac{w_{m}+x_{m}}{w_{f}+x_{f}}\right)=\left(\frac{w_{m}}{w_{f}}\right)^{\bar{i}} .
$$

Notice that the left-hand side is strictly decreasing in $\bar{i}$ while the right-hand side is increasing. Hence, there can be at most one solution to the equation. When the equation does not have a solution the equilibrium is a corner. Specifically, if:

$$
\left(\frac{3+\phi}{3-\phi}\right)\left(\frac{w_{m}+x_{m}}{w_{f}+x_{f}}\right)<1
$$

holds we have $\bar{i}=0$. In this case, the wife is sufficiently rich to provide all public goods. If this equation holds as an equality, the wife provides all individual-production public goods and all time inputs for the joint-production goods, and both wife and husband can provide to the goods component of the joint-production goods. Conversely, if:

$$
\left(\frac{3-\phi}{3+\phi}\right)\left(\frac{w_{m}+x_{m}}{w_{f}+x_{f}}\right)>\frac{w_{m}}{w_{f}}
$$

holds, we have $\bar{i}=1$, and the husband provides all public goods. If the equation holds as an equality, the husband provides all individual-production goods and all goods inputs for jointproduction goods, but the wife may still contribute some time to joint-production goods. In the cases where one of the last two expressions is an equality, the equilibrium is only generically unique because there is indeterminacy in terms of which spouse is providing inputs for which joint-production goods in this range. However, the private consumption and equilibrium provision of public goods is independent of who provides which goods in this range. 


\section{F The Model with More General Preferences}

In the main analysis above, we have relied on log utility and Cobb-Douglas technology to simplify the analysis. In this section, we discuss the extent to which our results can be extended to more general functional forms for utility and the home-production technology. Let preferences be given by:

$$
\begin{aligned}
& u\left(c_{f}\right)+\int_{0}^{1} U\left(C_{i}\right) d i, \\
& u\left(c_{m}\right)+\int_{0}^{1} U\left(C_{i}\right) d i,
\end{aligned}
$$

where $u(\cdot)$ and $U(\cdot)$ are strictly increasing, strictly concave, and continuously differentiable utility functions that satisfy Inada conditions. The maximization problem of the spouse of gender $g \in\{f, m\}$ is subject to the following constraints:

$$
\begin{aligned}
C_{i} & =C_{f, i}+C_{m, i}, \\
C_{g, i} & =F_{i}\left(E_{g, i}, T_{g, i}\right), \\
c_{g}+\int_{0}^{1} E_{g, i} d i & =w_{g}\left(1-T_{g}\right)+x_{g}, \\
\int_{0}^{1} T_{g, i} d i & =T_{g} .
\end{aligned}
$$

Here $F_{i}\left(E_{g, i}, T_{g, i}\right)$ is a home production function that, for each $i$, is strictly increasing in both inputs, displays constant returns to scale to both inputs combined, strictly diminishing returns to each input individually, and is continuously differentiable.

In equilibrium, each public good $i$ will be provided by only one of the spouses. Denoting by $\lambda_{g}$ the multiplier on the budget constraint, the first-order conditions for the individual maximization problem for private consumption $c_{g}$ and the provision of public goods $i$ that are provided by spouse $g$ are given by:

$$
\begin{aligned}
u^{\prime}\left(c_{g}\right) & =\lambda_{g}, \\
U^{\prime}\left(F_{i}\left(E_{g, i}, T_{g, i}\right)\right) F_{i, E}\left(E_{g, i}, T_{g, i}\right) & =\lambda_{g}, \\
U^{\prime}\left(F_{i}\left(E_{g, i}, T_{g, i}\right)\right) F_{i, H}\left(E_{g, i}, T_{g, i}\right) & =w_{g} \lambda_{g} .
\end{aligned}
$$

Notice that these constraints hold as equalities only for those $i$ that are provided by spouse $g$. Given this provision, the constraints have to hold as equalities because the utility functions are strictly concave, differentiable, and satisfy Inada conditions.

We can use the first-order conditions to derive the preferred provision of public good $i$ by spouse $g$ as a function of private consumption $c_{g}$. Namely, let:

$$
\tilde{C}_{g, i}\left(c_{g}\right)=F_{i}\left(\tilde{E}_{g, i}, \tilde{T}_{g, i}\right)
$$

where $\tilde{E}_{g, i}$ and $\tilde{T}_{g, i}$ are the solution to the system of equations:

$$
U^{\prime}\left(F_{i}\left(\tilde{E}_{g, i}, \tilde{T}_{g, i}\right)\right) F_{i, E}\left(\tilde{E}_{g, i}, \tilde{T}_{g, i}\right)=u^{\prime}\left(c_{g}\right)
$$




$$
U^{\prime}\left(F_{i}\left(\tilde{E}_{g, i}, \tilde{T}_{g, i}\right)\right) F_{i, H}\left(\tilde{E}_{g, i}, \tilde{T}_{g, i}\right)=w_{g} u^{\prime}\left(c_{g}\right)
$$

This system of equations can be defined for all $i \in[0,1]$. Intuitively, $\tilde{C}_{g, i}\left(c_{g}\right)$ is how much spouse $g$ would provide of good $i$ if he/she were the sole provider and if the value of the Lagrange multiplier on the budget constraint were given by $u^{\prime}\left(c_{g}\right)$.

We assume for now that a unique solution to the system (104)-(105) exists for all $i$ and all $c_{g}$, so that the preferred provision levels $\tilde{C}_{g, i}\left(c_{g}\right)$ are well defined (later, we will also discuss specific functional forms that guarantee that this is the case). We can then ask what properties the preferred provision levels have to satisfy in order to generate a generalized version of Proposition 2.1 above.

Assumption F.1. The function $\tilde{C}_{g, i}\left(c_{g}\right)$ is strictly increasing and continuous in $c_{g}$ for $g \in\{f, m\}$ and the expression:

$$
\frac{\tilde{C}_{f, i}\left(c_{f}\right)}{\tilde{C}_{m, i}\left(c_{m}\right)}
$$

is strictly increasing in $i$, for all $c_{f}, c_{m}>0$ (i.e., relative female willingness to pay is increasing in $i$ ).

Proposition F.1. If Assumption F.1 is satisfied, there exists a unique equilibrium characterized by a cutoff $\bar{i}$ such that all public goods in the interval $i \in[0, \bar{i}]$ are provided by the husband $m$ (i.e., the husband provides goods-intensive goods), while public goods in the range $i \in(\bar{i}, 1]$ are provided by the wife $f$ (the wife provides time-intensive goods). If the cutoff $\bar{i}$ is interior, it is determined such that female and male provision of public goods is equalized at the cutoff. Hence, if $\bar{i} \in(0,1)$, the cutoff and private consumption satisfy the condition:

$$
\tilde{C}_{f, \bar{i}}\left(c_{f}\right)=\tilde{C}_{m, \bar{i}}\left(c_{m}\right) .
$$

Consider now the effects of a transfer from the husband to the wife, i.e., the wife's wealth increases from $x_{f}$ to $\tilde{x}_{f}=x_{f}+\epsilon$, and the husband's wealth decreases from $x_{m}$ to $\tilde{x}_{m}=x_{m}-\epsilon$, where $\epsilon>0$. In the new equilibrium, the cutoff $\bar{i}$ is lower. Let $\tilde{i}$ be the new cutoff. If $w_{f}<w_{m}$ and if the cutoff is interior both before and after the change, i.e., if $0<\tilde{i}<\bar{i}<1$ holds, the provision of public goods that are femaleprovided both before and after the change $(i>\bar{i})$ goes up. In other words, a transfer to the low-wage spouse increases the provision of public goods provided by this spouse.

Proof of Proposition F.1: Equilibrium requires that each public good is provided by the spouse with the higher willingness to pay. Given that we assume that the ratio of willingness to pay (106) is strictly increasing in $i$, for any $c_{f}, c_{m}$ there either has to be a $\bar{i}\left(c_{f}, c_{m}\right) \in(0,1)$ that satisfies $\tilde{C}_{f, \bar{i}}\left(c_{f}\right)=\tilde{C}_{m, \bar{i}}\left(c_{m}\right)$, or we can set $\bar{i}=0$ with $\tilde{C}_{f, 0}\left(c_{f}\right) \geq \tilde{C}_{m, 0}\left(c_{m}\right)$ or $\bar{i}=1$ with $\tilde{C}_{f, 1}\left(c_{f}\right) \leq$ $\tilde{C}_{m, 1}\left(c_{m}\right)$. Moreover, given that willingness to pay is continuously increasing in $c_{g}, \bar{i}\left(c_{f}, c_{m}\right)$ is a continuous function of $c_{f}$ and $c_{m}$ and at least weakly decreasing in $c_{f}$ and weakly increasing in $c_{m}$. To have an equilibrium, in addition to the public-good provision condition we also need to satisfy individual budget constraints. We can define total spending by the two spouses as:

$$
\begin{aligned}
& Y_{f}\left(c_{f}, c_{m}\right)=c_{f}+\int_{\bar{i}\left(c_{f}, c_{m}\right)}^{1}\left(\tilde{E}_{f, i}\left(c_{f}\right)+w_{f} \tilde{T}_{f, i}\left(c_{f}\right)\right) d i \\
& Y_{m}\left(c_{f}, c_{m}\right)=c_{m}+\int_{0}^{\bar{i}\left(c_{f}, c_{m}\right)}\left(\tilde{E}_{m, i}\left(c_{m}\right)+w_{m} \tilde{T}_{m, i}\left(c_{m}\right)\right) d i
\end{aligned}
$$


Given Assumption F.1, these functions are guaranteed to be continuous, $Y_{f}\left(c_{f}, c_{m}\right)$ is strictly increasing in $c_{f}$, and $Y_{m}\left(c_{f}, c_{m}\right)$ is strictly increasing in $c_{m}$. An equilibrium is given by two numbers $c_{f}, c_{m}$ such that the two budget-clearing conditions:

$$
\begin{aligned}
Y_{f}\left(c_{f}, c_{m}\right) & =w_{f}+x_{f}, \\
Y_{m}\left(c_{f}, c_{m}\right) & =w_{m}+x_{m}
\end{aligned}
$$

are satisfied. A solution exists, because the functions are continuous, $Y_{f}\left(c_{f}, c_{m}\right)$ approaches zero as $c_{f}$ approaches zero, and exceeds $w_{f}+x_{f}$ as $c_{f}$ approaches $w_{f}+x_{f}$, with parallel conditions holding for $c_{m}$. The solution is also unique. To see why, assume to the contrary that there are two different equilibrium values of female consumption, $c_{f}$ and $\hat{c}_{f}<c_{f}$. For the female budget constraint to be satisfied, $\hat{c}$ would have to correspond to a larger female provision of public goods and thus a lower $\bar{i}$. The lower cutoff, in turn, implies that male consumption must be lower, $\hat{c}_{m}<c_{m}$, because male willingness to pay for public goods has to be lower. But this leads to a contradiction, because then the husband would both have lower private consumption and provide fewer public goods, implying that the budget constraint cannot be satisfied for $c_{m}$ and $\hat{c}_{m}$ at the same time.

So far, we have established that for given $w_{f}, w_{m}, x_{f}$, and $x_{m}$, there exists a unique equilibrium characterized by a cutoff $\bar{i}$ for the provision of public goods. Consider now the effects of a transfer from the husband to the wife, i.e., the wife's wealth increases from $x_{f}$ to $\tilde{x}_{f}=x_{f}+\epsilon$, and the husband's wealth decreases from $x_{m}$ to $\tilde{x}_{m}=x_{m}-\epsilon$, where $\epsilon>0$. Let $i$ be the provision cutoff in the new equilibrium, where we must have $\tilde{i} \leq \bar{i}$ because of the increase in female resources. Consider the case where the cutoff is interior both before and after the change, i.e., if $0<\tilde{i}<\bar{i}<1$ holds. We would like to show that the provision of public goods that are femaleprovided both before and after the change $(i>\bar{i})$ goes up. This is equivalent to showing that we must have $\tilde{c}_{f}>c_{f}$, i.e., private female consumption increases. To show this, assume to the contrary that $\tilde{c}_{f} \leq c_{f}$. Then we must have that goods with $i$ such that $\tilde{i} \leq i<\bar{i}$ are provided at a lower level than before, because provision is equal to female preferred provision, which has not increased and is strictly lower than the original preferred male provision (because of the restriction on (106) in Assumption F.1), which was the original equilibrium provision. This also implies that $\tilde{C}_{m, \tilde{i}}\left(\tilde{c}_{m}\right)<\tilde{C}_{m, \tilde{i}}\left(c_{m}\right)$ and hence we must have $\tilde{c}_{m}<c_{m}$. This, in turn, implies that all male provided goods are provided at a lower level than previously. The fact that male private consumption and male contributions to public goods both fall implies that the amount of the transfer has to be larger than the original full cost of providing the public goods in the range $[\tilde{i}, \bar{i}]$. But this leads to a contradiction, because then the wife receives a transfer that is more than sufficient (given $w_{f}<w_{m}$ ) for the original provision of public goods in the range $[\tilde{i}, \bar{i}]$, yet she lowers the provision of these goods and does not increase the provision of any other goods, implying that the budget constraint has to be violated.

The proposition shows that the key condition for our main result is that relative female willingness to pay varies across public goods. A wage difference combined with differences in the time-versus-goods intensity of different public goods is one way of generating such differences in the willingness to pay, but clearly any mechanism that creates variation in spouses' comparative advantage at providing different public goods would create similar results.

In the model contained in the main text we generate a difference in willingness to pay that depends only on the time-versus-goods intensity of the production function. While the log- 
Cobb-Douglas setup that we use leads to the most straightforward characterization, this feature carries over to CES production and CRRA utility. To demonstrate this, assume the following functional forms:

$$
\begin{aligned}
u\left(c_{g}\right) & =\frac{c_{g}^{1-\sigma}}{1-\sigma}, \\
u\left(C_{i}\right) & =\frac{C_{i}^{1-\sigma}}{1-\sigma}, \\
F_{i}\left(E_{i}, T_{i}\right) & =\left((1-i) E_{i}^{\rho}+i T_{i}^{\rho}\right)^{\frac{1}{\rho}} .
\end{aligned}
$$

Given these functional forms, the first-order conditions (104)-(105) that pin down the preferred goods and time contributions $\tilde{E}_{g, i}$ and $\tilde{T}_{g, i}$ to public goods can be written as:

$$
\begin{gathered}
\left(\left((1-i) \tilde{E}_{i}^{\rho}+i \tilde{T}_{i}^{\rho}\right)^{\frac{1}{\rho}}\right)^{-\sigma}(1-i) \tilde{E}_{i}^{\rho-1}\left((1-i) \tilde{E}_{i}^{\rho}+i \tilde{T}_{i}^{\rho}\right)^{\frac{1-\rho}{\rho}}=\left(c_{g}\right)^{-\sigma} \\
\left(\left((1-i) \tilde{E}_{i}^{\rho}+i \tilde{T}_{i}^{\rho}\right)^{\frac{1}{\rho}}\right)^{-\sigma} i \tilde{T}_{i}^{\rho-1}\left((1-i) \tilde{E}_{i}^{\rho}+i \tilde{T}_{i}^{\rho}\right)^{\frac{1-\rho}{\rho}}=w_{g}\left(c_{g}\right)^{-\sigma}
\end{gathered}
$$

Taking the ratio of (108) and (109), we get:

$$
\frac{1-i}{i}\left(\frac{\tilde{E}_{i}}{\tilde{T}_{i}}\right)^{\rho-1}=\frac{1}{w_{g}}
$$

or:

$$
\frac{\tilde{E}_{i}}{\tilde{T}_{i}}=\left(w_{g} \frac{1-i}{i}\right)^{\frac{1}{1-\rho}} .
$$

Not surprisingly, the spouse with a lower wage provides public goods in a more time-intensive manner. Notice that the first term in the two-first order conditions contains the preferred provision level $\tilde{C}_{g, i}\left(c_{g}\right)$. Rewriting (109) yields:

$$
\left(\tilde{C}_{g, i}\left(c_{g}\right)\right)^{-\sigma} i\left((1-i)\left(\frac{\tilde{E}_{i}}{\tilde{T}_{i}}\right)^{\rho}+i\right)^{\frac{1-\rho}{\rho}}=w_{g}\left(c_{g}\right)^{-\sigma} .
$$

Plugging in (110) gives:

$$
\left(\tilde{C}_{g, i}\left(c_{g}\right)\right)^{-\sigma} i\left((1-i)\left(w_{g} \frac{1-i}{i}\right)^{\frac{\rho}{1-\rho}}+i\right)^{\frac{1-\rho}{\rho}}=w_{g}\left(c_{g}\right)^{-\sigma}
$$

Simplifying and solving for the preferred provision gives:

$$
\begin{gathered}
\left(\tilde{C}_{g, i}\left(c_{g}\right)\right)^{-\sigma}\left((1-i)^{\frac{1}{1-\rho}}\left(w_{g}\right)^{\frac{\rho}{1-\rho}}+i^{\frac{1}{1-\rho}}\right)^{\frac{1-\rho}{\rho}}=w_{g}\left(c_{g}\right)^{-\sigma}, \\
\left(\tilde{C}_{g, i}\left(c_{g}\right)\right)^{-\sigma}\left((1-i)^{\frac{1}{1-\rho}}+\left(\frac{i}{w_{g}^{\rho}}\right)^{\frac{1}{1-\rho}}\right)^{\frac{1-\rho}{\rho}}=\left(c_{g}\right)^{-\sigma},
\end{gathered}
$$




$$
\tilde{C}_{g, i}\left(c_{g}\right)=c_{g}\left((1-i)^{\frac{1}{1-\rho}}+\left(\frac{i}{w_{g}^{\rho}}\right)^{\frac{1}{1-\rho}}\right)^{\frac{1-\rho}{\sigma \rho}}
$$

Notice that these preferred provision levels satisfy the continuity and monotonicity restrictions in Assumption F.1. Moreover, the ratio of preferred female to preferred male provision is:

$$
\frac{\tilde{C}_{f, i}\left(c_{f}\right)}{\tilde{C}_{m, i}\left(c_{m}\right)}=\frac{c_{f}}{c_{m}}\left(\frac{(1-i)^{\frac{1}{1-\rho}}+\left(\frac{i}{w_{f}^{\rho}}\right)^{\frac{1}{1-\rho}}}{(1-i)^{\frac{1}{1-\rho}}+\left(\frac{i}{w_{m}^{\rho}}\right)^{\frac{1}{1-\rho}}}\right)^{\frac{1-\rho}{\sigma \rho}} .
$$

Since we have $w_{f}<w_{m}$, this ratio is indeed strictly increasing in $i$, which meets the second part of Assumption F.1.

If we combine the CES production function with still more general preferences (such as StoneGeary), additional effects arise, because relative female willingness to pay for different public goods might vary with both relative and absolute female wealth. However, the presence of a wage gap combined with variation in the time intensity of public goods always creates a force towards female specialization in time-intensive goods. With more general utility functions additional forces may be present, but these will not completely offset the force towards specialization except in knife-edge cases. Even in cases where Assumption F.1 is not satisfied, income transfers between the spouses will have an effect on the equilibrium allocation as long as there is some variation in relative willingness to pay. The direction of the effects could be different, however, if the differences in willingness to pay are mainly due to a factor other than female specialization in time-intensive production.

\section{G Robustness Checks for Empirical Analysis of PROGRESA Data}

In Table 3 we present results for alternative measures of saving that attempt to correct for spending on investment goods. In our baseline regressions, the expenditure measure is total selfreported expenditure, and the savings measure is the difference between income and expenditures. If expenditures include spending on investment goods, the baseline measures may understate the overall saving and investment activity of the household. To deal with this concern, here we present results for alternative measures of saving and expenditure that correct for spending on investment goods. The downside of these measures is that a more detailed breakdown of expenditures is only available for a subset of the survey waves, which substantially reduces sample sizes compared to our baseline results. Nevertheless, despite the smaller samples are results hold up for the alternative measures of expenditures and savings.

Table 3 displays our results for the alternative measures of saving and investment. We display results for two alternative measures. All regressions include the full set of controls, and we present results both with and without instrumenting the female income share with PROGRESA income. In columns (1) and (2), we subtract net livestock investment from total expenditure (so that livestock investment is included in the savings measure). As emphasized by Rubalcava, Teruel, and Thomas (2009), livestock investment is a potentially important form of savings for rural households. Comparing the results to Table 2, we see that the estimates of the impact of changes in 
Table 3: Impact of Female Income Share on Total Expenditure and Savings Using Alternative Expenditure and Savings Measures

\begin{tabular}{lcccc}
\hline \hline & $(1)$ & $(2)$ & $(3)$ & $(4)$ \\
\hline \multirow{5}{*}{$\log$ (Expenditures) $)$} & $0.224^{* * *}$ & $0.255^{* * *}$ & $0.234^{* * *}$ & $0.153^{*}$ \\
& $(0.034)$ & $(0.052)$ & $(0.057)$ & $(0.080)$ \\
Savings Share & $-0.425^{* * *}$ & $-0.302^{* * *}$ & $-0.453^{* * *}$ & $-0.245^{* * *}$ \\
& $(0.061)$ & $(0.047)$ & $(0.105)$ & $(0.066)$ \\
\hline Estimation Method & OLS & IV & OLS & IV \\
Additional Controls & Yes & Yes & Yes & Yes \\
\hline
\end{tabular}

Notes: Robust standard errors (in parentheses) are adjusted for clusters by household. Stars denote significance at 10 percent, 5 percent, and 1 percent level, respectively. Sample size is 6,706 in columns (1) and (2) and 3,820 in columns (3) and (4). In Each estimate displayed is the estimated coefficient on the female income share in a linear regression for the left-hand side variable displayed in the first column. In columns (1) and (2), the measure of expenditure is total household expenditure minus net expenditures on livestock purchases. In columns (3) and (4), expenditures on durables and home repairs are also subtracted. All regressions include log household income, log household income squared, household size, number of children in school, number of children in primary school, number of girls, eligibility for the PROGRESA program, the wife's and husband's education, and the ages of wife and husband. In Regressions (2) and (4) the female income share is instrumented with PROGRESA income (estimation via two-stage least squares). 
the female income share on the balance of saving and spending are essentially unchanged. In columns (3) and (4), we subtract additional spending categories that can be interpreted as investments, namely purchases of durables and expenditures on home repairs. These measures are only available for a single survey wave, reducing sample size to 3,820 (compared to 9,506 in the baseline specification). Nevertheless, the results continue to hold up. The impact of the female income share on savings is now somewhat larger in the size in the OLS regression and somewhat smaller in the IV regression, but continues to be highly statistically significant and quantitatively large. 